\title{
A skill assessment of the biogeochemical model REcoM2 coupled to the Finite Element Sea Ice-Ocean Model (FESOM 1.3)
}

\author{
V. Schourup-Kristensen, D. Sidorenko, D. A. Wolf-Gladrow, and C. Völker \\ Alfred-Wegener-Institut Helmholtz-Zentrum für Polar- und Meeresforschung, Bremerhaven, Germany \\ Correspondence to: V. Schourup-Kristensen (vibe.schourup-kristensen@awi.de)
}

Received: 13 June 2014 - Published in Geosci. Model Dev. Discuss.: 9 July 2014

Revised: 25 September 2014 - Accepted: 26 September 2014 - Published: 25 November 2014

\begin{abstract}
In coupled biogeochmical-ocean models, the choice of numerical schemes in the ocean circulation component can have a large influence on the distribution of the biological tracers. Biogeochemical models are traditionally coupled to ocean general circulation models (OGCMs), which are based on dynamical cores employing quasiregular meshes, and therefore utilize limited spatial resolution in a global setting. An alternative approach is to use an unstructured-mesh ocean model, which allows variable mesh resolution. Here, we present initial results of a coupling between the Finite Element Sea Ice-Ocean Model (FESOM) and the biogeochemical model REcoM2 (Regulated Ecosystem Model 2), with special focus on the Southern Ocean.

Surface fields of nutrients, chlorophyll $a$ and net primary production (NPP) were compared to available data sets with a focus on spatial distribution and seasonal cycle. The model produces realistic spatial distributions, especially regarding NPP and chlorophyll $a$, whereas the iron concentration becomes too low in the Pacific Ocean. The modelled NPP is $32.5 \mathrm{Pg} \mathrm{C} \mathrm{yr}^{-1}$ and the export production $6.1 \mathrm{Pg} \mathrm{C} \mathrm{yr}^{-1}$, which is lower than satellite-based estimates, mainly due to excessive iron limitation in the Pacific along with too little coastal production. The model performs well in the Southern Ocean, though the assessment here is hindered by the lower availability of observations. The modelled NPP is 3.1 $\mathrm{Pg} \mathrm{C} \mathrm{yr}^{-1}$ in the Southern Ocean and the export production 1.1 $\mathrm{Pg} \mathrm{C} \mathrm{yr}^{-1}$.

All in all, the combination of a circulation model on an unstructured grid with a biogeochemical-ocean model shows similar performance to other models at non-eddy-permitting
\end{abstract}

resolution. It is well suited for studies of the Southern Ocean, but on the global scale deficiencies in the Pacific Ocean would have to be taken into account.

\section{Introduction}

Primary production plays a large role in ocean carbon cycling, and understanding the drivers behind primary production is therefore of paramount importance when it comes to understanding the changes that a future warmer climate will bring. Observations, as well as coupled biogeochemical-ocean models, indicate that climate change will decrease the oceanic net primary production (NPP) (Behrenfeld et al., 2006; Steinacher et al., 2010). This would have far-reaching implications, from changes of the carbon cycle to effects on fisheries.

Coupled biogeochemical-ocean models are important tools used to analyse the net primary production in the ocean and the effects of climate change on it (e.g. Le Quéré et al., 2003; Bopp et al., 2013). The biogeochemical results of such models are highly impacted by the mixing and circulation of the ocean model as it controls processes such as horizontal advection and nutrient supply to the surface layer (Doney et al., 2004). Supply of nutrients through upwelling is especially important when it comes to modelling the equatorial Pacific (Aumont et al., 1999) and the Southern Ocean, where production is iron limited and sensitive to new supply. Results from the second Ocean Carbon-Cycle Model Intercomparison Project (OCMIP-2) highlighted the importance of the ocean model; they showed how the representation of the 
ocean circulation in the Southern Ocean has a large impact on the calculations of present and future uptake of $\mathrm{CO}_{2}$ (Doney et al., 2004), and reported that the global export production varied between 9 and $28 \mathrm{GtC} \mathrm{yr}^{-1}$ when the same biogeochemical model was coupled to different OGCMs (Najjar et al., 2007).

Traditionally, global OGCMs employ structured grids with relatively uniform spatial resolution in the entire domain, and local refinement is done by utilizing nested models.

The unstructured-mesh technology is emerging as an alternative to nesting in ocean models, and is gradually becoming more widespread within the ocean modelling community (e.g., Chen et al., 2003; Danilov et al., 2004; Piggott et al., 2008). As solutions for the global ocean state provided by models formulated on unstructured meshes have improved (e.g., Sidorenko et al., 2011), it has become feasible to exploit the advantages offered by such models in biogeochemical modelling by coupling a biogeochemical model to an unstructured-mesh ocean model (Hill et al., 2014). One may then benefit from the possibility of aligning the grid with the bathymetry, or refining it in areas of interest without the loss of accuracy that the nesting introduces at boundaries. This is especially relevant when it comes to modelling features such as mixed layer depth, upwelling and the presence of fronts and eddies that are of vital importance for realistic modelling of ecosystems.

A drawback of the unstructured-mesh technology is that, although computer time is saved by using high resolution in chosen areas only, it still uses a substantial amount of computer time as it is less efficient per degree of freedom as compared to structured models. Furthermore, extra care must be taken for models formulated using the continuous finite elements as their local conservation of volume and tracers is formulated in the cluster-weighted sense. This brings some ambiguity into analyzing fluxes between grid cells, while divergences are well defined (Sidorenko et al., 2009).

Before using a newly coupled biogeochemical-ocean model for scientific studies, the skill of the model must be assessed (e.g. Assmann et al., 2010). Performing a skill assessment is not a trivial exercise, considering both the lack of data, especially for parameters such as dissolved iron and export production, and also the inherent uncertainty of the biogeochemical models, in which complex biochemical processes are described by comparably simple mathematical parameterizations. We have coupled the Regulated Ecosystem Model 2 (REcoM2) to the Finite Element Sea Ice-Ocean Model (FESOM), and in this paper a skill assessment of the coupled model is carried out with emphasis on the Southern Ocean. We show to what extent the results are comparable to observations and discuss how they compare to results from other models.

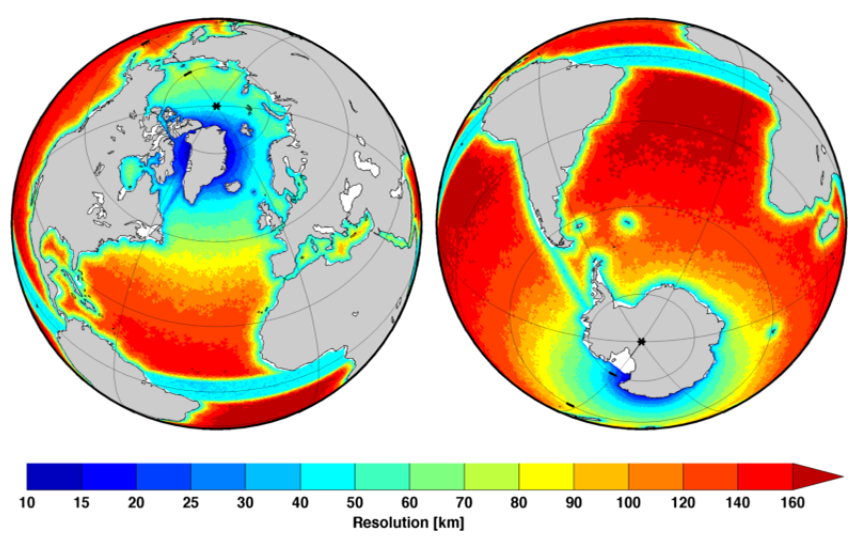

Figure 1. Horizontal resolution of FESOM's unstructured grid.

\section{Method}

\subsection{Ocean model}

The ocean component of FESOM solves the hydrostatic primitive equations under the Boussinesq approximations (Danilov et al., 2004; Wang et al., 2008). Elastic viscous plastic (EVP) sea ice dynamics is used together with the thermodynamics adopted from Parkinson and Washington (1979) as described in detail by Timmermann et al. (2009). Currently, FESOM is used for simulation of the three-dimensional global ocean with special focus on the Arctic and the Antarctic (Haid and Timmermann, 2013; Wekerle et al., 2013). The latest FESOM version is comprehensively described in Q. Wang et al. (2014).

FESOM operates on unstructured meshes that permit the main feature of the model: the capability of local grid refinement in an otherwise global set-up without nesting. The model domain is discretized by a horizontally triangulated and unstructured, but vertically stratified, mesh with tetrahedral volumes. Integration is carried out on an Arakawa Agrid, which uses vertical $z$ coordinates for simplicity. The mesh used in this study (Fig. 1) is similar to the one used by Sidorenko et al. (2011), in which the horizontal resolution ranges from $15 \mathrm{~km}$ in the polar regions to $180 \mathrm{~km}$ in the subtropical gyres. In the vertical it has 32 layers, nine of which are located in the upper $100 \mathrm{~m}$.

The bottom topography of FESOM's grid is constructed using a combination of different data products; the bulk of FESOMS bathymetry, from $60^{\circ} \mathrm{S}$ to $64^{\circ} \mathrm{N}$, is based on topography data from the General Bathymetric Chart of the Oceans (GEBCO, 1 min resolution), south of $60^{\circ} \mathrm{S}$, the bottom topography from Timmermann et al. (2010) with a resolution of $1 \mathrm{~min}$ (Rtopo-1) is used and north of $69^{\circ} \mathrm{N}$ it is based on data from the International Bathymetric Chart of the Arctic Oceans with $2 \mathrm{~km}$ resolution (IBCAO, version 2; Jakobsson et al., 2008). Between 64 and $69^{\circ} \mathrm{N}$, a combination of the GEBCO and IBCAO data sets is used. FESOM's bottom topography is created using bilinear interpo- 
lation, whereupon smoothing is performed to remove gridscale noise. The topography data also defines the coastline using bilinear interpolation from the data to the model's grid points. For a further description of the creation of bottom topography for FESOM, please refer to Q. Wang et al. (2014).

The version of FESOM used here utilizes a linear representation on triangles (in 2-D) and tetrahedrals (in 3-D) for all model variables. The same is true for the biological tracers, which are treated similar to temperature and salinity. The temporal discretization is implicit for sea surface elevation and a second order Taylor-Galerkin method together with the flux-corrected transport (FCT) is used for advection-diffusion equations. The forward and backward Euler methods are used for lateral and vertical diffusivities, respectively, and the Coriolis force is treated with a second order Adams-Bashforth method.

The vertical mixing is calculated using the PP-scheme first described by Pacanowski and Philander (1981) with a background vertical diffusivity of $1 \times 10^{-4} \mathrm{~m}^{2} \mathrm{~s}^{-1}$ for momentum and $1 \times 10^{-5} \mathrm{~m}^{2} \mathrm{~s}^{-1}$ for tracers. Redi diffusion (Redi, 1982) and Gent and McWilliams parameterization of the eddy mixing (Gent et al., 1990) are applied with a critical slope of 0.004 .

The skill of FESOM has been assessed within the CORE framework (Griffies et al., 2009; Sidorenko et al., 2011; Downes et al., 2014), where several sea ice-ocean models were forced with the normal year (CORE-I) and interannually varying (CORE-II) atmospheric states (Large and Yeager, 2004, 2009) and results compared. In these assessments, the full flexibility of FESOM's unstructured mesh was not utilized, but the results from FESOM were still within the spread of the other models, and it was consequently concluded that FESOM is capable of simulating the large-scale ocean circulation to a satisfactory degree.

\subsection{Biogeochemical model}

The Regulated Ecosystem Model 2 (REcoM2) belongs to the class of so-called quota models (Geider et al., 1996, 1998), in which the internal stoichiometry of the phytoplankton cells varies depending on light, temperature and nutrient conditions. Uptake of macronutrients is controlled by internal concentrations as well as the external nutrient concentrations, and the growth depends only on the internal nutrient concentrations (Droop, 1983). Iron uptake is controlled by Michaelis-Menten kinetics. An overview of the compartments and fluxes in REcoM2 can be seen in Fig. 2.

The model simulates the carbon cycle, including calcium carbonate as well as the nutrient elements nitrogen, silicon and iron. It has two classes of phytoplankton: nanophytoplankton and diatoms, and additionally describes zooplankton and detritus. The model's carbon chemistry follows the guidelines provided by the Ocean Carbon Model Intercomparison Project (Orr et al., 1999), and the air-sea flux cal-

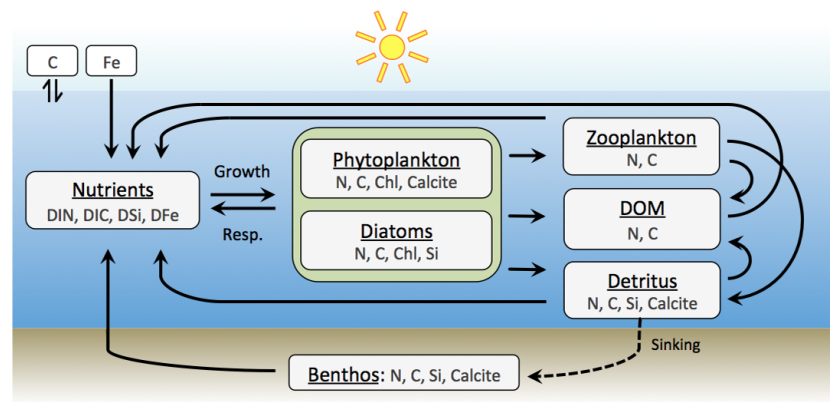

Figure 2. The pathways in the biogeochemical model REcoM2.

culations for $\mathrm{CO}_{2}$ are performed using the parameterizations suggested by Wanninkhof (1992).

We do not add external sources to the macronutrient pools since the timescale of the runs is short compared to the residence time of the macronutrients in the ocean (Broecker et al., 1982).

Iron has a much shorter residence time (Moore and Braucher, 2008) and is strongly controlled by external sources as well as scavenging. Dissolved iron is taken up and remineralized by phytoplankton, it reacts with ligands and it is scavenged by detritus in the water column (Parekh et al., 2005). New iron is supplied to the ocean by dust and sedimentary input. For dust input, REcoM2 uses monthly averages (Mahowald et al., 2003; Luo et al., 2003), which have been modified to fit better to the observations from Wagener et al. (2008) (N. M. Mahowald, personal communication, 2011). The model assumes that $3.5 \%$ of the dust field consists of iron and that $1.5 \%$ of this iron dissolves when deposited in the surface ocean. This gives a total aeolian in-

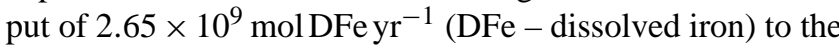
ocean on average. A flux of iron from the sediment has been

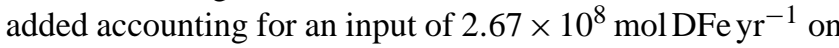
average. It is incorporated following Elrod et al. (2004) with the magnitude of the iron concentration released by the sediment being dependent on the rate of carbon remineralization in the sediment.

The model has 1 zooplankton class, which is the model's highest trophic level. Grazing is calculated by a sigmoidal Holling type 3 model with fixed preferences on both phytoplankton classes (Gentleman et al., 2003).

The sinking speed of detritus increases with depth, from $20 \mathrm{mday}^{-1}$ at the surface, to $192 \mathrm{mday}^{-1}$ at $6000 \mathrm{~m}$ depth (Kriest and Oschlies, 2008). Sinking detritus is subject to remineralization.

REcoM2 has sediment compartments for nitrogen, silicon, carbon and calcium carbonate, which consist of one layer into which the detritus sinks when reaching the lower-most ocean layer. Remineralization of the sunken material subsequently occurs in the benthos, and the nutrients are returned to the water column in dissolved state. 
REcoM1 and 2 have previously been used for large-scale simulations with focus on the Southern Ocean in set-ups with the MITgcm (MIT general circulation model) (Hohn, 2009; Taylor et al., 2013; Hauck et al., 2013), and the purpose of the current coupling between REcoM2 and FESOM is likewise studies of the Southern Ocean.

A full description of the model equations can be found in Appendix A along with lists of parameters used in the current run.

\subsection{Model experiment}

We present a numerical hindcast experiment with a newly coupled biogeochemical-ocean general circulation model. The run was forced using the CORE-II data set, which was developed for the use of coupled sea ice-ocean models and gives an interannually varying forcing for the years 1949 to 2008 (Large and Yeager, 2009). As focus here is on evaluating the biological surface processes of a newly coupled model, we follow the example of Vichi and Masina (2009) and Yool et al. (2011) and let the coupled model run for a total of 38 years, from 1971 to 2008 . The first 33 years are considered spin-up and we present the results for the years 2004 to 2008. Prior to activating the biogeochemical module, the ocean model had been spun up for 300 years, which is sufficient to reach a quasi-equilibrium state (Fig. 8 in Sidorenko et al., 2011). The length of the time step used throughout the run was $1800 \mathrm{~s}$.

In REcoM2, the tracers for dissolved inorganic nitrogen (DIN) and dissolved silicon (DSi) were initialized with values from the Levitus World Ocean Atlas climatology of 2005 (Garcia et al., 2006), and the dissolved inorganic carbon (DIC) and total alkalinity (TA) tracers were initialized with contemporary values from the Global Ocean Data Analysis Project (GLODAP) data set (Key et al., 2004). Due to scarcity of observations for DFe, the iron field was initialized with an output from the Pelagic Interaction Scheme for Carbon and Ecosystem Studies (PISCES) model (Aumont et al., 2003), which has been modified south of $45^{\circ} \mathrm{S}$ with mean observed profiles from Tagliabue et al. (2012). All other tracers were initialized with arbitrary small values.

We used a constant value for the atmospheric $\mathrm{CO}_{2}$ during the simulation. Because of the duration of the simulation, the carbon cycle is not in equilibrium at the end of the run, and we do not to focus on this part of the model here.

\subsection{Data and skill metrics}

The focus of this skill assessment is on the key parameters of the physical, chemical and biological surface fields, for which we examine the model behaviour on the global scale and in the ocean regions shown in Fig. 3. We have a special interest in the Southern Ocean and therefore also look further into the production and its drivers there. On the temporal scale we primarily focus on annual climatologies of the modelled fields, but also show the seasonal development for certain parameters.

The performance of the model regarding sea surface temperature (SST), sea surface salinity (SSS), mixed layer depth (MLD), DIN, DSi, chlorophyll $a$ (Chl), NPP and export production (EP) is summarized in Taylor diagrams, one displaying the spatial agreement between the modelled surface multi-year means and the observations, and one also taking the seasonal variations into account. Due to a lack of monthly data, EP is only plotted in the former Taylor plot. The spatial distribution of the modelled and observed surface climatologies of these same fields, except SST and SSS, have additionally been plotted to show the bias which is not captured by the Taylor diagrams. SST and SSS were omitted as they have been evaluated elsewhere (Sidorenko et al., 2011). Global climatologies of dissolved iron concentrations do not exist, making it impossible to evaluate the modelled iron fields in the manner described above. Instead, the modelled surface climatology of the iron concentration is plotted on its own, and mean values of the ocean basins are compared to observation compilations in table form. NPP is the model's end result, and we have therefore additionally plotted the mean seasonal cycle of the NPP for each of the ocean basins defined in Fig. 3, for the model result as well as satellite-based observations. Due to the large effect the modelled mixed layer has on the prediction of the NPP, we have also chosen to illustrate the seasonal cycle of the modelled and observed mean MLD in these same ocean basins.

The Taylor diagrams (Taylor, 2001) show the correlation $(r)$, the normalized root mean square error (RMSE) and the normalized standard deviation (SD) between the model results and the observations. The correlation between the model and the observations show whether the two data sets increase and decrease simultaneously, the SDs tells us about the magnitude of the changes in the data, but not when these changes occur and the centered RMSE reflects differences in the overall patterns of the two fields after the bias has been removed. The perfect fit between model and observations will have a correlation and a SD of 1 and a RMSE of 0 .

A full list of the observations used can be seen in Table 1. For the NPP we use the Vertically Generalized Productivity Model (VGPM) product from the ocean productivity web page (http://www.science.oregonstate.edu/ocean. productivity/index.php), which is based on the Sea-viewing Wide Field-of-view Sensor (SeaWIFS, 2012) chlorophyll measurements and the VGPM NPP model (Behrenfeld and Falkowski, 1997). We have downloaded monthly values from the web page, and from these calculated the spatial and seasonal means. The EP fields from Schlitzer (2004), Siegel et al. (2014) and Laws et al. (2000) were provided as climatologies. The field from Laws et al. (2000) and Siegel et al. (2014) are satellite based, whereas the field from Schlitzer (2004) comes from an inverse model.

Satellite-based estimates of chlorophyll $a$, NPP and EP provide detailed spatial and temporal data, but obtaining 
Table 1. List of the observational data sets used for the skill assessment.

\begin{tabular}{lcll}
\hline Data set & Variable name & Temporal coverage & Reference \\
\hline Sea surface temperature & SST & Monthly climatology & Garcia et al. (2010) \\
Sea surface salinity & SSS & Monthly climatology & Garcia et al. (2010) \\
Mixed layer depth & MLD & Monthly climatology & de Boyer Montegut et al. (2004) \\
Dissolved inorganic nitrogen & DIN & Monthly climatology & Garcia et al. (2010) \\
Dissolved inorganic silicon & DSi & Monthly climatology & Garcia et al. (2010) \\
Chlorophyll $a$ concentration & Chl & Monthly (1998-2010) & Globcolour (2012) \\
Net primary production & NPP & Monthly (2003-2008) & SeaWIFS (2012), Behrenfeld and Falkowski (1997) \\
Export production & EP & Annual climatologies & Schlitzer (2004), Laws et al. (2000) \\
\end{tabular}

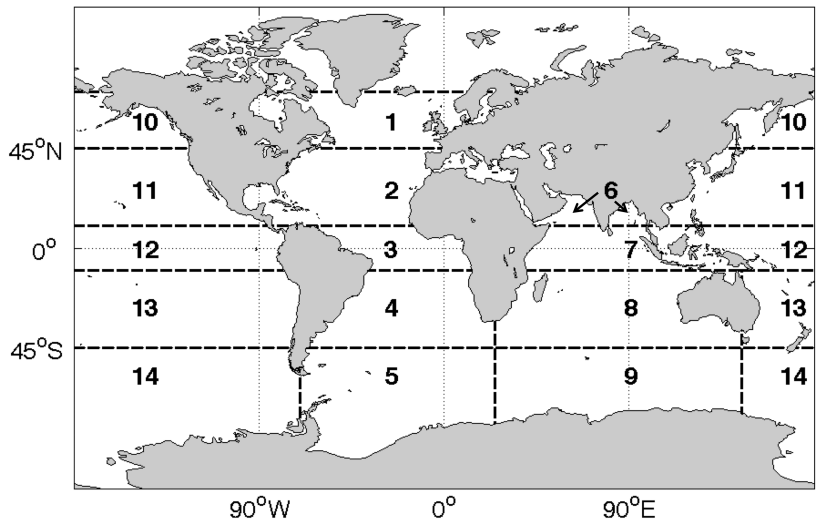

Figure 3. Map of the ocean regions used to examine the model results on a basin scale.

them is not trivial. Remotely sensed global ocean colour values are first converted to chlorophyll $a$, and under a number of assumptions about, for instance, mixed layer depth, temperature and light, NPP (Behrenfeld and Falkowski, 1997) and finally EP (e.g. Laws et al., 2000; Siegel et al., 2014) can be estimated. Increasing uncertainty is introduced during the process, and the satellite-based estimates are not as such observations, but rather another way of modelling the chlorophyll $a$, NPP and EP. The spread between the different satellite-based estimates of NPP is large. Carr et al. (2006) showed that estimates of the global NPP differed by a factor 2 between 24 models, with the largest discrepancies occurring in the high-nutrient low-chlorophyll and extreme temperature areas. The SeaWIFS (2012) algorithms have further been shown to significantly underestimate chlorophyll $a$ concentrations in the Southern Ocean (Gregg and Casey, 2004), and one must consequently be aware of this when using satellitebased estimates from the Southern Ocean.

The Arctic Ocean is likewise an area in which observations are scarce, and for the seasonal Taylor diagrams the modelled results have consequently been removed in both of the polar regions when comparable observational values did not exist. As is the case in the Southern Ocean, it is especially the satellite-based observation of NPP that is affected by this during the winter months. The missing seasonal data has likewise led us to cut off the northern basins at $70^{\circ} \mathrm{N}$ in Fig. 3 .

In addition to comparing our results to available observations, we discuss them in relation to those of other biogeochemical models. For Dfe, Chl and NPP we have plotted our bias plots to the scale used by Schneider et al. (2008). They present the results of the IPSL (Institut Pierre Simon Laplace) model, the MPI (Max Planck Institute) model and the NCAR (National Center for Atmospheric Research) model, providing a range of results to hold our model against. We additionally compare our model to the results from Assmann et al. (2010), who present the results of another nontraditional ocean model coupled to a biogeochemical model, and to Yool et al. (2011). For the export production, Moore et al. (2004) provided a thorough discussion of the export of particulate organic matter as well as opal, and our spatial plots of export production is consequently plotted to the scale used by them.

\section{Model results}

\subsection{Physics: mixed layer depth, salinity and temperature}

The fit between the spatial distributions of modelled and observed surface temperature and salinity is very good for both spatial (Fig. 4a) and monthly spatial fields (Fig. 4b), with the correlations being higher than 0.99 and the normalized SDs close to 1 for both fields. As is general practice in oceanonly models (Griffies et al., 2009), FESOM's surface salinity is weakly restored towards the Polar Science Center Hydrographic Climatology (PHC) (Steele et al., 2001) with a piston velocity of $20 \mathrm{~m} \mathrm{yr}^{-1}$.

In both FESOM and the observations (de Boyer Montegut et al., 2004), the mixed layer depth is defined as the depth at which the difference between the potential density at $10 \mathrm{~m}$ depth and the MLD is greater than $0.03 \mathrm{~kg} \mathrm{~m}^{-3}$. The spatial distribution of the mean MLD has a correlation of 0.68 and a normalized SD of 0.85 when compared to the data-based estimates (Fig. 4). 


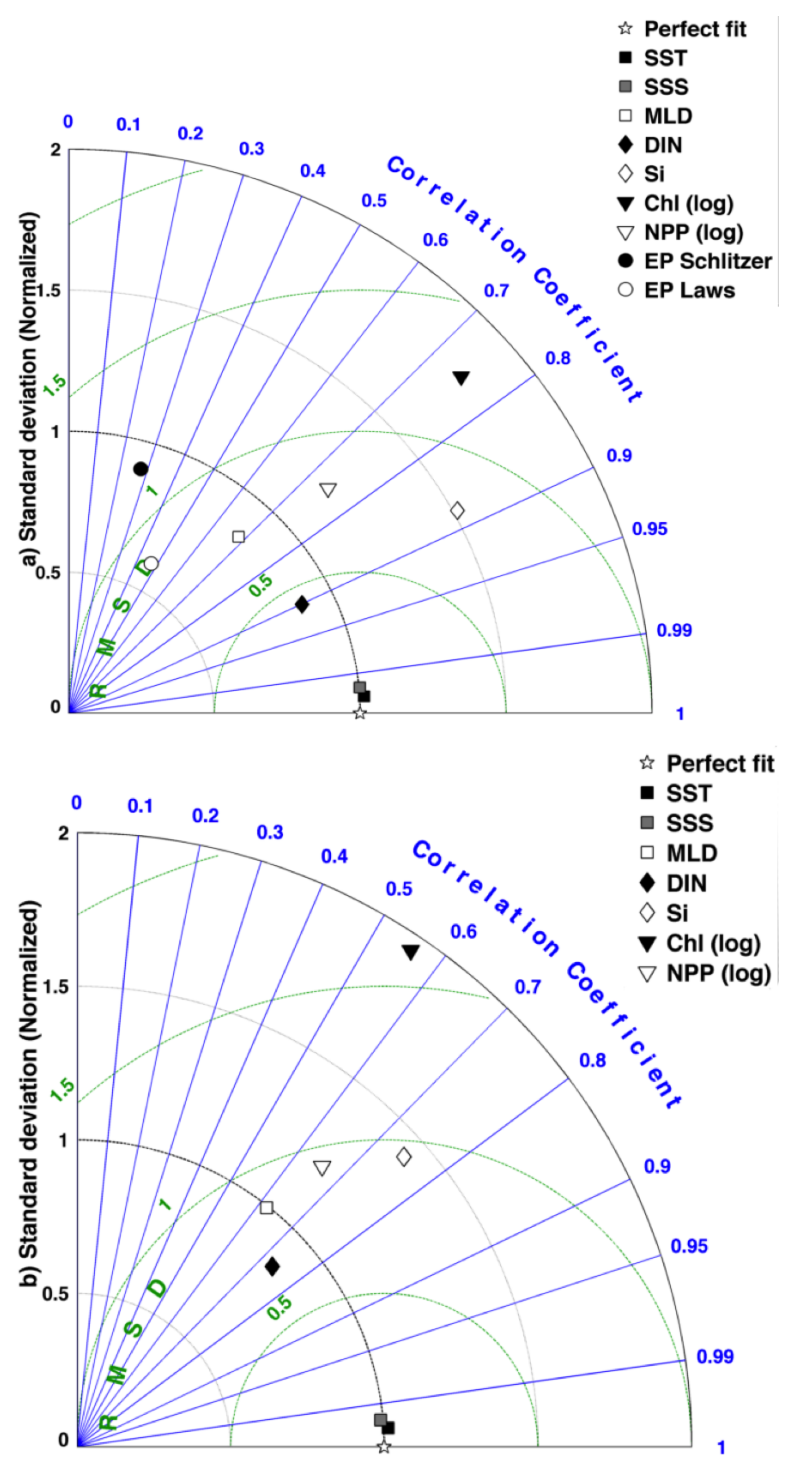

Figure 4. Taylor diagrams (Taylor, 2001) showing correlation, normalized SD and the normalized root mean square error between values of the model results and observations (Table 1), weighted by area. (a) Spatial distribution; (b) spatial-seasonal distribution. All values are surface values, except the mixed layer depth and the vertically integrated NPP. (a) Uses the yearly mean calculated over 2004-2008 and (b) uses the monthly means of the same years. All fields have been interpolated to a $1^{\circ} \times 1^{\circ}$ grid, using linear interpolation.

The seasonal variability of the MLD leads to entrainment of water with high nutrient concentrations to the surface water during winter, and the maximum depth of the mixed layer during the year $\left(M L D_{\max }\right)$ is therefore especially important from a biological point of view. Overall, the modelled $M D_{\max }$ fits well with the observations, but it is generally too shallow in the Southern Ocean (Fig. 5), with the consequence that limiting nutrients are not adequately replenished during winter. This may lead to a too small NPP in the area as
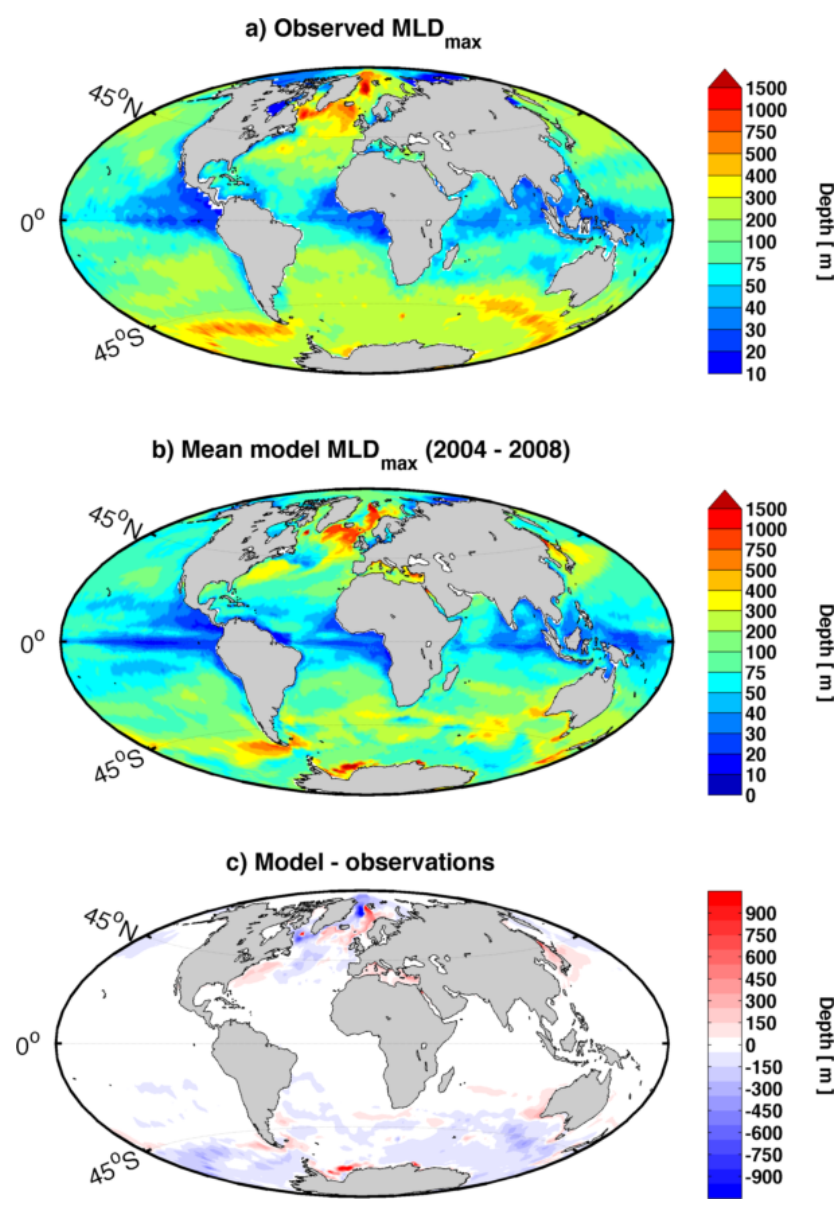

Figure 5. Mean spatial distribution of the $M L D_{\max }$ over the years 2004-2008. (a) Observation based (de Boyer Montegut et al., 2004). (b) Modelled. (c) Residual: modelled - observation based.

well as a dominance of nanophytoplankton over diatoms, as the former needs a lower iron concentration for production. This will be further discussed in Sect. 3.5.

For the monthly fields, the correlation between the modelled MLD and the observations is above 0.6 and the SD equals 1 (Fig. 4b). We investigate this further by plotting the mean depth of the mixed layer in different ocean regions defined in Fig. 3. All basins have correlations above 0.9, except the northern Indian and equatorial basins (Fig. 6), leading us to conclude that the seasonal change in the MLD is well predicted by FESOM.

\subsection{Nutrients and nutrient limitation}

The annual mean surface distribution of DIN and DSi have correlations between model results and observations of 0.91 and 0.86 , respectively (Fig. 4a). In the Southern Ocean, the surface DIN concentrations have a negative bias for DIN (Fig. 7) and a positive for DSi (Fig. 8) when the spatial distribution of modelled and observed values are compared. The DIN concentration additionally becomes too high in the sub- 

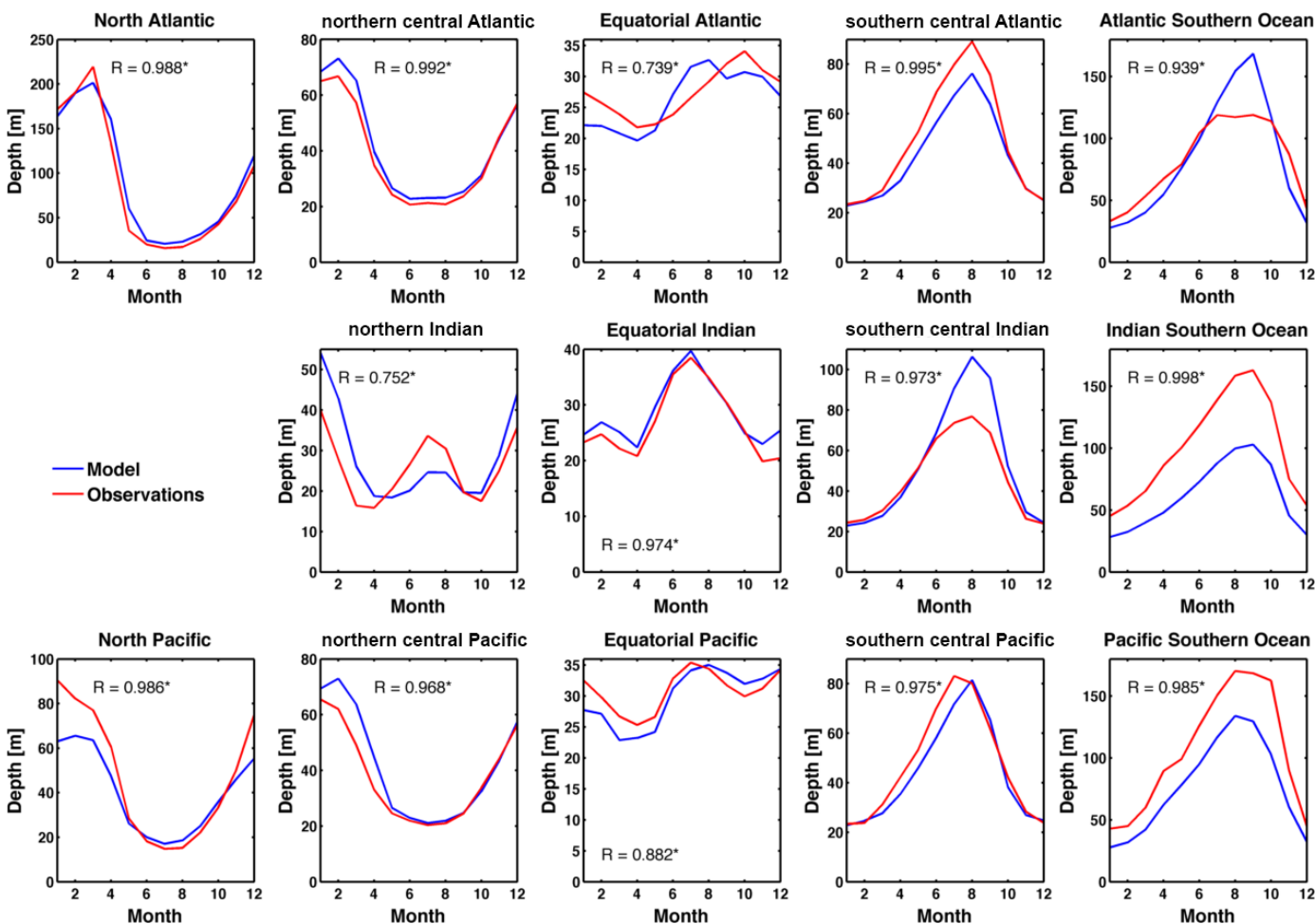

Figure 6. Mean MLD over the year in the ocean basins depicted in Fig. 3. The correlation coefficient is written in each plot, and the statistically significant correlations $(p$ values $<0.05)$ are marked with *.

tropical Pacific Ocean (Fig. 7), something we will later argue happens due to a strong iron limitation in the area.

The correlation between model results and observations for the spatial-seasonal distribution of DIN and DSi is close to 0.75 for both fields (Fig. 4b). For both nutrients, the seasonal cycle has the best agreement with the observations in the polar regions (not shown).

Iron has been shown to play a large role as limiting nutrients for phytoplankton in the Southern Ocean, as well as the equatorial and subarctic Pacific (Martin et al., 1991), and is therefore a key parameter in the model. We compare the model's surface iron concentration to compilations of observations (Moore and Braucher, 2008; Tagliabue et al., 2012) and to other biogeochemical models (i.e. Schneider et al., 2008). It must be mentioned here that the model is not independent of the observations from Tagliabue et al. (2012) as they are also used for initialization of dissolved iron. But as we only compare surface values, and the residence time of iron in the Southern Ocean is much shorter than the model run, the surface iron concentrations at the end of the model run should not be affected by the initialized values.

The pattern of the surface iron concentration in the Atlantic Ocean (Fig. 9) fits well with the observations in Table 2 as well as with the results from the MPI and NCAR models in Schneider et al. (2008), with relative high concentrations in the equatorial region fed by the dust plume from the Sahara, and concentrations decreasing towards the poles. The
Table 2. Modelled mean surface iron concentrations $(0-100 \mathrm{~m})$ in the different ocean basins shown in Fig. 3. Observed values are from Moore and Braucher (2008), except those marked with *, which are from Tagliabue et al. (2012), Table 2. The latter is the mean of the values given for the Antarctic and Subantarctic regions.

\begin{tabular}{llcc}
\hline Basin & $\begin{array}{l}\text { Latitudinal } \\
\text { extent }\end{array}$ & $\begin{array}{c}\text { Model } \\
{[\mathrm{nM}]}\end{array}$ & $\begin{array}{c}\text { Obs } \\
{[\mathrm{nM}]}\end{array}$ \\
\hline North Atlantic & $45-70^{\circ} \mathrm{N}$ & 0.34 & 0.68 \\
Northern central Atlantic & $10-45^{\circ} \mathrm{N}$ & 1.03 & 0.68 \\
Southern central Atlantic & $45-10^{\circ} \mathrm{S}$ & 0.28 & 0.44 \\
Northern Indian & $45-10^{\circ} \mathrm{S}$ & 1.10 & 1.21 \\
North Pacific & $45-70^{\circ} \mathrm{N}$ & 0.14 & 0.31 \\
Equatorial Pacific & $10^{\circ} \mathrm{S}-10^{\circ} \mathrm{N}$ & 0.02 & 0.84 \\
Southern central Pacific & $45-10^{\circ} \mathrm{S}$ & 0.02 & 0.31 \\
Atlantic Southern Ocean & $90-45^{\circ} \mathrm{S}$ & 0.14 & $0.39^{*}$ \\
Indian Southern Ocean & $90-45^{\circ} \mathrm{S}$ & 0.08 & $0.33^{*}$ \\
Pacific Southern Ocean & $90-45^{\circ} \mathrm{S}$ & 0.09 & $0.15^{*}$ \\
\hline
\end{tabular}

iron concentrations in the IPSL model and Assmann et al. (2010) are somewhat lower in the equatorial and southern part of the Atlantic Ocean than our result.

In the Indian Ocean, our surface iron concentrations agree well with the IPSL and NCAR models as well as with the results from Yool et al. (2011), with values higher than $1 \mathrm{nM}$ in the Arabian Sea and falling towards $0.3 \mathrm{nM}$ in the main In- 


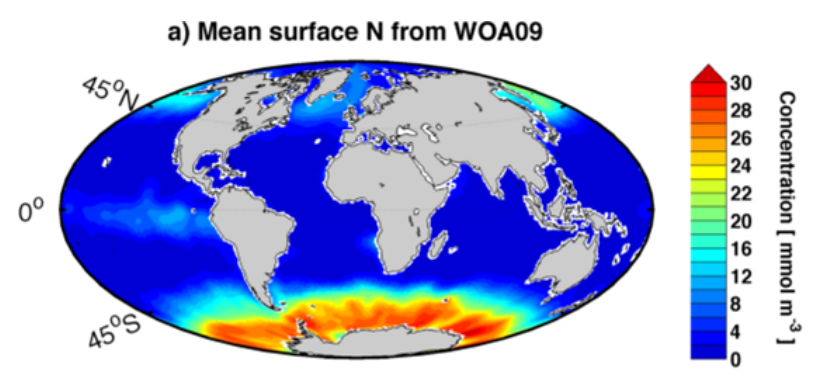

b) Mean model surface $\mathrm{N}$ ( 2004 - 2008 )

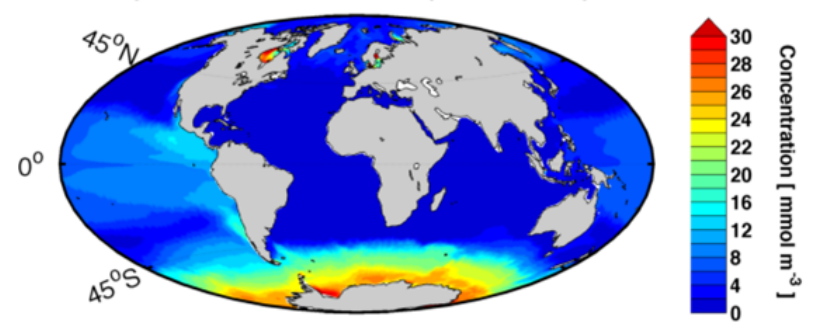

c) $\triangle \mathrm{N}$ : Model - WOA

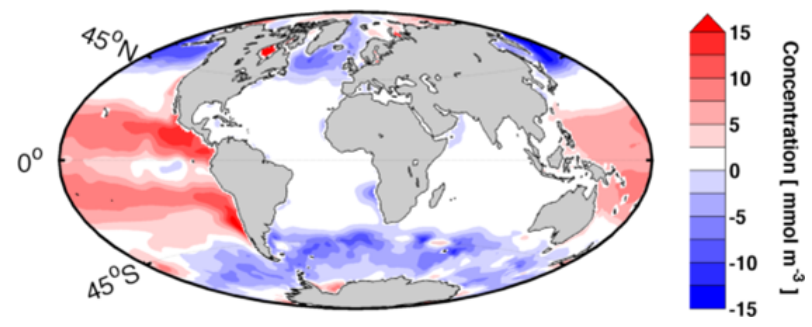

Figure 7. Spatial distribution of mean surface concentration of dissolved inorganic nitrogen. (a) Observed (Garcia et al., 2010) (b) Modelled. (c) Residual: modelled - observed.

dian Ocean. Our values also fit well with the observations in the northern Indian Ocean (Table 2), and this, along with the agreement between the models using varying magnitudes of sedimentary iron input, indicates that the coastal upwelling in the Arabian Sea is well captured in these models, and that this upwelling is responsible for the high surface iron concentrations in the area. The lower surface iron concentration in South East Asia is on the other hand evident in all of these models with the exception of the IPSL model, indicating that the sediment source plays a larger role in this area. Here, unfortunately we do not have observations to validate the models. In the Pacific Ocean, our result is closest to the one from Assmann et al. (2010), though they have a higher iron concentration along the North and South American west coast, indicating a stronger coastal upwelling in their ocean model. We have a lower surface iron concentration than all models presented by Schneider et al. (2008), even though they all have low concentrations locally. The observations in Table 2 indicate that all models underestimate the surface iron concentrations in the Pacific, especially in the equatorial region where the upwelling plays the largest

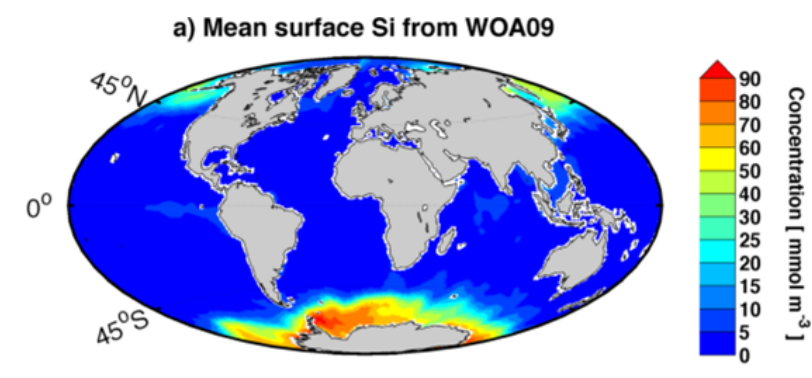

b) Mean model surface Si ( 2004 - 2008)

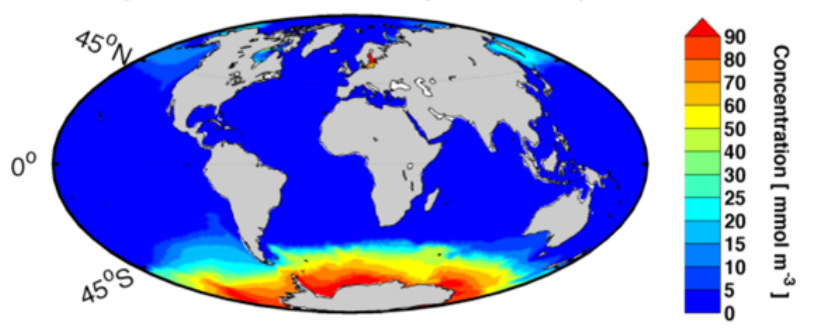

c) $\triangle \mathrm{Si}$ : Model - WOA

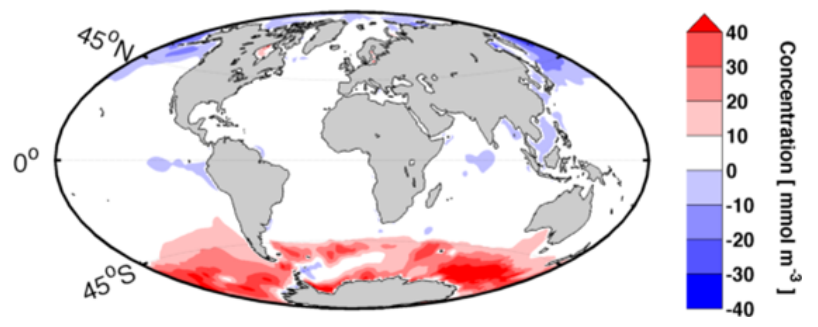

Figure 8. Spatial distribution of mean surface concentration of dissolved inorganic silicon. (a) Observed (Garcia et al., 2010) (b) Modelled. (c) Residual: modelled - observed.

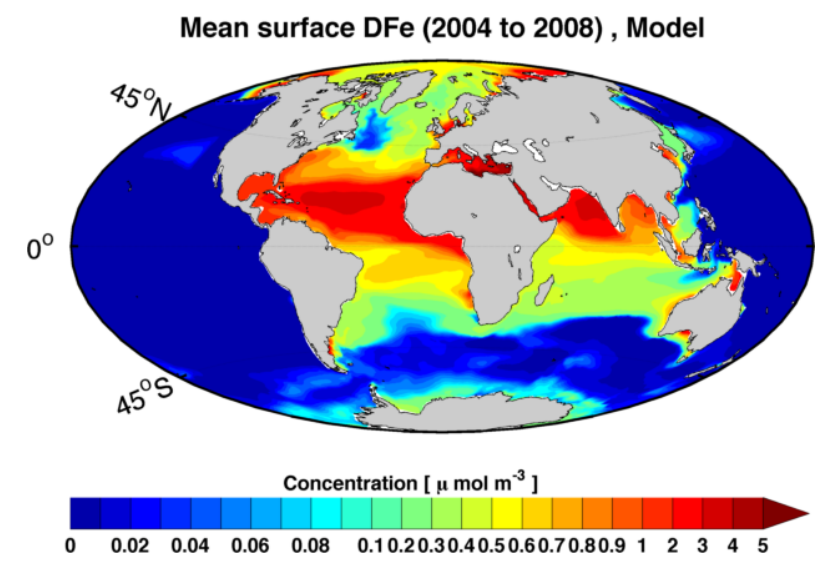

Figure 9. Spatial distribution of the mean surface concentration of dissolved iron. Plotted to the scale used by Schneider et al. (2008).

role. In the Southern Ocean, Table 2 shows that our surface iron concentration is too low, but the spatial distribution of the surface iron fits well with observed values, with the highest values found in the vicinity of the Antarctic and east of the 
Patagonian shelf (Tagliabue et al., 2012). This distribution can mainly be attributed to the sediment and dust sources of iron and the seasonal ice coverage impeding iron uptake by phytoplankton near the Antarctic continent. These factors are also responsible for maintaining the relatively high surface iron concentration in the Arctic, which becomes iron limited in the absence of the sediment source of iron. Assmann et al. (2010) and Moore and Braucher (2008) also experienced this, with the latter mentioning that the missing sediment source has a modest impact on productivity and iron concentrations away from the Arctic. In the Southern Ocean, our result agrees the best with the IPSL model, with a relatively high coastal concentration, which then falls towards the north. Both the MPI and NCAR models have relatively constant higher values in the area south of $40^{\circ} \mathrm{S}$ of around 0.5 and $0.3 \mathrm{nM}$, respectively.

The comparison to observations is, however, hindered by the different definitions of the ocean basins. The value of the North Atlantic from Moore and Braucher (2008), for instance, roughly covers the North Atlantic as well as the northern central Atlantic of our definition (Fig. 3). For the equatorial Pacific, Moore and Braucher (2008) report the value $0.84 \mathrm{nM}$ for the whole ocean, and $0.11 \mathrm{nM}$ for the open ocean, where our value is closer to the latter due to the missing coastal processes in the model.

Nutrient uptake limitation is described by Michaelis-Menten kinetics in the model. The Michaelis-Menten coefficient (MM) is computed as $\mathrm{MM}=[\mathrm{Nut}] /\left([\mathrm{Nut}]+K_{\mathrm{Nut}}\right)$, with $[\mathrm{Nut}]$ being the nutrient concentration, and $K_{\mathrm{Nut}}$ a nutrient and phytoplankton dependent half-saturation constant.

To plot the distribution of the mean surface limitation we follow the example of Schneider et al. (2008), where the nutrient with the lowest MM in a given place is seen as limiting and it is assumed that other factors, such as temperature and light, are limiting when all Michaelis-Menten coefficients are above 0.7 (Fig. 10).

When looking at the yearly mean, iron limits nutrient uptake for both nanophytoplankton and diatoms up to $45^{\circ} \mathrm{S}$ and in most of the Pacific. Nanophytoplankton is mainly nitrogen limited in the Atlantic and Indian oceans, concurring with the result by Assmann et al. (2010), Yool et al. (2011) and the IPSL model in Schneider et al. (2008). For diatoms, silicon is limited in the Atlantic and Indian oceans as well as in the Arctic, a feature that we only share with Yool et al. (2011).

In the high latitudes, the modelled nanophytoplankton become light limited during the respective winter months. For the Arctic this is most pronounced in February, where the light limitation reaches down to $45^{\circ} \mathrm{N}$ in the Atlantic Ocean. For the Southern Ocean, the highest degree of light limitation occurs in August when the area south of $55^{\circ} \mathrm{S}$ is affected. The higher nutrient demand by diatoms means that they are co-limited by iron and light during winter (not shown).

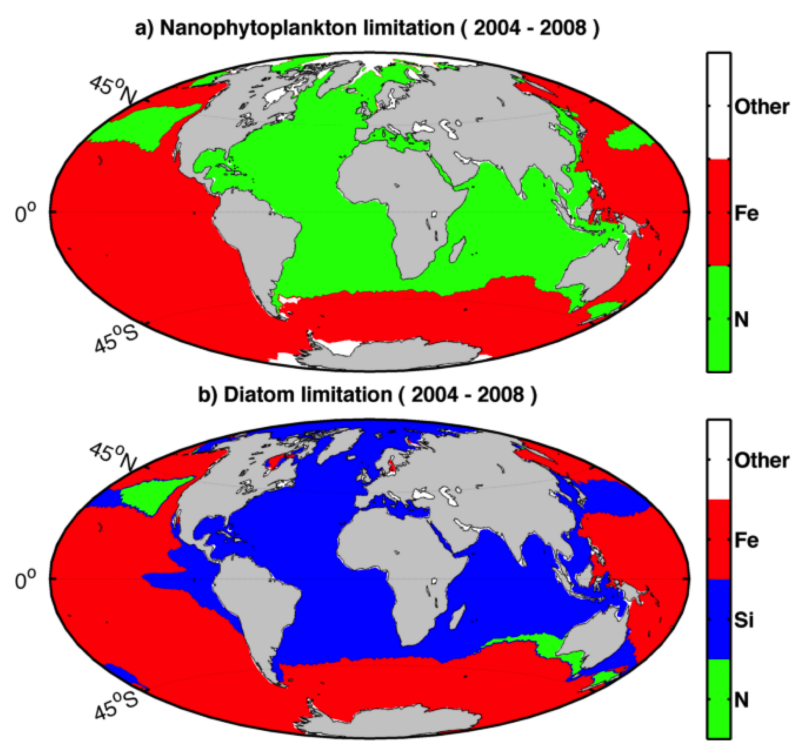

Figure 10. Following the example of Schneider et al. (2008), the spatial distribution of the annually mean limiting nutrients in the model's surface water has been calculated. (a) Nanophytoplankton $(\mathrm{Fe}=56.6 \%, \mathrm{DIN}=40.1 \%$ of total area). (b) Diatoms $(\mathrm{Fe}=53.6 \%, \mathrm{DIN}=2.5 \%$ and $\mathrm{DSi}=43.8 \%$ of total area $)$.

\subsection{Chlorophyll and net primary production}

Global NPP sums up to $32.5 \mathrm{PgCyr}^{-1}$ in the model (Table 3), which is lower than the satellite-based estimate of 47.3 $\mathrm{PgC} \mathrm{yr}^{-1}$ (SeaWIFS, 2012; Behrenfeld and Falkowski, 1997) and also slightly below the estimate range of $35-70 \mathrm{PgC} \mathrm{yr}^{-1}$ given by Carr et al. (2006), but higher than the modelled values ranging from 23.7 to $30.7 \mathrm{PgC}^{-1}$ reported by Schneider et al. (2008).

On a global scale, diatoms account for $25.9 \%$ of all production in the model. In the subtropical gyres, we see close to zero percent of NPP from diatoms, whereas it constitutes close to $100 \%$ in the Arctic Ocean (not shown).

The correlations between the spatial distribution of modelled results and satellite data are 0.75 for both chlorophyll $a$ and NPP (Fig. 4a), with the mean surface chlorophyll $a$ concentration being somewhat overestimated as compared to the satellite-based estimates in the high latitudes, while the equatorial regions have concentrations that are too low (Fig. 11) and the extent of the subtropical gyres is too large. Yool et al. (2011) have a higher equatorial chlorophyll $a$ concentration in the equatorial regions of the Atlantic and Pacific oceans as compared to our model, but their concentration in the Southern Ocean is even higher than ours. Furthermore, when we compare our model to the IPSL model (Schneider et al., 2008), we again see that our equatorial chlorophyll $a$ concentrations are lower, whereas the concentrations in the North Atlantic and Southern Ocean are fairly similar to our result. 
Table 3. Net primary and export production for the global domain and the Southern Ocean south of $50^{\circ} \mathrm{S}$, for REcoM2 and from literature.

\begin{tabular}{|c|c|c|c|}
\hline & Units & FESOM-REcoM2 & Previous studies \\
\hline $\mathrm{NPP}_{\text {glo }}$ & {$\left[\mathrm{PgCyr}^{-1}\right]$} & 32.5 & $\begin{array}{l}\text { 35-70 (Carr et al., 2006) } \\
\text { 23.7-30.7 (Schneider et al., 2008) } \\
\text { 47.3 (Behrenfeld and Falkowski, 1997) }\end{array}$ \\
\hline $\mathrm{EP}_{\text {glo }}$ & {$\left[\mathrm{PgC}_{\mathrm{yr}}{ }^{-1}\right]$} & 6.1 & $\begin{array}{l}5.8-13.0 \text { (Dunne et al., 2007) } \\
6 \text { (Siegel et al., 2014) }\end{array}$ \\
\hline Opal $_{\text {glo }}$ & {$\left[\right.$ Tmol Si yr $\left.^{-1}\right]$} & 74.5 & 69-185 (Dunne et al., 2007) \\
\hline $\mathrm{NPP}_{\mathrm{SO}}$ & {$\left[\mathrm{PgCyr}^{-1}\right]$} & 3.1 & $1.1-4.9$ (Carr et al., 2006) \\
\hline $\mathrm{EP}_{\mathrm{SO}}$ & {$\left[\mathrm{PgCyr}^{-1}\right]$} & 1.1 & 1 (Schlitzer, 2002; Nevison et al., 2012) \\
\hline $\mathrm{Opal}_{\mathrm{SO}}$ & {$\left[\mathrm{Tmol} \mathrm{Si} \mathrm{yr}^{-1}\right]$} & 21.5 & 21-54 (Dunne et al., 2007) \\
\hline
\end{tabular}

a) Obs. mean surface Chl ( $1998-2010)$

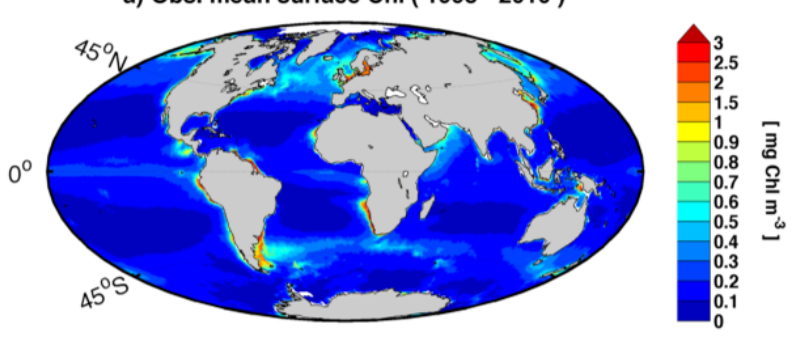

b) Model mean surface Chl (2004 - 2008)

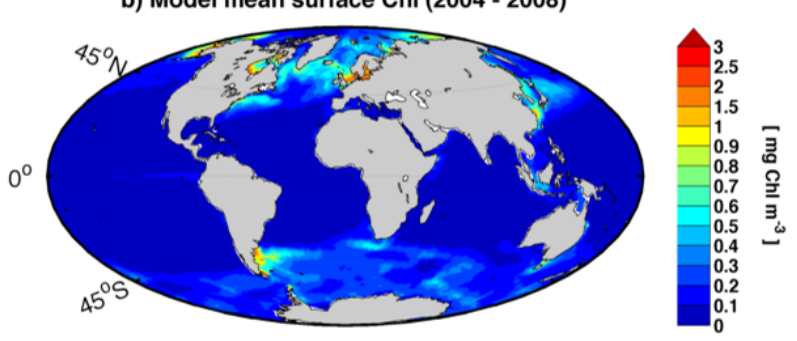

c) Model - observations

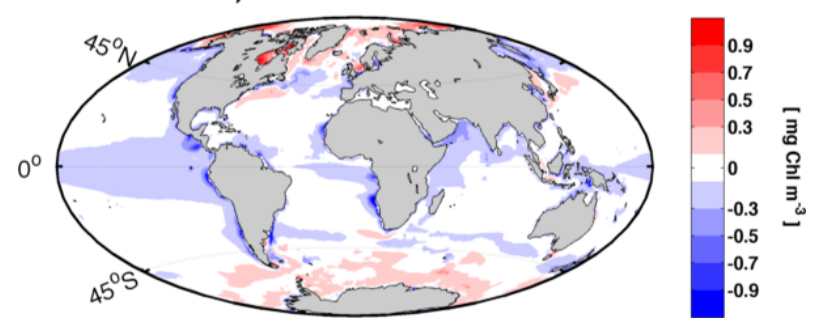

Figure 11. Spatial distribution of mean surface concentrations of chlorophyll $a$ plotted to the scale used by Schneider et al. (2008). (a) Satellite-based estimate (www.globcolour.info). (b) Modelled. (c) Residual: modelled - satellite-based estimate.

The spatial distribution of NPP (Fig. 12), follows the same pattern as chlorophyll $a$, with low production in the oligotrophic gyres along with a higher production in the temperate regions. Production in the gyres is on the low side compared to the satellite-based estimate (Fig. 13), and as they are known to underestimate production here (Friedrichs et al., 2009), our result is most likely much too low here. An explanation may be that the nanophytoplankton in the model does not represent the smallest phytoplankton classes, such as Prochlorococcus and Synechococcus, which are important in the gyres. Even though adaption of the modelled intracellular $\mathrm{N}: \mathrm{C}$ ratio is possible, this is not enough to increase production here to the level seen in satellite-based estimates.

The missing coastal primary production along the west coast of Africa and South America (Fig. 12) along with a positive temperature bias in these areas (not shown) indicate that the upwelling is too weak here. FESOM has a coastal resolution of $40 \mathrm{~km}$, which is relatively high, but this resolution only covers a narrow path along the coast (Fig. 1), which may not be sufficient for the upwelling zones to be resolved properly; additionally, the low resolution further out in the subtropical gyres could play a role. Furthermore, the driving force for the upwelling is the coastal winds, and the missing upwelling may partially result from a too low resolution of the atmospheric forcing; moreover, higher resolution allows strong surface winds closer to the coast, thereby increasing the strength of the upwelling (Gent et al., 2010).

Another explanation for the low coastal NPP is the missing riverine input of macronutrients, which at least in the case of silicon plays a role locally in places like Amazonas and the Arctic (Bernard et al., 2011). Yool et al. (2011) deal with the missing riverine nutrient input by restoring the nutrient fields along the coasts. Although Yool et al. (2011) have a larger coastal production in their model (especially along the coast of West Africa), they show that the nutrient restoring only has a small influence on this.

When comparing the mean spatial distribution of NPP with other models, our result is the closest to the NCAR model presented by Schneider et al. (2008), with a relatively high production rate in the North and equatorial Atlantic as well as the Indian Ocean. Moderate production in the area of the polar front in the Southern Ocean is a feature that 

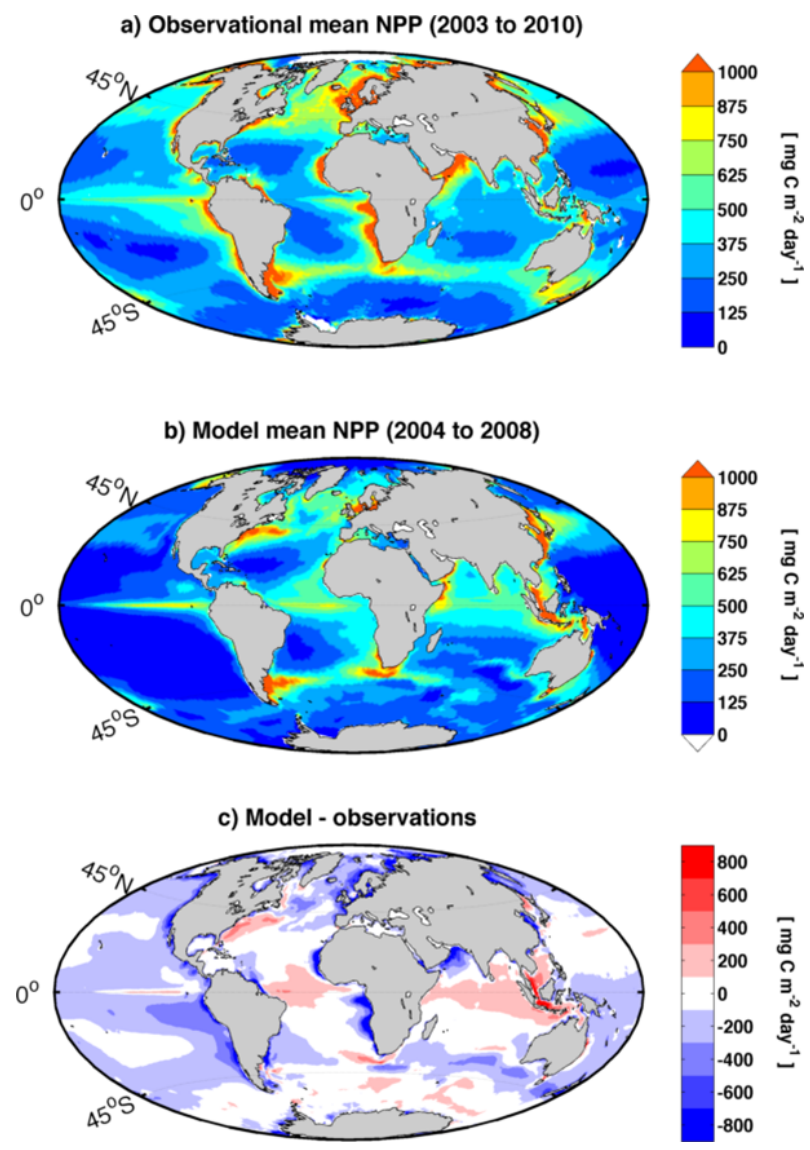

Figure 12. Mean spatial distribution of vertically integrated NPP plotted to the scale used by Schneider et al. (2008). (a) Satellitebased estimate (SeaWIFS, 2012; Behrenfeld and Falkowski, 1997). (b) Model. (c) Residual: modelled - satellite-based estimate.

our model shares with the satellite-based estimate (Fig. 12) and with the NCAR and IPSL models from Schneider et al. (2008). Despite our model's strong iron limitation in the Pacific Ocean, our results fit well with the IPSL model, though we have a smaller production rate in the southern Pacific.

Taking seasonal variations into account, NPP and surface chlorophyll $a$ have correlations of 0.66 and 0.57 , respectively, when comparing the model and the satellite-based estimate (Fig. 4b), and the normalized SDs are equal to 1.47 and 1.94 for chlorophyll $a$ and NPP, respectively. Both are on the same order as the values presented by Doney et al. (2009).

The timing of the seasonal cycle of NPP is well captured in the majority of the ocean regions defined in Fig. 3 (Fig. 13). The Pearson's correlation coefficients $(R)$ range from 0.31 in the equatorial Atlantic to 0.93 in the southern central Atlantic (Fig. 13), with significant correlations in eight of the fourteen basins. In general, the modelled seasonal cycle is closest to the satellite-based estimate between 10 and $45^{\circ} \mathrm{N}$ and $\mathrm{S}$, where the modelled NPP is low, but the magnitude of the seasonal variations fits well with the satellite-based estimate.
This is the case for all basins in the mentioned area, except the northern Indian basin.

The Southern Ocean stands out as it has a modelled NPP of the same magnitude as the satellite-based estimate, but the spring bloom occurs too early here, compared to the satellitebased estimate. This will be further discussed in Sect. 3.5.

\subsection{Export production}

The export of organic carbon out of the euphotic zone (export production-EP), is calculated at a reference depth, which in our case is set to the standard $100 \mathrm{~m}$ (e.g. Schneider et al., 2008; Doney et al., 2009). Here, we regard EP as the organic matter that sinks due to the effect of gravity, whereas the total EP also entails the vertical movement of POC by advection and diffusion plus a contribution from semi-labile DOC.

The global export production sums up to $6.1 \mathrm{PgCyr}^{-1}$ in the model (Table 3), close to the satellite-based estimate of $6 \mathrm{PgC} \mathrm{yr}^{-1}$ from Siegel et al. (2014). It is also within the range of estimates presented by Dunne et al. (2007), but on the low side and closer to modelled estimates than to estimates based on observations or inverse models.

The modelled EP constitutes $20 \%$ of NPP on a global scale, which is similar to the ratio predicted by Laws et al. (2000). The EP field presented by Laws et al. (2000) is calculated at $100 \mathrm{~m}$ depth and is based on satellite observations of ocean colour, whereas the EP field calculated by Schlitzer (2004) is based on an inverse model and is calculated at $133 \mathrm{~m}$. Comparing our model to these fields can consequently be argued to be more of a model-model comparison than a model-observation comparison.

The correlation is 0.28 and 0.48 , when comparing the spatial distribution of EP in our model to the fields by Schlitzer (2004) and Laws et al. (2000), respectively (Fig. 4a), indicating that our spatial distribution is closer to the field from Laws et al. (2000), and the normalized SDs are 0.90 and 0.60, respectively.

The EP fields from Schlitzer (2004) and Laws et al. (2000) both have high export along the Equator, in the upwelling regions and along $45^{\circ} \mathrm{N}$ and S (Fig. 14a and b). In the Southern Ocean, Schlitzer (2004) has a comparably higher export in the Indian and Pacific sector and in the North Atlantic Schlitzer (2004) has less than Laws et al. (2000).

REcoM2 captures the overall pattern with high EP around $45^{\circ} \mathrm{N}$ and $\mathrm{S}$ and along the Equator (Fig. 14c and d), and the elevated EP in the North Atlantic is a feature that REcoM2 shares with the field from Laws et al. (2000). Turning to the differences, our EP is lower in the North Atlantic, slightly lower in the gyres and higher south of $45^{\circ} \mathrm{S}$ when compared to the field by Laws et al. (2000) (Fig. 14e). Compared to the climatology presented by Schlitzer (2004) (Fig. 14b), our EP is generally lower in the Pacific and in the upwelling regions along West Africa and western North and South America, whereas it is higher in the North and South Atlantic (Fig. 14f). In the Southern Ocean, the differences between 

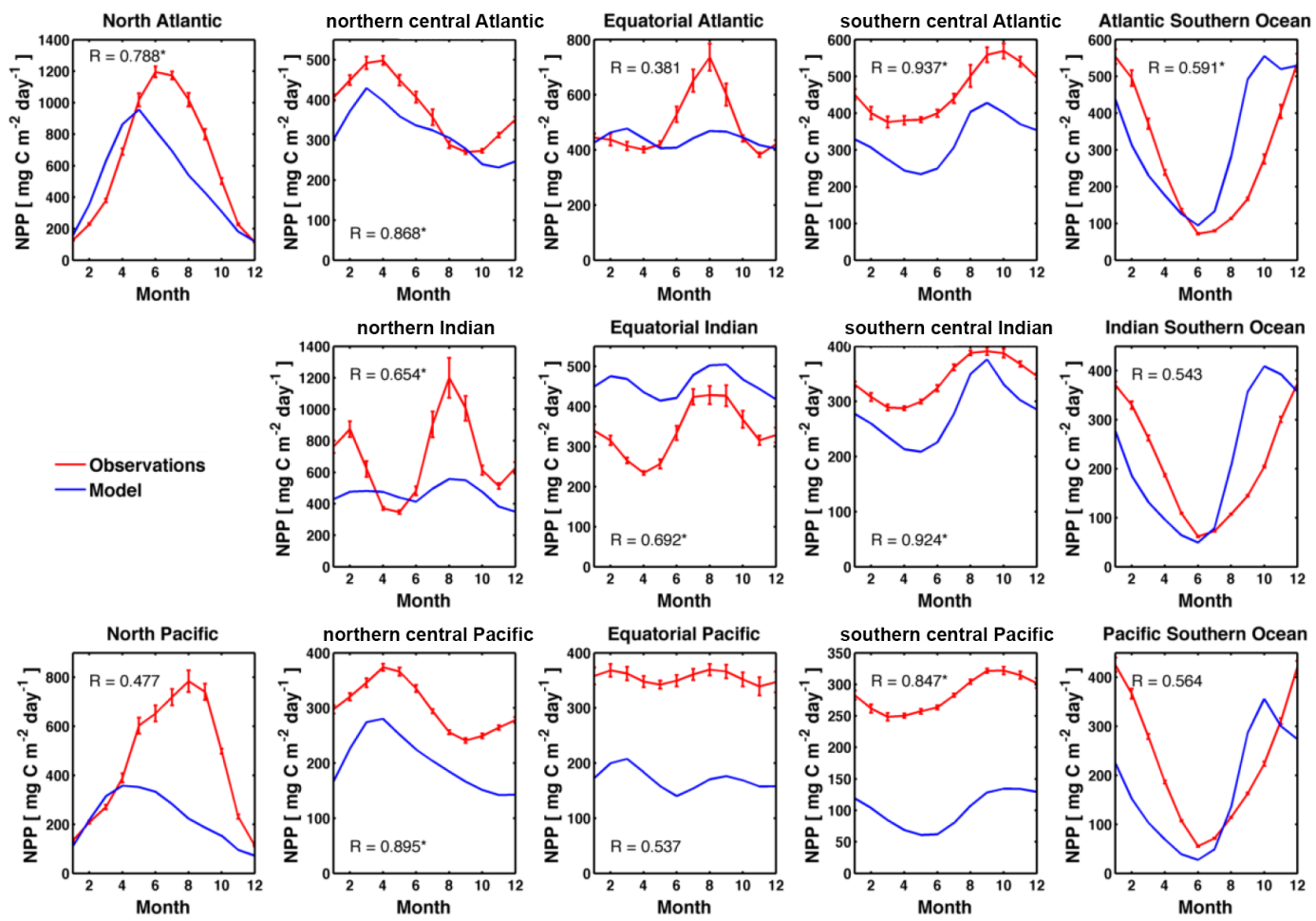

Figure 13. Mean NPP over the year in the ocean basins depicted in Fig. 3. The correlation coefficient is written in each plot, and the statistically significant correlations $(p$ values $<0.05)$ are marked with *
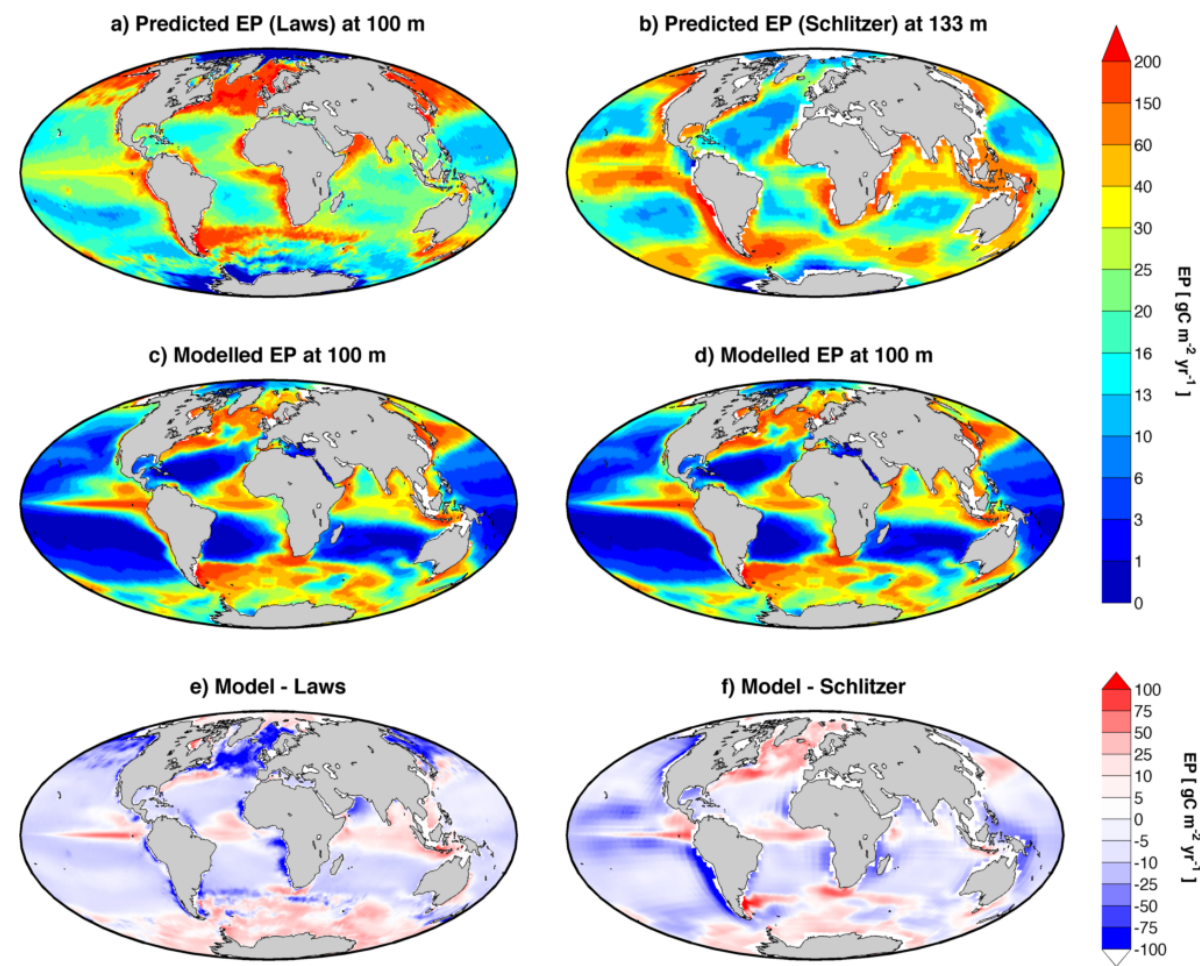

Figure 14. Spatial distribution of export of particulate organic matter plotted to the scale used by Moore et al. (2004). (a) Laws. (b) Schlitzer. (c) and (d) modelled (same figure). (e) Residual: modelled - Laws. (f) Residual: modelled - Schlitzer. 
the fields are especially visible in the Indian and Pacific sectors, where Laws et al. (2000) have very low export, Schlitzer has a rather high export and REcoM2's export lies in between the two. Schlitzer argues that the satellites do not capture the deep blooms that occur in the area, thereby explaining the lack of EP in the satellite-based estimate.

Both the spatial distribution and magnitude of EP in our model are very similar to what was found by Moore et al. (2004).

Vertical export of opal is similarly calculated across a reference depth of $100 \mathrm{~m}$. On a global scale we have a total opal export of $74.5 \mathrm{Tmol} \mathrm{yr}^{-1}$. Previous estimates of global export of opal vary widely (Table 3), and our value is in the lower end of the estimates, as are our global values for NPP and EP.

\subsection{The Southern Ocean}

The coupled model FESOM-REcoM2, as a first step, will be used for studies regarding biogeochemical processes in the Southern Ocean south of $50^{\circ} \mathrm{S}$, and we are therefore especially interested in its performance here. The reasons for this focus are further discussed in Sect. 4.

The model's surface salinity and temperature as well as the nutrient fields are well represented in the spatial domain of the Southern Ocean, with all of them having correlation coefficients above 0.9 when compared to observations (Fig. 15). The chlorophyll $a$ and NPP fields both have somewhat lower correlations, with the correlation for NPP and chlorophyll $a$ being equal to 0.75 and 0.48 , respectively.

For the MLD, the correlation between the model results and the observational-based estimate (de Boyer Montegut et al., 2004) is 0.63 in the Southern Ocean (Fig. 15). The $\mathrm{MLD}_{\max }$ is too shallow in the Indian and Pacific sections of the Southern Ocean, especially in the area of the polar front (Fig. 5), causing this low value. Furthermore, FESOM simulates a too deep $\mathrm{MLD}_{\max }$ in the convection area of the Weddell Sea associated with deep-water formation. This is a common feature in sea ice-ocean models (e.g. Griffies et al., 2009) and should in itself not have a large impact on the production in the Southern Ocean.

The modelled NPP south of $50^{\circ} \mathrm{S}$ sums up to $3.1 \mathrm{Pg} \mathrm{Cyr}^{-1}$ (Table 3). Carr et al. (2006) summarize previous studies of NPP based on ocean colour and report an average NPP of 2.6 ${\mathrm{PgC} \mathrm{yr}^{-1}}^{-1}$ for the Southern Ocean. They also show that the largest uncertainties in satellite-based estimates regarding NPP are found in the Southern Ocean and that biogeochemical models generally predict higher NPP in the area than satellites.

The model's export production equals $1.1 \mathrm{PgC} \mathrm{yr}^{-1}$ in the Southern Ocean, close to the $1 \mathrm{PgC}^{-1}$ found by both Schlitzer (2002) and Nevison et al. (2012), and the EP : NPP ratio equals $36 \%$ in the Southern Ocean, similar to what was found by Nevison et al. (2012).

Considering the spatial distribution of EP in the Southern Ocean (Fig. 14), the model is closer to the estimate from

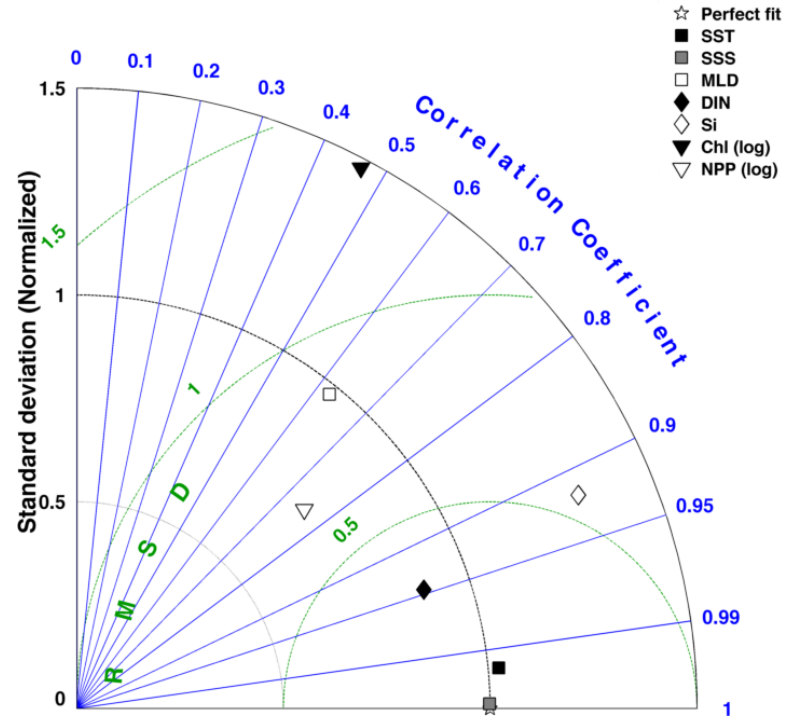

Figure 15. Taylor diagram for the Southern Ocean south of $50^{\circ} \mathrm{S}$ showing correlation, normalized SD and the normalized root mean square error between the spatial distribution of the model results and observed data sets, weighted by area. All values are surface values, except the mixed layer depth and the vertically integrated NPP. The fields have been linearly interpolated to a $1^{\circ} \times 1^{\circ}$ grid, similar to the World Ocean Atlas. he model SD and root mean square error have been normalized by the observational SD.

Laws et al. (2000) with the highest export fluxes occurring in the northern part of the Atlantic and eastern Indian sectors of the Southern Ocean. REcoM2 does however have a larger EP closer to the Antarctic.

The fraction of the the total biomass comprised by diatoms in the Southern Ocean defers between studies (Alvain et al., 2005; Hirata et al., 2011). In the present study, the diatoms are responsible for $25 \%$ of the NPP south of $50^{\circ} \mathrm{S}$, varying from $0 \%$ in the very iron limited waters of the South Pacific to $100 \%$ in the iron replete regions of the Weddell Sea and on the Patagonian shelf (Fig. 16). Vogt et al. (2013) compared the results of four ecosystem models and showed that the percentage of diatom biomass in the Southern Ocean differed significantly between them, ranging from 20 to $100 \%$. Our diatom percentage is accordingly within the spread of other models.

Production of the silicon-containing diatoms creates a sinking flux of biogenic silica that sums up to 21.5 $\mathrm{Tmol} \mathrm{Siyr}^{-1}$ south of $50^{\circ} \mathrm{S}$ in the model (Table 3), which is close to the satellite-based estimate of $25 \pm$ $4 \mathrm{Tmol} \mathrm{Si} \mathrm{yr}^{-1}$ calculated south of $45^{\circ} \mathrm{S}$ (Dunne et al., 2007), but estimates vary significantly between studies (e.g. Moore et al., 2004; Jin et al., 2006; Holzer et al., 2014).

In REcoM2, the opal export in the Southern Ocean accounts for $29 \%$ of the global opal export (Table 3). This number similarly varies widely between studies, with ours being lower than the $70 \%$ suggested by Jin et al. (2006) and 


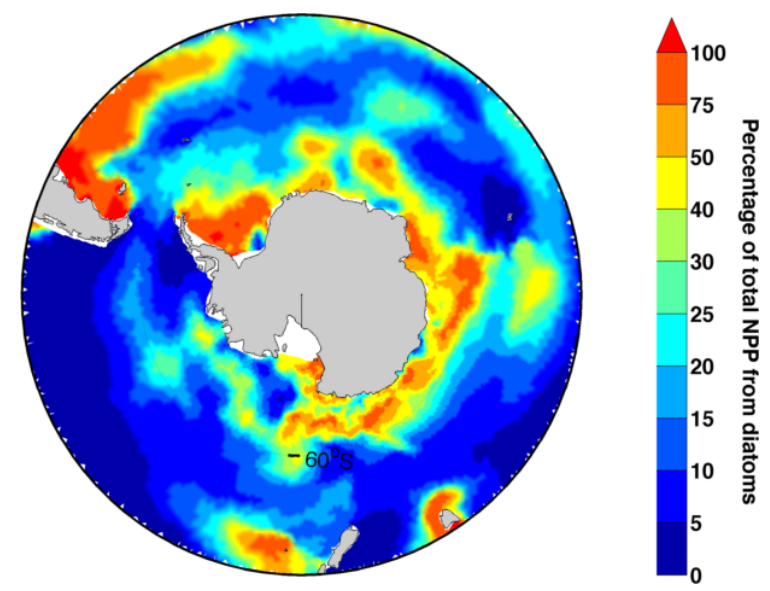

Figure 16. Contribution of diatoms to NPP in the model.

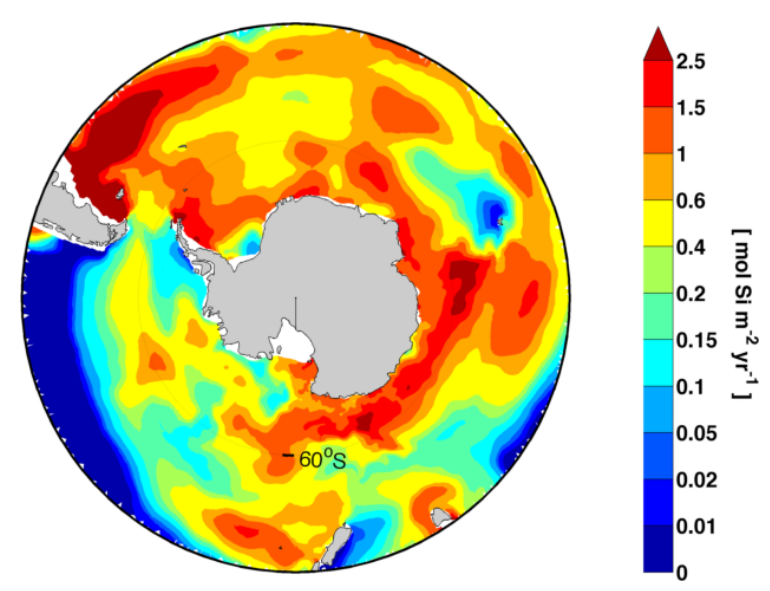

Figure 17. Modelled export of opal across $100 \mathrm{~m}$ depth plotted to the scale used by Moore et al. (2004).

Holzer et al. (2014), but considering the area of the Southern Ocean, its contribution to the global opal flux is still large in our model.

High export fluxes of biogenic silica (Fig. 17) naturally occur in places with a corresponding high percentage of diatom production (Fig. 16). The largest values are found in the temporary ice zone between 60 and $70^{\circ} \mathrm{S}$, as well as in the area east of Patagonia (Fig. 17), where dust and sediments supply iron to the surface water. A band of relatively high opal export is also present in the polar front in the Atlantic and Indian sectors of the Southern Ocean (Fig. 17). In most of the Southern Ocean, the modelled opal flux falls within a range of $0.4-2.5 \mathrm{~mol} \mathrm{Si} \mathrm{m}^{-2} \mathrm{yr}^{-1}$. This is slightly higher than the values given by Moore et al. (2004) and lower than the values of up to $9 \mathrm{~mol} \mathrm{Si} \mathrm{m}^{-2} \mathrm{yr}^{-1}$ in Jin et al. (2006).

The absence of diatom production in the Pacific sector of the Southern Ocean (Fig. 16), leading to a low opal export in the area (Fig. 17), is notable and can be explained by the

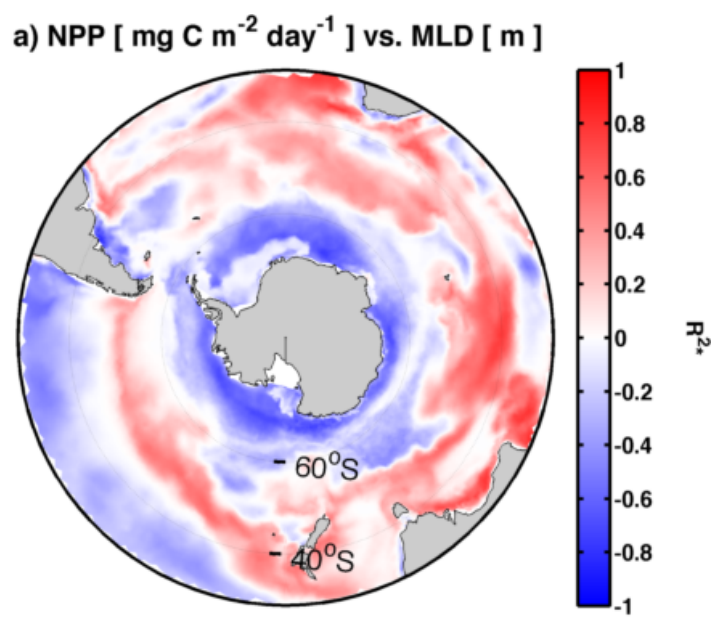

b) NPP $\left[\mathrm{mg} \mathrm{C} \mathrm{m}^{-2}\right.$ day $\left.^{-1}\right]$ vs. DFe $\left[\mu \mathrm{mol} \mathrm{m}^{-3}\right.$ ]

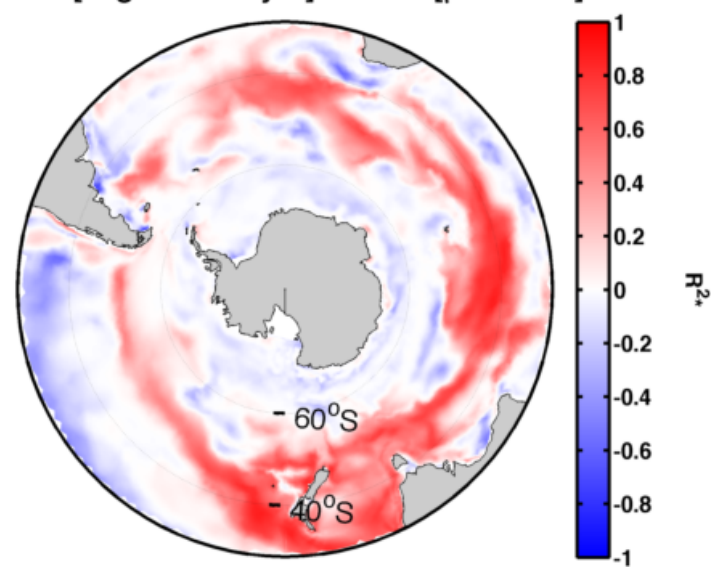

Figure 18. Maps showing coefficients of determination for crosscorrelation between model results of (a) NPP and MLD and (b) NPP and DFe. DFe has been averaged over the upper $100 \mathrm{~m}$ of the water for the calculation. $R^{2 *}$ is defined as the temporal coefficient of correlation multiplied by the sign of the regression coefficient.

pronounced iron limitation of the Pacific, which also reaches into the Southern Ocean and limits production here.*

\section{Control of bloom in the Southern Ocean}

We will now examine the roles of MLD and iron concentration in explaining the seasonal variability of NPP. For this purpose we define $R^{2 *}$ as the temporal coefficient of determination multiplied by the sign of the regression slope. $R^{2 *}$ is calculated for each spatial point in the domain south of $30^{\circ} \mathrm{S}$ between NPP and the MLD (Fig. 18a) and between NPP and DFe (Fig. 18b), using the average iron concentration over the top $100 \mathrm{~m}$ of the ocean. The $R^{2 *}$ values show that the Southern Ocean is roughly divided into two zonal bands; one north of $60^{\circ} \mathrm{S}$, in the area of the polar front (Moore et al., 1999), and one south of $60^{\circ} \mathrm{S}$ (Fig. 18). 
a) 40 to $60^{\circ} \mathrm{S}$

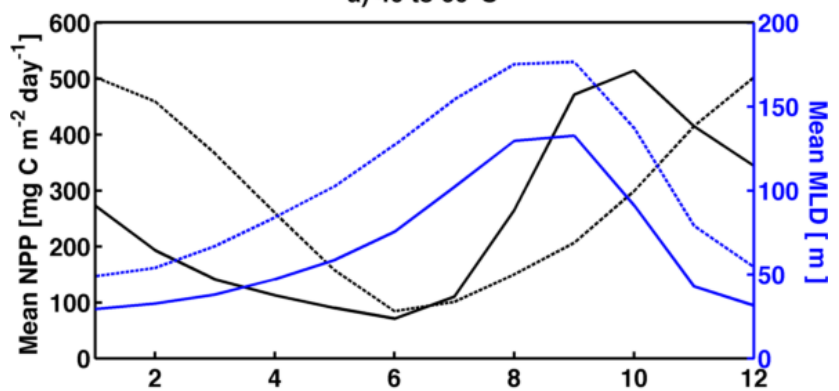

b) South of $60^{\circ} \mathrm{S}$

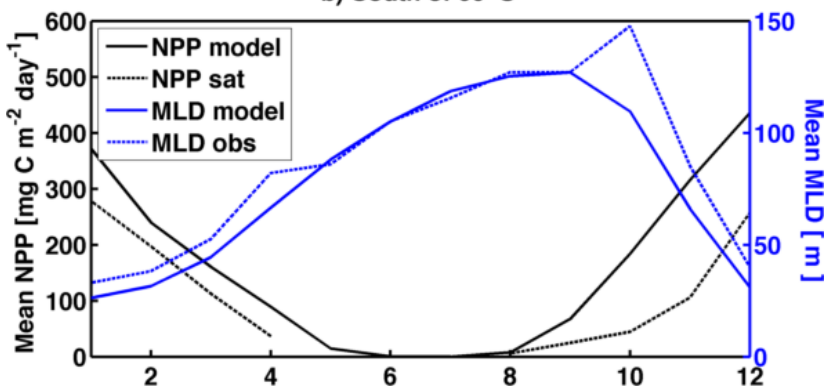

Figure 19. Seasonal change in mean modelled and observed NPP (SeaWIFS, 2012; Behrenfeld and Falkowski, 1997) and MLD (de Boyer Montegut et al., 2004) for (a) the Southern Ocean from 40 to $60^{\circ} \mathrm{S}$ and (b) south of $60^{\circ} \mathrm{S}$.

The general picture north of $60^{\circ} \mathrm{S}$ is that the concentration of dissolved iron and the mixed layer depth both correlate positively with NPP (Fig. 18), indicating that production in the area mainly is iron controlled, and that production starts when the mixed layer deepens and brings iron and other nutrients to the surface. For the mean seasonal cycle of MLD and NPP north of $60^{\circ} \mathrm{S}$ (Fig. 19a), the magnitude of the modelled bloom fits nicely with the one from the satellite-based estimate, but the maximum occurs two months earlier. The mean MLD is well predicted by FESOM in the area (Fig. 19a), but it is consistently shallower than what is observed. This has the effect that the modelled phytoplankton receives a larger light intensity than is the case in the ocean, something that may affect the timing of the bloom. The mean iron concentration in the surface water is highly correlated with the depth of the mixed layer north of $60^{\circ} \mathrm{S}$ (Fig. 20a). The phytoplankton concentration starts increasing in July, when the iron concentration is high, and reaches a maximum in October, after which a combination of high grazer concentration and decreasing iron concentrations most likely causes the bloom to decline. Under nutrient and light replete conditions, the increase in biomass is a result of the balance between phytoplankton's maximum growth rate and the grazing (Behrenfeld, 2010; Hashioka et al., 2013). On the one hand, this indicates that the model's timing of the bloom could be changed by a smaller maximum growth rate, something that would change the phyto- plankton dynamics on a global scale. On the other hand, the modelled zooplankton concentration is tightly coupled to the increase in phytoplankton concentration (Fig. 20a), and increasing the maximum grazing rate is another way of keeping the growth in biomass down. As modelled grazers are set to prefer nanophytoplankton over diatoms, this may further increase the diatom percentage in the Southern Ocean (Hashioka et al., 2013).

The NPP and MLD fields are negatively correlated south of $60^{\circ} \mathrm{S}$, whereas correlation between NPP and DFe is close to zero here (Fig. 18). This indicates that light is the main limiting factor in this area and that iron is less important as a controlling factor. The intensity of the incoming light decreases with latitude, and is further decreased or blocked by the presence of sea ice during parts of the year, south of $60^{\circ} \mathrm{S}$. The role of the sea ice for the timing of the spring bloom was highlighted by Taylor et al. (2013), who argued that the sea ice melting induces a shallower and more stable mixed layer, increasing the average light intensity received by the phytoplankton, thereby instigating growth. In our study, the modelled bloom is larger than what is estimated by the satellites south of $60^{\circ} \mathrm{S}$, but the timing fits well (Fig. 19b). The difference can be explained by the aforementioned underestimation of NPP by the satellites. NPP starts increasing when the iron concentration is high and decreasing again when the iron concentration is low and the grazer concentration high (Fig. 20b).

It is worth noticing that the increase in production begins at the correct time in both areas, but that the rate of biomass increase is too high.

The sparse observations make it difficult to assess the validity of the modelled seasonal cycles of iron and zooplankton. Tagliabue et al. (2012) presented a seasonal cycle of DFe from the SR3 transect south of Tasmania. Their results indicate that the highest iron concentrations occur in January and February suggesting that our seasonal change in iron concentration, which peaks in September, is off. Our results, however, fit well with the model result from Hoppema et al. (2003), who also see a peak in the iron concentration in September.

\section{Discussion}

We have presented a skill assessment of an initial coupling between the biogeochemical REcoM2 and the Finite Element Sea Ice-Ocean Model (FESOM). FESOM's capability of locally increased resolution has not been fully utilized in the current study, with the smallest distance between neighbouring grid points being only a factor of about 10 smaller than the largest, and as with most biogeochemical models (e.g. Yool et al., 2011) we do not resolve eddies. The model run presented here can thus be regarded as a baseline run, from which future work that further explores the capabilities of the new coupling can proceed. 

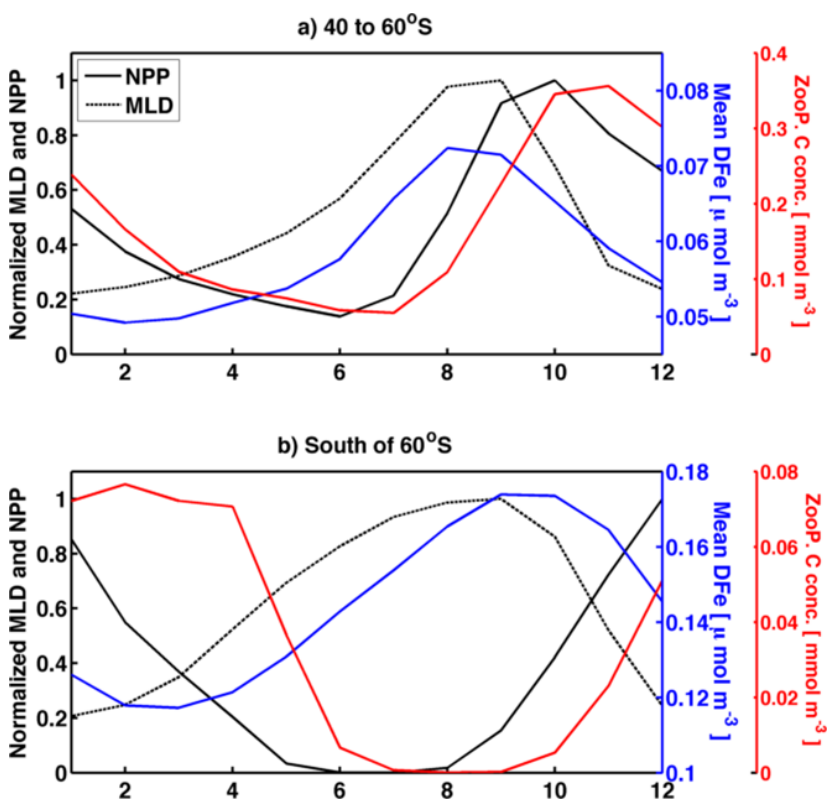

Figure 20. Seasonal change in the modelled NPP, MLD, DFe and zooplankton concentration for (a) the Southern Ocean from 40 to $60^{\circ} \mathrm{S}$ and (b) south of $60^{\circ} \mathrm{S}$. DFe and zooplankton concentrations are averaged over the top $100 \mathrm{~m}$ of the ocean. NPP and MLD are normalized by the maximum of the monthly values.

Using the current resolution, the advantage of the new FESOM-REcoM2 coupling over the older MITgcm-REcoM2 coupling is not obvious, especially taking FESOM's larger demand for computer time into account. The strength of the new coupling will become clearer when new studies on specialized meshes have been carried out. We are currently looking into the effect of the ocean model on the biogeochemistry of the Southern Ocean by comparing two model runs between which only the ocean model differs. We assess the differences of the supply of iron to the surface mixed layer from below, and how it affects the NPP in the area (SchourupKristensen et al., 2014).

In regional models of the Southern Ocean, fixed boundary conditions must be added along the northern boundary where the Southern Ocean is connected to the Atlantic, Indian and Pacific oceans, introducing an extra potential for error in such models. Running the model in a global configuration has the advantage that the boundary conditions can be omitted.

As the dynamics of the iron supply is something we plan to study further in the future, and it is a feature we would like to improve, especially in the Pacific Ocean, we will now discuss how changes to the iron cycle may change the results of the model.

In the Southern Ocean, the spatial distribution of iron in the model is reasonable, but it tends towards low values (Table 2), something that may be explained by the crudely constrained external iron sources in the area. The strength of the sediment source varies widely between models (e.g.
Moore and Braucher, 2008; Aumont and Bopp, 2006), and in REcoM2 we have an input of iron from the dust and the sediment source, which is in the smaller end of the range. Increasing the strength of the sediment source would especially impact the iron concentration locally in the Southern Ocean, though it has been shown that iron from the sediments can be carried far from the source region (Lam and Bishop, 2008). The Atlantic sector of the Southern Ocean would have an especially large input due to the presence of the Patagonian shelf and the Antarctic Peninsula (e.g. Lancelot et al., 2009), but it would most likely not change the supply to the pelagic areas in the Indian and Pacific Southern Ocean substantially. For the Southern and Pacific Oceans it would be especially important to further explore the influence of the aeolian and sedimentary iron sources as well as the input from ice in the polar areas.

In the remote parts of the Southern Ocean, the input of iron to the mixed layer from below plays a large role (De Baar et al., 1995; Löscher et al., 1997), and Tagliabue et al. (2014) showed that the entrainment of iron during deepening of the mixed layer was especially important. FESOM's MLD $_{\max }$ is too shallow in the Southern Ocean, especially in the region of the polar front in the Indian and Pacific sectors (Fig. 5), something likely affecting the degree of iron limitation in these two areas. The tight coupling between iron concentrations, NPP and MLD in the polar frontal area (Fig. 20a), further confirms the importance of entrainment as a supply mechanism of iron.

The lower iron input favors the smaller nanophytoplankton, which have a lower iron half-saturation constant, and thereby a lower requirement for iron. A larger input of iron would probably change the species composition towards more diatoms, but would not necessarily increase primary production (e.g. S. Wang et al., 2014). A higher percentage of diatoms would also possibly decrease the models surface silicon concentration, which tends towards high values in the Southern Ocean (Fig. 8). The effect on the silicon concentration is however complicated by the fact that the model's carbon and silicate cycles are decoupled under iron limitation, leading to a higher silicate uptake when the phytoplankton is iron stressed (Hohn, 2009).

In the Pacific Ocean, the surface iron concentration is very low (Fig. 9), inducing iron limitation (Fig. 10), which leads to a build-up of DIN in the surface water (Fig. 7) and low NPP (Fig. 12). The external input of iron from dust and sediment in the model is marginal in the equatorial and southern part of the Pacific and input from upwelling is consequently important here. FESOM produces a reasonable upwelling of $40 \mathrm{~Sv}$ along the Equator (Johnson et al., 2001), whereas upwelling is small along the west coast of South America. We have a low iron flux in the upwelled water along the equatorial Pacific in our model $\left(\sim 10 \mu \mathrm{molm}^{-2} \mathrm{yr}^{-1}\right)$ compared to the values suggested by Gordon et al. (1997) and Aumont et al. (2003), who reported 44 and $68 \mu \mathrm{mol} \mathrm{m}^{-2} \mathrm{yr}^{-1}$, respectively. Our result is however higher 
than the $5.1 \mu \mathrm{mol} \mathrm{m}{ }^{-2} \mathrm{yr}^{-1}$ suggested by Fung et al. (2000). The $\mathrm{Fe}: \mathrm{C}$ ratio in the upwelled water in the equatorial area is $0.0015 \mu \mathrm{mol} \mathrm{Fe} \mathrm{mmol} \mathrm{C}^{-1}\left(6.66 \times 10^{6} \mathrm{mmolC} \mathrm{mmol} \mathrm{Fe}^{-1}\right)$, which is significantly lower than the prescribed constant intracellular ratio of $0.005 \mu \mathrm{molFe} \mathrm{mmolC}^{-1}(2 \times$ $10^{6} \mathrm{mmolC} \mathrm{mmol} \mathrm{Fe}^{-1}$ ) in the modelled phytoplankton. The upwelled water consequently contains too little Fe to sustain growth, explaining why biological production is not able to utilize the upwelled DIN.

Allowing the model's phytoplankton to adapt to the conditions in the water with a varying intracellular $\mathrm{Fe}: \mathrm{C}$ ratio would be a possible way to increase production, as the ratio would then decrease in areas with low iron concentrations. Variable intracellular $\mathrm{Fe}: \mathrm{C}$ stoichiometry, as found by Sunda and Huntsman (1995) and Wilhelm et al. (2013), is used in other models (e.g. Moore et al., 2002; Aumont and Bopp, 2006). The intracellular $\mathrm{Fe}: \mathrm{C}$ ratio in diatoms ranged from $0.002 \mu \mathrm{molFe} \mathrm{mmolC}^{-2}$ in the equatorial $\mathrm{Pa}$ cific to $0.007 \mu \mathrm{molFe} \mathrm{mmolC}^{-2}$ in the subtropical gyres in Moore et al. (2002) and the former value fits remarkably well with our $\mathrm{Fe}: \mathrm{C}$ ratio in the upwelled water in the Pacific. A lower intracellular $\mathrm{Fe}: \mathrm{C}$ ratio in our model would lower the intracellular $\mathrm{Fe}: \mathrm{N}$ ratio and bring it closer to the observed nutrient ratio in the upwelled water, indicating that implementing varying ratios would indeed improve the model's performance in the Pacific.

Other features that could potentially improve the iron cycle are spatially varying solubility of iron in the water, spatially varying ligand concentration and scavenging of iron onto dust particles in the water. The latter is present in the iron cycle used by Moore and Braucher (2008) and would likely counter the relatively high iron concentrations in the equatorial Atlantic and Indian oceans that are present in our model (Fig. 9).

\section{Conclusions}

In the current study we show that the newly coupled model FESOM-REcoM2 reproduces the large-scale productivity and surface nutrient patterns, with the main deficiency being the strongly iron limited Pacific Ocean. The totals NPP and EP are within the range of previous estimates, but in the lower end, mainly due to the low productivity in the Pacific. The ratio between EP and NPP is $20 \%$, similar to the result from Laws et al. (2000).

In the Southern Ocean, the modelled spatial mean fields are likewise reasonable, though the comparison here is hindered by the scarcity of observed data. South of $50^{\circ} \mathrm{S}$, the totals NPP and EP agree well with previous estimates, as does the EP : NPP ratio of $36 \%$. Production is iron and light limited in the Southern Ocean making the external input of iron important as a controller of production.

On a global scale, the model provides reasonable seasonal variations of the NPP, but the main deficiency in the Southern Ocean is the early onset of the spring bloom in the area between 40 and $60^{\circ} \mathrm{S}$.

Overall, the model results at the present resolution are comparable to those of other non-eddy-resolving biogeochemical models and it is well suited for studies of surface processes in the Southern Ocean on a timescale similar to the one used here. 


\section{Appendix A: Equations}

In biogeochemical models, the biological state variables are subject to change by the ocean circulation through advection and turbulent mixing as well as by biological processes. Detritus further sinks vertically through the water column due to gravity, and exchange occurs across the surface and bottom boundaries for certain variables.

For a given volume of water, the change in concentration of a given biological state variable $C$ can be expressed as follows:

$$
\frac{\partial C}{\partial t}=-\boldsymbol{U} \cdot \nabla C+\nabla \cdot(\kappa \cdot \nabla C)+\operatorname{SMS}(C) .
$$

Here, the term $-\boldsymbol{U} \cdot \nabla C$ represents the change in $C$ due to advection, and $\boldsymbol{U}=(u, v, w)$ denotes the velocity of the water in the $x, y$ and $z$ directions, respectively.

For sinking state variables, the speed of vertical sinking $\left(\boldsymbol{V}_{\mathrm{det}}=\left(0,0, w_{\mathrm{det}}\right)\right)$ is added to water's velocity in the advection term.

The turbulent motion is taken into account through the term $\nabla \cdot(\kappa \cdot \nabla C)$ where $\kappa$ is the diffusivity tensor.

The term SMS $(C)$, where SMS stands for sources minus sinks, represents the changes due to biological processes. This is the term that comprises the main body of biogeochemical models.

Certain state variables are subject to fluxes across the boundaries of the ocean model. For these, the flux between the ocean and the benthos (BenF) is calculated at the bottom of the ocean and the flux between the ocean and the atmosphere $(\mathrm{AtmF})$ is calculated for the surface layer of the ocean.

In the following, the equations that make up the source minus sink code in the biogeochemical model REcoM2 are described.

The quota approach makes it necessary to have more tracers than in a model based on fixed ratios, as we need to know the intracellular concentration of each of the modelled elements. REcoM2 has a total of 21 oceanic state variables (Table A1) and four benthos compartments (Table A2).
Table A1. State variables; ocean

\begin{tabular}{|c|c|}
\hline Variable & Description and unit \\
\hline DIN & Dissolved inorganic nitrogen $\left[\mathrm{mmolNm}^{-3}\right]$ \\
\hline DSi & Dissolved inorganic silicon $\left[\mathrm{mmol} \mathrm{N} \mathrm{m}^{-3}\right]$ \\
\hline $\mathrm{DFe}$ & Dissolved inorganic iron $\left[\mu \mathrm{molFe} \mathrm{F}^{-3}\right]$ \\
\hline DIC & Dissolved inorganic carbon $\left[\mathrm{mmol} \mathrm{Cm}^{-3}\right]$ \\
\hline Alk & Alkalinity $\left[\mathrm{mmol} \mathrm{Cm}^{-3}\right]$ \\
\hline $\mathrm{PhyN}_{\text {nano }}$ & $\begin{array}{l}\text { Intracellular nitrogen concentration } \\
\text { in nanophytoplankton }\left[\mathrm{mmol} \mathrm{N} \mathrm{m}^{-3}\right]\end{array}$ \\
\hline PhyC $_{\text {nano }}$ & $\begin{array}{l}\text { Intracellular carbon concentration } \\
\text { in nanophytoplankton }\left[\mathrm{mmolCm}^{-3}\right]\end{array}$ \\
\hline PhyCalc & $\begin{array}{l}\text { Intracellular calcite concentration } \\
\text { in nanophytoplankton }\left[\mathrm{mmolCaCO}_{3} \mathrm{~m}^{-3}\right]\end{array}$ \\
\hline PhyChl $_{\text {nano }}$ & $\begin{array}{l}\text { Intracellular chl } a \text { concentration } \\
\text { in nanophytoplankton }\left[\mathrm{mg} \mathrm{Chl} \mathrm{m}^{-3}\right]\end{array}$ \\
\hline PhyN $_{\text {dia }}$ & $\begin{array}{l}\text { Intracellular nitrogen concentration in diatoms } \\
{\left[\mathrm{mmol} \mathrm{N} \mathrm{m}^{-3}\right]}\end{array}$ \\
\hline $\mathrm{PhyC}_{\mathrm{dia}}$ & $\begin{array}{l}\text { Intracellular carbon concentration in diatoms } \\
{\left[\mathrm{mmolC} \mathrm{m}^{-3}\right]}\end{array}$ \\
\hline PhySi & $\begin{array}{l}\text { Intracellular silicon concentration in diatoms } \\
{\left[\mathrm{mmol} \mathrm{Si} \mathrm{m}^{-3}\right]}\end{array}$ \\
\hline PhyChl dia $_{\text {di }}$ & $\begin{array}{l}\text { Intracellular chl } a \text { concentration in diatoms } \\
{\left[\mathrm{mg} \mathrm{Chl} \mathrm{m}^{-3}\right]}\end{array}$ \\
\hline ZooN & Zooplankton nitrogen concentration $\left[\mathrm{mmol} \mathrm{N} \mathrm{m}^{-3}\right]$ \\
\hline ZooC & Zooplankton carbon concentration $\left[\mathrm{mmolCm}^{-3}\right]$ \\
\hline DetN & Detritus nitrogen concentration $\left[\mathrm{mmol} \mathrm{Nm}^{-3}\right]$ \\
\hline DetC & Detritus carbon concentration $\left[\mathrm{mmolCm}^{-3}\right]$ \\
\hline DetCalc & Detritus calcite concentration $\left[\mathrm{mmolCaCO}_{3} \mathrm{~m}^{-3}\right]$ \\
\hline DetSi & Detritus silicon concentration $\left[\mathrm{mmol} \mathrm{Si} \mathrm{m}^{-3}\right]$ \\
\hline DON & Extracellular dissolved organic nitrogen $\left[\mathrm{mmol} \mathrm{N} \mathrm{m}^{-3}\right]$ \\
\hline DOC & Extracellular dissolved organic carbon $\left[\mathrm{mmolCm}^{-3}\right]$ \\
\hline
\end{tabular}

\section{A1 Sources minus sinks}

\section{A1.1 DIN and DSi}

$$
\begin{aligned}
\mathrm{SMS}(\mathrm{DIN}) & =\underbrace{\rho_{\mathrm{N}} \cdot f_{T} \cdot \mathrm{DON}}_{\mathrm{DON} \text { remineralization }} \\
& -\underbrace{V_{\text {nano }}^{\mathrm{N}} \cdot \mathrm{PhyC}_{\text {nano }}}_{\mathrm{N} \text { assimilation, diatoms }} \\
& -\underbrace{V_{\mathrm{dia}}^{\mathrm{N}} \cdot \mathrm{PhyC}_{\mathrm{dia}}}_{\mathrm{N} \text { assimilation, nanophytoplankton }} \\
\mathrm{SMS}(\mathrm{DSi}) & =\underbrace{\underbrace{\rho_{\text {Si }}^{T} \cdot \text { DetSi }}_{\text {Si }}}_{\text {Ri assimilation, diatoms }}
\end{aligned}
$$

The state variables DON, $\mathrm{PhyC}_{\mathrm{nano}}$, $\mathrm{PhyC}_{\mathrm{dia}}$ and DetSi are listed in Table A1. The value of the remineralization rate $\left(\rho_{\mathrm{N}}\right)$ is listed in Table A3. The temperature dependency of remineralization $\left(f_{T}\right)$ is calculated in Eq. (A54) and the nitrogen and silicon assimilation rates $\left(V_{\text {nano }}^{\mathrm{N}}, V_{\mathrm{dia}}^{\mathrm{N}}\right.$ and $V^{\mathrm{Si}}$, Table A4) 
Table A2. State variables; benthos.

\begin{tabular}{ll}
\hline Variable & Description and unit \\
\hline BenthosN & Benthos, vertically integrated $\mathrm{N}$ concentration $\left[\mathrm{mmol} \mathrm{N} \mathrm{m}^{-2}\right]$ \\
BenthosC & Benthos, vertically integrated $\mathrm{C}$ concentration $\left[\mathrm{mmol} \mathrm{C} \mathrm{m}^{-2}\right]$ \\
BenthosSi & Benthos, vertically integrated $\mathrm{Si}$ concentration $\left[\mathrm{mmol} \mathrm{si} \mathrm{m}^{-2}\right]$ \\
BenthosCalc & Benthos, vertically integrated calcite concentration $\left[\mathrm{mmol} \mathrm{CaCO}_{3} \mathrm{~m}^{-2}\right]$ \\
\hline
\end{tabular}

Table A3. Degradation parameters for sources minus sinks equations.

\begin{tabular}{|c|c|c|}
\hline Parameter & Value & Description and Unit \\
\hline$\epsilon_{\mathrm{N}}^{\text {phy }}$ & 0.05 & Phytoplankton excretion of organic $\mathrm{N}\left[\mathrm{day}^{-1}\right]$ \\
\hline$\epsilon_{\mathrm{C}}^{\text {phy }}$ & 0.1 & Phytoplankton excretion of organic $\mathrm{C}\left[\mathrm{day}^{-1}\right]$ \\
\hline$\epsilon_{\mathrm{N}}^{\mathrm{ZOO}}$ & 0.1 & Zooplankton excretion of organic $\mathrm{N}\left[\mathrm{day}^{-1}\right]$ \\
\hline$\epsilon_{\mathrm{C}}^{\mathrm{zOO}}$ & 0.1 & Zooplankton excretion of organic $\mathrm{C}\left[\right.$ day $\left.^{-1}\right]$ \\
\hline$\rho_{\mathrm{N}}^{\mathrm{ben}}$ & 0.005 & Remineralization rate for benthos $\mathrm{N}\left[\mathrm{day}^{-1}\right]$ \\
\hline$\rho_{\mathrm{Si}}^{\mathrm{ben}}$ & 0.005 & Remineralization rate for benthos $\mathrm{Si}\left[\mathrm{day}^{-1}\right]$ \\
\hline$\rho_{\mathrm{C}}^{\mathrm{ben}}$ & 0.005 & Remineralization rate for benthos $\mathrm{C}\left[\mathrm{day}^{-1}\right]$ \\
\hline$\rho_{\mathrm{N}}$ & 0.11 & Temperature dependent remineralization of DON $\left[\mathrm{day}^{-1}\right]$ \\
\hline$\rho_{\mathrm{C}}$ & 0.1 & Temperature dependent remineralization of DOC $\left[\right.$ day $\left.^{-1}\right]$ \\
\hline$\rho_{\mathrm{Si}}$ & 0.02 & Temperature dependent remineralization of DetSi $\left[\right.$ day $^{-1}$ ] \\
\hline$\rho_{\operatorname{DetN}}$ & 0.165 & Temperature dependent degradation of DetN $\left[\right.$ day $^{-1}$ ] \\
\hline$\rho_{\text {DetC }}$ & 0.15 & Temperature dependent degradation of $\operatorname{DetN}\left[\right.$ day $\left.^{-1}\right]$ \\
\hline $\operatorname{deg}_{\text {Chl }}$ & 0.3 & Chlorophyll $a$ degradation rate $\left[\right.$ day $\left.^{-1}\right]$ \\
\hline
\end{tabular}

are calculated in Eqs. (A48) and (A49), respectively. $\rho_{\mathrm{Si}}^{T}$ will now be explained.

Silicon remineralization: the temperature dependent remineralization rate of silicon $\left(\rho_{\mathrm{Si}}^{T}\right.$, Table A4) is calculated following Kamatani (1982) up until a set maximum value:

$\rho_{\mathrm{Si}}^{T}=\min \left(1.32 \times 10^{16} \mathrm{day}^{-1} \cdot \exp \left(\frac{-11200 \mathrm{~K}}{T}\right), \rho_{\mathrm{Si}} \cdot f_{T}\right)$.

$T$ is the local temperature (Table A4). The remineralization rate $\left(\rho_{\mathrm{Si}}\right)$ is listed in Table $\mathrm{A} 3$ and the temperature dependency $\left(f_{T}\right)$ is calculated in Eq. (A54).

Input from benthos: the bottom grid point of the water further receives remineralized inorganic matter from the benthos:

$$
\begin{aligned}
\text { BenF }_{\mathrm{DIN}} & =\rho_{\mathrm{N}}^{\text {ben }} \cdot \text { BenthosN } \\
\text { BenF }_{\mathrm{DSi}} & =\rho_{\mathrm{Si}}^{\mathrm{ben}} \cdot \text { BenthosSi. }
\end{aligned}
$$

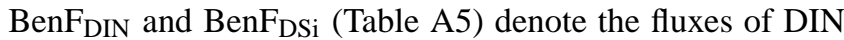
and DSi into the bottom layer of the ocean. $\rho_{\mathrm{N}}^{\text {ben }}$ and $\rho_{\mathrm{Si}}^{\text {ben }}$ (Table A3) are constant remineralization rates. BenthosN and BenthosSi denote the vertically integrated benthos concentration of dissolved nitrogen and silicate, respectively (Table A2).

\section{A1.2 DFe}

The intracellular iron concentration is connected to the intracellular carbon concentration through an assumed constant ratio ( $q^{\mathrm{Fe}: \mathrm{C}}$; Table A6). Biological uptake and release of iron is likewise connected to uptake and release of carbon.

$$
\begin{aligned}
& \mathrm{SMS}(\mathrm{DFe})=-q^{\mathrm{Fe}: \mathrm{C}} \cdot \underbrace{\left(P_{\text {nano }}-r_{\text {nano }}\right) \cdot \mathrm{PhyC}_{\text {nano }}}_{\text {Nanophytoplankton net growth }} \\
& -q^{\mathrm{Fe}: \mathrm{C}} \cdot \underbrace{\left(P_{\mathrm{dia}}-r_{\mathrm{dia}}\right) \cdot \mathrm{PhyC}_{\mathrm{dia}}}_{\text {Diatom net growth }} \\
& +q^{\mathrm{Fe}: \mathrm{C}} \cdot \underbrace{\epsilon_{\mathrm{C}}^{\mathrm{phy}} \cdot f_{\text {lim, nano }}^{\mathrm{N}: \mathrm{Cmax}} \cdot \mathrm{PhyC}_{\mathrm{nano}}}_{\text {Excretion from nanophytoplankton }} \\
& +q^{\mathrm{Fe}: \mathrm{C}} \cdot \underbrace{\epsilon_{\mathrm{C}}^{\mathrm{phy}} \cdot f_{\text {lim, dia }}^{\mathrm{N}: \mathrm{Cmax}} \cdot \mathrm{PhyC}_{\mathrm{dia}}}_{\text {Excretion from diatoms }} \\
& +q^{\mathrm{Fe}: \mathrm{C}} \cdot \underbrace{\rho_{\operatorname{DetC}} \cdot f_{T} \cdot \operatorname{DetC}}_{\text {Remineralization of detritus }} \\
& +q^{\mathrm{Fe}: \mathrm{C}} \cdot(\underbrace{\epsilon_{\mathrm{C}}^{\mathrm{zoo}} \cdot \mathrm{ZooC}}_{\text {Zooplankton excretion }}+\underbrace{r_{\mathrm{zoo} \cdot \mathrm{ZooC}}}_{\text {and respiration }}) \\
& -\underbrace{\kappa_{\mathrm{Fe}} \cdot \mathrm{DetC} \cdot \mathrm{Fe}^{\prime}}_{\text {Scavenging }}
\end{aligned}
$$

The state variables $\mathrm{PhyC}_{\text {nano }}, \mathrm{PhyC}_{\mathrm{dia}}$, DetC and ZooC are listed in Table A1. The value for the constant $\mathrm{Fe}: \mathrm{C}$ ratio $\left(q^{\mathrm{Fe}} \mathrm{C}\right)$ is listed in Table A6 and the DOC excretion rates from phyto- and zooplankton $\left(\epsilon_{\mathrm{C}}^{\mathrm{phy}}\right.$ and $\left.\epsilon_{\mathrm{C}}^{\mathrm{zoo}}\right)$ and the degradation rate for detritus $\mathrm{C}\left(\rho_{\text {DetC }}\right)$ are listed in Table A3. The 
Table A4. Model variables.

\begin{tabular}{|c|c|}
\hline Variable & Description and unit \\
\hline Agg & Aggregation rate $\left[\mathrm{day}^{-1}\right]$ \\
\hline Diss Calc & Rate of calcium carbonate dissolution $\left[\mathrm{day}^{-1}\right]$ \\
\hline $\mathrm{Fe}^{\prime}$ & Concentration of free iron $\left[\mu \mathrm{mol} \mathrm{Fe} \mathrm{m}{ }^{-3}\right]$ \\
\hline$f_{T}$ & Temperature dependence of rates, dimensionless \\
\hline$G^{\prime}$ & Phytoplankton available for food intake $\left[\mathrm{mmol} \mathrm{Nm}^{-3}\right]$ \\
\hline$G_{\text {tot }}$ & Total zooplankton grazing rate $\left[\mathrm{mmolNm} \mathrm{Nay}^{-3} \mathrm{da}^{-1}\right.$ \\
\hline$G_{\text {nano }}$ & Nanophytoplankton-specific zooplankton grazing rate $\left[\mathrm{mmolN} \mathrm{m}^{-3} \mathrm{day}^{-1}\right]$ \\
\hline$G_{\text {dia }}$ & Diatom-specific zooplankton grazing rate $\left[\mathrm{mmolN} \mathrm{m}^{-3} \mathrm{day}^{-1}\right]$ \\
\hline PAR & Photosynthetically available radiation $\left[\mathrm{W} \mathrm{m}^{-2}\right]$ \\
\hline$P_{\text {nano }}, P_{\text {dia }}$ & C-specific actual rate of photosynthesis $\left[\mathrm{day}^{-1}\right]$ \\
\hline$P_{\max }$ & C-specific light saturated rate of photosynthesis $\left[\right.$ day $\left.^{-1}\right]$ \\
\hline$r_{\text {nano }}, r_{\text {dia }}$ & Phytoplankton respiration rate $\left[\right.$ day $\left.^{-1}\right]$ \\
\hline$r_{\mathrm{ZoO}}$ & Zooplankton respiration rate $\left[\mathrm{day}^{-1}\right]$ \\
\hline$\rho_{\mathrm{Si}}^{T}$ & Temperature dependent remineralization rate of $\mathrm{Si}\left[\mathrm{day}^{-1}\right]$ \\
\hline$S_{\text {nano }}^{\text {chl }}, S_{\text {dia }}^{\text {chl }}$ & Rate of chlorophyll $a$ synthesis $\left[\mathrm{mg} \mathrm{Chl} \mathrm{mmolC}^{-1}\right.$ day $^{-1}$ ] \\
\hline & Local temperature $[\mathrm{K}]$ \\
\hline$V_{\text {nano }}^{\mathrm{N}}, V_{\text {dia }}^{\mathrm{N}}$ & $\mathrm{N}$ assimilation rate for nanophytoplankton and diatoms, respectively $\left[\mathrm{mmol} \mathrm{N} \mathrm{mmolC} \mathrm{C}^{-1} \mathrm{day}^{-1}\right]$ \\
\hline & Diatom $\mathrm{Si}$ assimilation rate $\left[\mathrm{mmol} \mathrm{Si} \mathrm{mmolC}^{-1} \mathrm{day}^{-1}\right]$ \\
\hline$w_{\text {det }}$ & Sinking velocity of detritus $\left[\mathrm{mday}^{-1}\right]$ \\
\hline
\end{tabular}

Table A5. Benthos variables.

\begin{tabular}{|c|c|}
\hline Variable & Description and unit \\
\hline $\mathrm{BenF}_{\mathrm{Alk}}$ & Flux of alkalinity from benthos to bottom water $\left[\mathrm{mmolm}^{-2} \mathrm{day}^{-1}\right.$ \\
\hline BenF $_{\text {DIC }}$ & Flux of $\mathrm{C}$ from benthos to bottom water $\left[\mathrm{mmolCm}^{-2} \mathrm{day}^{-1}\right]$ \\
\hline BenF $_{\text {DIN }}$ & Flux of $\mathrm{N}$ from benthos to bottom water $\left[\mathrm{mmolNm}^{-2} \mathrm{day}^{-1}\right]$ \\
\hline BenF $_{\mathrm{DSi}}$ & Flux of Si from benthos to bottom water $\left[\mathrm{mmol} \mathrm{Si} \mathrm{m}^{-2} \mathrm{day}^{-1}\right]$ \\
\hline $\mathrm{BenF}_{\mathrm{Fe}}$ & Flux of Fe from benthos to bottom water $\left[\mu \mathrm{molFe}^{-2} \mathrm{day}^{-1}\right]$ \\
\hline BenF $F_{\text {DetCalc }}$ & Flux of detritus calcite from the water to the benthos $\left[\mathrm{mmol} \mathrm{CaCO}_{3} \mathrm{~m}^{-2} \mathrm{day}^{-1}\right]$ \\
\hline BenF $F_{\text {DetC }}$ & Flux of detritus $\mathrm{C}$ from the water to the benthos $\left[\mathrm{mmol} \mathrm{Cm}^{-2}\right.$ day $\left.^{-1}\right]$ \\
\hline BenF ${ }_{\text {DetN }}$ & Flux of detritus $\mathrm{N}$ from the water to the benthos $\left[\mathrm{mmol} \mathrm{N} \mathrm{m}^{-2}\right.$ day $\left.^{-1}\right]$ \\
\hline BenF $_{\text {DetSi }}$ & Flux of detritus $\mathrm{Si}$ from the water to the benthos $\left[\mathrm{mmol} \mathrm{Sim}^{-2}\right.$ day $\left.^{-1}\right]$ \\
\hline
\end{tabular}

Table A6. Parameters for iron calculations.

\begin{tabular}{lcl}
\hline Parameter & Value & Description and unit \\
\hline$q^{\mathrm{Fe}: \mathrm{C}}$ & 0.005 & Intracellular $\mathrm{Fe}: \mathrm{C}$ ratio $\left[\mu \mathrm{mol} \mathrm{Fe} \mathrm{mmol} \mathrm{mm}^{-1}\right]$ \\
$K_{\mathrm{Fe}}$ & 100.0 & Iron stability constant $\left[\mathrm{m}^{-3} \mu \mathrm{mol}\right]$ \\
$L_{\mathrm{T}}$ & 1.0 & Total ligand concentration $\left[\mu \mathrm{mol} \mathrm{m}{ }^{-3}\right]$ \\
$\kappa_{\mathrm{Fe}}$ & 0.0312 & Scavenging rate of iron $\left[\mathrm{m}^{3} \mathrm{mmolC}^{-1} \mathrm{day}^{-1}\right]$ \\
$q_{\mathrm{sed}}^{\mathrm{Fe}} \mathrm{C}$ & 0.011 & $\mathrm{Fe}: \mathrm{C}$ ratio for remineralization of $\mathrm{Fe}$ from benthos $\left[\mu \mathrm{mol} \mathrm{Fe} \mathrm{mmolC}^{-1}\right]$ \\
\hline
\end{tabular}


phytoplankton respiration ( $r_{\text {nano }}$ and $\left.r_{\mathrm{dia}}\right)$ is calculated in Eq. (A45), the photosynthesis ( $P_{\text {nano }}$ and $\left.P_{\text {dia }}\right)$ in Eq. (A44), the limitation by intracellular nitrogen $\left(f_{\lim }^{\mathrm{N}: \mathrm{Cmax}}\right)$ is described in Sect. A6.1, and the temperature dependency $\left(f_{T}\right)$ is calculated in Eq. (A54). The respiration by zooplankton $\left(r_{\text {zoo }}\right)$ is calculated in Eq. (A46) and the scavenging will now be explained.

Scavenging: the calculation of the scavenging in REcoM2 is based on Parekh et al. (2004), case III. Here, the total concentration of dissolved iron $\left(\mathrm{Fe}_{\mathrm{T}}\right)$ is divided into iron bound to ligands $\left(\mathrm{Fe}_{L}\right)$ and free iron $\left(\mathrm{Fe}^{\prime}\right.$, Table A4):

$\mathrm{Fe}_{\mathrm{T}}=\mathrm{Fe}_{L}+\mathrm{Fe}^{\prime}$

Iron complexed with organic ligands is protected from scavenging. The total ligand concentration $\left(L_{\mathrm{T}}\right)$ can be written:

$L_{\mathrm{T}}=\mathrm{Fe}_{L}+L^{\prime}$.

Here $L^{\prime}$ denotes the free ligands.

We assume that the reaction between free iron and free ligand $\left(L^{\prime}+\mathrm{Fe}^{\prime} \rightleftharpoons \mathrm{Fe}_{L}\right)$ is fast enough to be in equilibrium:

$K_{\mathrm{Fe}_{L}}=\frac{\left[\mathrm{Fe}_{L}\right]}{\left[\mathrm{Fe}^{\prime}\right] \cdot\left[L^{\prime}\right]}$

By prescribing the value of the conditional stability constant $\left(K_{\mathrm{Fe}_{L}}\right)$ as well as the assumed constant total ligand concentration $\left(L_{\mathrm{T}}\right)$ and combining Eqs. (A8), (A9) and (A10), we can calculate the concentration of free iron $\left(\mathrm{Fe}^{\prime}\right)$. This is then used to calculate the scavenging of $\mathrm{Fe}^{\prime}$, which is assumed to be correlated with the concentration of detritus carbon (Eq. A7). The values for $K_{\mathrm{Fe}_{L}}$ and $L_{\mathrm{T}}$ are listed in Table A6.

The value for the scavenging rate $\left(\kappa_{\mathrm{Fe}}\right.$, Table A6) is an important controller of deep-water iron concentrations.

Iron input from dust: the surface layer of the ocean receives an input of iron from aeolian dust deposition. Dust is assumed to contain $3.5 \%$ iron of which $1.5 \%$ is instantaneously dissolved in the ocean. Sea ice blocks dust, and the dust falling here is lost from the system.

Iron input from the benthos: the release of iron to the bottom layer of water is assumed to be proportional to the release of inorganic carbon. This parameterization is based on the work by Elrod et al. (2004). It is calculated as follows:

$\mathrm{BenF}_{\mathrm{Fe}}=\rho_{\mathrm{C}}^{\text {ben }} \cdot$ BenthosC $\cdot q_{\mathrm{sed}}^{\mathrm{Fe}: \mathrm{C}}$.

Here $\mathrm{BenF}_{\mathrm{Fe}}$ (Table A5) is the flux of iron into the bottom layer of the ocean. $\rho_{\mathrm{C}}^{\text {ben }}$ (Table A3) is the remineralization rate for the benthos carbon and $q_{\mathrm{sed}}^{\mathrm{Fe}: \mathrm{C}}$ (Table A6) is the iron : carbon ratio for the flux. BenthosC (Table A2) denotes the vertically integrated carbon concentration in the benthos compartment.
A1.3 DIC

$$
\begin{aligned}
\operatorname{SMS}(\mathrm{DIC}) & =\underbrace{\left(r_{\text {nano }}-P_{\text {nano }}\right) \cdot \mathrm{PhyC}_{\text {nano }}}_{\text {Nanophytoplankton net respiration }} \\
& +\underbrace{\left(r_{\mathrm{dia}}-P_{\mathrm{dia}}\right) \cdot \mathrm{PhyC}_{\mathrm{dia}}}_{\text {Diatom net respiration }} \\
& +\underbrace{\rho_{\mathrm{C}} \cdot f_{T} \cdot \mathrm{DOC}}_{\text {Reo respiration }} \\
& +\underbrace{\text { Remineralization of DOC }}_{\text {Calcite dissolution from detritus }} \\
& \underbrace{\psi \cdot P_{\text {nano }} \cdot \text { PhyC }}_{\text {Calcification }}
\end{aligned}
$$

The state variables $\mathrm{PhyC}_{\mathrm{nano}}, \mathrm{PhyC}_{\mathrm{dia}}, \mathrm{DOC}, \mathrm{ZooC}$ and DetCalc are described in Table A1. Respiration by nanophytoplankton $\left(r_{\text {nano }}\right)$, diatoms $\left(r_{\mathrm{dia}}\right)$ and zooplankton $\left(r_{\mathrm{zoo}}\right)$ is calculated in Eqs. (A45) and (A46) and the photosynthesis terms $\left(P_{\text {nano }}\right.$ and $\left.P_{\text {dia }}\right)$ in Eq. (A44).

The value of the remineralization rate $\rho_{\mathrm{C}}$ is listed in Table A3 and the temperature dependency $\left(f_{T}\right)$ is calculated in Eq. (A54).

The dissolution of calcite from detritus (Diss calc $_{\text {c }}$ ) is calculated in Eq. (A34), and the value of the calcite production ratio $(\psi)$ is listed in Table A7. $\psi$ denotes the percentage of the nanophytoplankton that are calcifiers, and their PIC : POC ratio.

Atmospheric input: the DIC concentration of the surface grid point is affected by the air-sea flux of $\mathrm{CO}_{2}$. It is calculated according to the guidelines provided by the Ocean Carbon Model Intercomparison Project (Orr et al., 1999). In the calculations the surface water $\mathrm{CO}_{2}$ concentration, alkalinity, temperature and salinity are taken into account.

Input from benthos: the bottom grid point of the water further receives remineralized inorganic carbon from the benthos:

$\mathrm{BenF}_{\mathrm{DIC}}=\rho_{\mathrm{C}}^{\mathrm{ben}} \cdot$ BenthosC + Diss $_{\mathrm{calc}} \cdot$ BenthosCalc . (A13)

BenF $_{\text {DIC }}$ (Table A5) denotes the flux of DIC into the bottom layer of the ocean and $\rho_{\mathrm{C}}^{\text {ben }}$ (Table A3) is a constant remineralization rate. The calcite dissolution rate (Diss calc $_{\text {c }}$ ) is calculated in Eq. (A34). BenthosC and BenthosCalc (Table A2) denote the vertically integrated carbon and calcium carbonate concentration in the benthos compartment.

\section{A1.4 Total alkalinity}

The model's total alkalinity is changed by phytoplankton uptake of nutrients (nitrate and phosphate), precipitation and dissolution of calcium carbonate and remineralization of organic matter (Wolf-Gladrow et al., 2007). Phosphorous is not described in the model, but is taken into account using the 
Table A7. Parameters for sources minus sinks equations.

\begin{tabular}{|c|c|c|}
\hline Parameter & Value & Description and unit \\
\hline$\psi$ & 0.1 & $\begin{array}{l}\text { Calcite production ratio, } \\
\text { dimensionless }\end{array}$ \\
\hline$\gamma$ & 0.3 & $\begin{array}{l}\text { Fraction of grazing flux to } \\
\text { zooplankton pool, dimensionless }\end{array}$ \\
\hline$m_{\text {zoo }}$ & 0.05 & $\begin{array}{l}\text { Zooplankton mortality rate } \\
{\left[\mathrm{m}^{3} \mathrm{mmol} \mathrm{N}^{-1} \text { day }^{-1}\right]}\end{array}$ \\
\hline$\phi_{\text {phy }}$ & 0.02 & $\begin{array}{l}\text { Max aggregation loss parameter for } \\
\text { phytoplankton } \mathrm{N}\left[\mathrm{m}^{3} \mathrm{mmolN}^{-1} \mathrm{day}^{-1}\right]\end{array}$ \\
\hline$\phi_{\text {det }}$ & 0.22 & $\begin{array}{l}\text { Max aggregation loss parameter for } \\
\text { detritus } \mathrm{N}\left[\mathrm{m}^{3} \mathrm{mmolN}^{-1} \text { day }^{-1}\right]\end{array}$ \\
\hline$w_{0}$ & 20.0 & $\begin{array}{l}\text { Detritus sinking speed at surface } \\
{\left[\mathrm{mday}^{-1}\right]}\end{array}$ \\
\hline
\end{tabular}

constant $\mathrm{P}: \mathrm{N}$ ratio of $1: 16$.

$$
\begin{aligned}
& \operatorname{SMS}(\mathrm{Alk})=(1+1 / 16) \cdot \underbrace{V_{\text {nano }}^{\mathrm{N}} \cdot \mathrm{PhyC}_{\text {nano }}}_{\mathrm{N} \text { assimilation, nanophytoplankton }} \\
& +(1+1 / 16) \cdot \underbrace{V_{\mathrm{dia}}^{\mathrm{N}} \cdot \mathrm{PhyC}_{\mathrm{dia}}}_{\mathrm{N} \text { assimilation, diatoms }} \\
& -(1+1 / 16) \cdot \underbrace{\rho_{\mathrm{N}} \cdot f_{T} \cdot \mathrm{DON}}_{\text {Remineralization of DON }} \\
& +2 \cdot \underbrace{\text { Diss }_{\text {calc }} \cdot \text { DetCaCO}_{3}}_{\text {Calcite dissolution from detritus }} \\
& -2 \cdot \underbrace{\psi \cdot P_{\text {nano }} \cdot \mathrm{PhyC}_{\text {nano }}}_{\text {Calcification }}
\end{aligned}
$$

The state variables $\mathrm{PhyC}_{\text {nano }}$, $\mathrm{PhyC}_{\mathrm{dia}}$, DON and DetCalc are described in Table A1. The $\mathrm{N}$ assimilation $\left(V_{\text {nano }}^{\mathrm{N}}\right.$ and $\left.V_{\text {dia }}^{\mathrm{N}}\right)$ is calculated in Eq. (A48). The remineralization rate $\left(\rho_{\mathrm{N}}\right)$ can be found in Table A3 and the temperature dependency $\left(f_{T}\right)$ is calculated in Eq. (A54).

Dissolution of calcium carbonate from detritus adds $\mathrm{CO}_{3}^{2-}$ to the water and thereby increases the alkalinity with two moles for each dissolved mole calcium carbonate. Diss calc $_{\text {is }}$ calculated in Eq. (A34).

The parameter $\psi$, specifying the calcifying fraction of the nanophytoplankton, is listed in Table A7 and the photosynthesis $\left(P_{\text {nano }}\right)$ is calculated in Eq. (A44).

Input from benthos: the alkalinity of the bottom grid point of the water is affected by the remineralization of DIN, and thereby also DIP as well as dissolution of calcite from the benthos:

$$
\begin{aligned}
\text { BenF }_{\text {Alk }} & =(1+1 / 16) \cdot \rho_{\mathrm{N}}^{\text {ben }} \cdot \text { BenthosN } \\
& +2 \cdot \text { Diss }_{\text {calc }} \cdot \text { BenthosCalc. }
\end{aligned}
$$

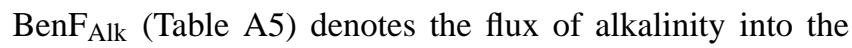
bottom layer of the ocean. The dissolution rate (Diss calc $_{\text {c }}$ ) is calculated in Eq. (A34), and the remineralization rate $\rho_{N}^{\text {ben }}$ is listed in Table A3. BenthosN and BenthosC (Table A2) denote the vertically integrated nitrogen and carbon concentration in the benthos compartment.

\section{A1.5 Phytoplankton N}

$$
\begin{aligned}
& \operatorname{SMS}\left(\operatorname{PhyN}_{\text {nano }}\right)=\underbrace{V^{\mathrm{N}_{\text {nano }}} \cdot \mathrm{PhyC}_{\text {nano }}}_{\text {N assimilation }} \\
& -\underbrace{\epsilon_{\mathrm{N}}^{\mathrm{phy}} \cdot f_{\text {lim, nano }}^{\mathrm{N}: \text { Cmax }} \cdot \text { PhyN }_{\text {nano }}}_{\text {DON excretion }} \\
& -\underbrace{\mathrm{Agg} \cdot \text { PhyN }_{\text {nano }}}_{\text {Aggregation loss }}-\underbrace{G_{\text {nano }}}_{\text {Grazing loss }} \\
& \operatorname{SMS}\left(\operatorname{PhyN}_{\text {dia }}\right)=\underbrace{V_{\text {dia }}^{\mathrm{N}} \cdot \text { PhyC }_{\text {dia }}}_{\text {N assimilation }} \\
& -\underbrace{\epsilon_{\mathrm{N}}^{\mathrm{phy}} \cdot f_{\text {lim, dia }}^{\mathrm{N}: \text { Cmax }} \cdot \mathrm{PhyN}_{\mathrm{dia}}}_{\text {DON excretion }} \\
& -\underbrace{\mathrm{Agg} \cdot \mathrm{PhyN}_{\text {dia }}}_{\text {Aggregation loss }}-\underbrace{G_{\text {dia }}}_{\text {Grazing loss }}
\end{aligned}
$$

The state variables $\mathrm{PhyC}_{\text {nano, }}$ PhyN $\mathrm{N}_{\text {nano }}, \mathrm{PhyC}_{\mathrm{dia}}$ and Phy $_{\text {dia }}$ are described in Table A1.

The nitrogen assimilation ( $V_{\text {nano }}^{\mathrm{N}}$ and $V_{\mathrm{dia}}^{\mathrm{N}}$ ) is calculated in Eq. (A48) and the constant excretion rate $\left(\epsilon_{\mathrm{N}}^{\mathrm{phy}}\right)$ is listed in Table A3. When the $\mathrm{N}: \mathrm{C}$ ratio becomes too high, excretion of DOC is downregulated by the limiter function $\left(f_{\lim }^{\mathrm{N}: \mathrm{Cmax}}\right)$ described in Sect. A6.1. A further loss term is phytoplankton aggregation (Agg), which transfers $\mathrm{N}$ to the detritus pools (Eq. A27).

The grazing loss $\left(G_{\text {nano }}\right.$ and $\left.G_{\text {dia }}\right)$ is calculated in Eqs. (A52) and (A53), respectively.

\section{A1.6 Phytoplankton C}

$$
\begin{aligned}
& \operatorname{SMS}\left(\operatorname{PhyC}_{\text {nano }}\right)=\underbrace{\left(P_{\text {nano }}-r_{\text {nano }}\right) \cdot \text { PhyC }_{\text {nano }}}_{\text {Net photosynthesis }} \\
& -\underbrace{\mathrm{Agg} \cdot \mathrm{PhyC}_{\text {nano }}}_{\text {Aggregation loss }} \\
& -\underbrace{\epsilon_{\mathrm{C}}^{\mathrm{phy}} \cdot f_{\text {lim, nano }}^{\mathrm{N}: \text { Cmax }} \cdot \mathrm{PhyC}_{\text {nano }}}_{\text {Excretion of DOC }} \\
& -\underbrace{q_{\text {nano }}^{\mathrm{C}: \mathrm{N}} \cdot G_{\text {nano }}}_{\text {Grazing loss }} \\
& \operatorname{SMS}\left(\mathrm{PhyC}_{\text {dia }}\right)=\underbrace{\left(P_{\text {dia }}-r_{\text {dia }}\right) \cdot \text { PhyC }_{\text {dia }}}_{\text {Net photosynthesis }} \\
& -\underbrace{\mathrm{Agg} \cdot \mathrm{PhyC}_{\mathrm{dia}}}_{\text {Aggregation loss }}-\underbrace{\epsilon_{\mathrm{C}}^{\mathrm{phy}} \cdot f_{\text {lim, dia }}^{\mathrm{N}: \mathrm{Cmax}} \cdot \mathrm{PhyC}_{\mathrm{dia}}}_{\text {Excretion of DOC }} \\
& -\underbrace{q_{\mathrm{dia}}^{\mathrm{C}: \mathrm{N}} \cdot G_{\mathrm{dia}}}_{\text {Grazing loss }}
\end{aligned}
$$

The state variables $\mathrm{PhyC}_{\text {nano }}$ and $\mathrm{PhyC}_{\mathrm{dia}}$ are described in Table A1. The photosynthesis $\left(P_{\text {nano }}\right.$ and $\left.P_{\text {dia }}\right)$ is calculated 
in Eq. (A44) and the respiration ( $r_{\text {nano }}$ and $\left.r_{\text {dia }}\right)$ in Eq. (A45). The constant DOC excretion rate $\left(\epsilon_{\mathrm{C}}^{\text {phy }}\right.$, Table A3) is downregulated by the limitation factor $f_{\lim }^{\mathrm{N}: \mathrm{C} m a x}$ (Sect. A6.1) when the $\mathrm{N}$ : C ratio becomes too high.

Aggregation of phytoplankton (Agg) is calculated in Eq. (A27) and grazing $\left(G_{\text {nano }}\right.$ and $\left.G_{\text {dia }}\right)$ in Eqs. (A52) and (A53), respectively. $q^{\mathrm{C}: \mathrm{N}}=\mathrm{PhyC} / \mathrm{PhyN}$, is used to convert the grazing units from $\mathrm{mmolN}$ to $\mathrm{mmol} C$.

\section{A1.7 Phytoplankton $\mathrm{CaCO}_{3}$}

Calcifiers are assumed to comprise a certain fraction of the total nanophytoplankton concentration, specified by the parameter $\psi$ (Table A7), tying the calcite production of calcifiers to the growth of nanophytoplankton.

$$
\begin{aligned}
& \mathrm{SMS}(\mathrm{PhyCalc})=\underbrace{\psi \cdot P_{\text {nano }} \cdot \mathrm{PhyC}_{\mathrm{nano}}}_{\text {Calcification }}-\underbrace{r_{\text {nano }} \cdot \text { PhyCalc }}_{\text {Respiration }} \\
& -\underbrace{G_{\text {nano }} \cdot q_{\text {nano }}^{\mathrm{CaCO}_{3}: \mathrm{N}}}_{\text {Grazing loss }} \\
& -\underbrace{\epsilon_{\mathrm{C}}^{\text {phy }} \cdot f_{\text {lim, nano }}^{\mathrm{N}: \text { Cmax }} \cdot \text { PhyCalc }}_{\text {Excretion loss }} \\
& -\underbrace{\text { Agg } \cdot \text { PhyCalc }} \\
& \text { Aggregation loss }
\end{aligned}
$$

The state variables $\mathrm{PhyC}_{\text {nano }}$ and PhyCalc are described in Table A1. The value for the calcifier fraction $(\psi)$ is listed in Table A7 and the excretion parameter $\left(\epsilon_{\mathrm{C}}^{\text {phy }}\right)$ in Table A3. The excretion loss is downregulated by the limiter function $f_{\text {lim, nano }}^{\mathrm{N} \text { : Cmax }}$ (Sect. A6.1) when the intracellular N : C ratio approaches a maximum value. The photosynthesis $\left(P_{\text {nano }}\right)$ is calculated in Eq. (A44), the respiration $\left(r_{\text {nano }}\right)$ in Eq. (A45), the grazing on nanophytoplankton $\left(G_{\text {nano }}\right)$ in Eq. (A52) and the aggregation rate (Agg) is calculated in Eq. (A27). $q_{\text {nano }}^{\mathrm{CaCO}_{3}: \mathrm{N}}=\mathrm{PhyCaCO}_{3} / \mathrm{PhyN}_{\text {nano }}$.

\section{A1.8 Diatom silicon}

$$
\begin{aligned}
\operatorname{SMS}(\mathrm{PhySi}) & =\underbrace{V^{\mathrm{Si}} \cdot \mathrm{PhyC}_{\mathrm{dia}}}_{\text {Diatom Si assimilation }}-\underbrace{\epsilon_{\mathrm{N}}^{\mathrm{phy}} \cdot f_{\text {lim, dia }}^{\mathrm{N}: \text { Cmax }} \cdot \text { PhySi }}_{\text {Excretion to detritus }} \\
& -\underbrace{\mathrm{Agg} \cdot \mathrm{PhySi}}_{\text {Aggregation loss }}-\underbrace{G_{\text {dia }} \cdot q^{\mathrm{Si}: \mathrm{N}}}_{\text {Grazing loss }} \text { (A21) }
\end{aligned}
$$

The state variables $\mathrm{PhyC}_{\mathrm{dia}}$ and $\mathrm{PhySi}$ are described in Table A1. The silicon assimilation rate $\left(V^{\mathrm{Si}}\right)$ is calculated in Eq. (A49), the aggregation rate (Agg) in Eq. (A27) and the grazing on diatoms $\left(G_{\text {dia }}\right)$ is calculated in Eq. (A53). The limiter function $\left(f_{\lim }^{\mathrm{N}: \mathrm{Cmax}}\right)$ is described in Sect. A6.1. The value of the excretion parameter $\left(\epsilon_{\mathrm{N}}^{\text {phy }}\right)$ is listed in Table A3 and the intracellular ratio between diatom silicon and carbon is defined as $q^{\mathrm{Si}: \mathrm{N}}=\mathrm{PhySi} / \mathrm{PhyN}_{\mathrm{dia}}$.

\section{A1.9 Phytoplankton Chl $a$}

$$
\begin{aligned}
& \operatorname{SMS}\left(\mathrm{PhyChl}_{\mathrm{nano}}\right)=\underbrace{S_{\mathrm{nano}}^{\mathrm{chl}} \cdot \mathrm{PhyC}_{\mathrm{nano}}}_{\text {Chl } a \text { synthesis }}-\underbrace{G_{\text {nano }} \cdot q_{\text {nano }}^{\mathrm{Chl}: \mathrm{N}}}_{\text {Grazing loss }} \\
& -\underbrace{\operatorname{deg}_{\text {chl }} \cdot \text { PhyChl }}_{\text {Degradation loss }} \\
& -\underbrace{\mathrm{Agg} \cdot \mathrm{PhyCh}_{\text {nano }}}_{\text {Aggregation loss }} \\
& \operatorname{SMS}\left(\mathrm{PhyChl}_{\mathrm{dia}}\right)=\underbrace{S_{\mathrm{dia}}^{\mathrm{chl}} \cdot \mathrm{PhyC}_{\mathrm{dia}}}_{\text {Chl } a \text { synthesis }}-\underbrace{G_{\mathrm{dia}} \cdot q_{\mathrm{dia}}^{\mathrm{Chl}: \mathrm{N}}}_{\text {Grazing loss }} \\
& -\underbrace{\operatorname{deg}_{\text {chl }} \cdot \text { PhyChl }_{\text {dia }}}_{\text {Degradation loss }} \\
& -\underbrace{\text { Agg } \cdot \mathrm{PhyCh}_{\text {dia }}}_{\text {Aggregation loss }}
\end{aligned}
$$

The state variables $\mathrm{PhyC}_{\text {nano }}, \mathrm{PhyC}_{\mathrm{dia}}, \mathrm{PhyChl}_{\text {nano }}$ and PhyChl $_{\text {dia }}$ are described in Table A1. The chlorophyll $a$ synthesis $\left(S^{\mathrm{chl}}\right)$ is calculated in Eq. (A47), the aggregation (Agg) in Eq. (A27) and the degradation parameter $\left(\operatorname{deg}_{\mathrm{chl}}\right)$ is listed in Table A3. The grazing fluxes $\left(G_{\text {nano }}\right.$ and $\left.G_{\text {dia }}\right)$ are calculated in Eqs. (A52) and (A53), respectively. The conversion factor from mmol $\mathrm{N}$ to $\mathrm{mgChl} a$ is defined as $q^{\mathrm{Chl}: \mathrm{N}}=$ PhyChl $/$ PhyN .

\section{A1.10 Zooplankton}

$$
\begin{aligned}
\operatorname{SMS}(\mathrm{ZooN}) & =\underbrace{\gamma \cdot\left(G_{\text {nano }}+G_{\text {dia }}\right)}_{\text {Grazing on phytoplankton }}-\underbrace{m_{\text {zoo }} \cdot \mathrm{ZooN}^{2}}_{\text {Zooplankton mortality }} \\
& -\underbrace{\epsilon_{\mathrm{N}}^{\text {Zoo }} \cdot \mathrm{ZooN}}_{\text {Excretion of DON }} \\
\mathrm{SMS}(\mathrm{ZooC}) & =\underbrace{\gamma \cdot\left(G_{\text {nano }} \cdot q_{\text {nano }}^{\mathrm{C}: \mathrm{N}}+G_{\mathrm{dia}} \cdot q_{\mathrm{dia}}^{\mathrm{C}: \mathrm{N}}\right)}_{\text {Grazing on phytoplankton }} \\
& -\underbrace{m_{\text {zoo }} \cdot \mathrm{ZOoN}^{2} \cdot q_{\mathrm{ZoO}}^{\mathrm{C}: \mathrm{N}}}_{\text {Zooplankton mortality }}-\underbrace{r_{\text {zoo }} \cdot \text { ZooC }}_{\text {Respiration loss }} \\
& -\underbrace{\epsilon_{\mathrm{C}}^{\text {Zoo }} \cdot \text { ZooC }}_{\text {Excretion of DOC }}
\end{aligned}
$$

The state variables ZooN and ZooC are described in Table A1. It is assumed, due to sloppy feeding, that only a fraction of the grazed phytoplankton ( $\gamma$, Table A7) enters the zooplankton pool. The rest is transferred to detritus.

Grazing by nanophytoplankton and diatoms $\left(G_{\text {nano }}\right.$ and $G_{\text {dia }}$ ) is calculated in Eqs. (A52) and (A53), respectively. The respiration by zooplankton $\left(r_{\mathrm{zoo}}\right)$ is calculated in Eq. (A46). The value of the mortality parameter $\left(m_{\text {zoo }}\right)$ is listed in Table A7 and the DON and DOC excretion $\left(\epsilon_{\mathrm{N}}^{\mathrm{zoo}}\right.$ and $\left.\epsilon_{\mathrm{C}}^{\mathrm{zoo}}\right)$ in Table A3. 
The quotas $q_{\text {nano }}^{\mathrm{C}: \mathrm{N}}$ and $q_{\text {dia }}^{\mathrm{C}: \mathrm{N}}$ convert the units of the grazing from mmol $\mathrm{N}$ to $\mathrm{mmol} \mathrm{C}$ and are defined as follows: $q_{\text {nano }}^{\mathrm{C}: \mathrm{N}}=$ $\mathrm{PhyC}_{\text {nano }} / \mathrm{PhyN}_{\text {nano }}$ and $q_{\mathrm{dia}}^{\mathrm{C}: \mathrm{N}}=\mathrm{PhyC}_{\mathrm{dia}} / \mathrm{PhyN}_{\mathrm{dia}}$.

\section{A1.11 Detritus $\mathbf{N}$ and $\mathrm{C}$}

$$
\begin{aligned}
& \operatorname{SMS}(\operatorname{DetN})=\underbrace{\left(G_{\text {nano }}+G_{\text {dia }}\right) \cdot(1-\gamma)}_{\text {Sloppy feeding }}+\underbrace{m_{\text {zoo }} \cdot \mathrm{ZooN}^{2}}_{\text {Zooplankton mortality }} \\
& +\underbrace{\mathrm{Agg} \cdot\left(\mathrm{PhyN}_{\text {nano }}+\mathrm{PhyN}_{\mathrm{dia}}\right)}_{\text {Phytoplankton aggregation }} \\
& -\underbrace{\rho_{\operatorname{DetN}} \cdot f_{T} \cdot \operatorname{DetN}}_{\text {Degradation to DON }} \\
& \mathrm{SMS}(\operatorname{DetC})=\underbrace{\left(G_{\text {nano }} \cdot q_{\text {nano }}^{\mathrm{C}: \mathrm{N}}+G_{\text {dia }} \cdot q_{\mathrm{dia}}^{\mathrm{C}: \mathrm{N}}\right) \cdot(1-\gamma)}_{\text {Sloppy feeding }} \\
& +\underbrace{m_{\mathrm{zoo}} \cdot \mathrm{ZooN}^{2} \cdot q_{\mathrm{zoo}}^{\mathrm{C}: \mathrm{N}}}_{\text {Zooplankton mortality }} \\
& +\underbrace{\mathrm{Agg} \cdot\left(\mathrm{PhyC}_{\mathrm{nano}}+\mathrm{PhyC}_{\mathrm{dia}}\right)}_{\text {Phytoplankton aggregation }} \\
& -\underbrace{\rho_{\text {DetC }} \cdot f_{T} \cdot \operatorname{DetC}}_{\text {Degradation to DOC }}
\end{aligned}
$$

The state variables $\mathrm{ZooN}$, PhyN $\mathrm{Pano}_{\text {no }}$, PhyN $\mathrm{N}_{\mathrm{dia}}$, DetN and DetC are described in Table A1. Due to sloppy feeding, the grazed phytoplankton partly goes to the zooplankton pool and partly to the detritus pool, depending on the grazing efficiency $\gamma$ (Table A7). The grazing $\left(G_{\text {nano }}\right.$ and $\left.G_{\text {dia }}\right)$ is calculated in Eqs. (A52) and (A53), respectively.

The quadratic mortality loss from zooplankton $\left(m_{\mathrm{zoo}}\right)$ is listed in Table A7. The temperature dependent degradation of detritus to DOM ( $\rho_{\text {DetN }}$ and $\left.\rho_{\text {DetC }}\right)$ in Table A3, and the temperature dependency $\left(f_{T}\right)$ is calculated in Eq. (A54).

The quotas $q_{\text {nano }}^{\mathrm{C}: \mathrm{N}}=\mathrm{PhyC}_{\text {nano }} / \mathrm{PhyN}_{\mathrm{nano}}, \quad q_{\mathrm{dia}}^{\mathrm{C}: \mathrm{N}}=$ $\mathrm{PhyC}_{\text {dia }} / \mathrm{PhyN}_{\text {dia }}$ and $q_{\mathrm{zoo}}^{\mathrm{C}: \mathrm{N}}=\mathrm{ZooC} / \mathrm{ZooN}$ are used to convert the units from mmol $\mathrm{N}$ to $\mathrm{mmol} \mathrm{C}$.

Aggregation: the aggregation rate (Agg, Table A4) is proportional to the concentration of nanophytoplankton, diatoms and detritus:

Agg $=\phi_{\text {phy }} \cdot\left(\right.$ PhyN $_{\text {nano }}+$ PhyN $\left._{\text {dia }}\right)+\phi_{\text {det }} \cdot \operatorname{DetN}$.

The values of the maximum aggregation loss parameters $\left(\phi_{\text {phy }}\right.$ and $\left.\phi_{\text {det }}\right)$ are listed in Table A7. The state variables PhyN $_{\text {nano }}$, PhyN $\mathrm{N}_{\text {dia }}$ and DetN are described in Table A1.

Sinking: in the model the detritus is subject to sinking, which increases linearly with depth. The sinking speed $\left(w_{\text {det }}\right.$, Table A4) is based on the work by Kriest and Oschlies (2008).

$w_{\text {det }}=0.0288$ day $^{-1} \cdot z+w_{0}$

Here $z$ denotes the current depth and $w_{0}$ is the sinking speed at the surface (Table A7).
Loss to benthos: when the sinking detritus reaches the bottom grid point it is assumed that it continues sinking into the benthic compartment with the speed $w_{\text {det }}$ (Eq. A28). This leads to a detrital flux (BenF $F_{\text {DetN }}$ and BenF $F_{\text {DetC }}$, Table A5) from the water column to the benthos:

$$
\begin{aligned}
& \mathrm{BenF}_{\text {DetN }}=-w_{\text {det }} \cdot \operatorname{Det} \mathrm{N} \\
& \mathrm{BenF}_{\text {DetC }}=-w_{\text {det }} \cdot \operatorname{DetC} .
\end{aligned}
$$

The state variables DetN and DetC are described in Table A1.

\section{A1.12 Detritus Si}

$$
\begin{aligned}
\mathrm{SMS}(\text { DetSi }) & =(\underbrace{\epsilon_{\mathrm{N}}^{\mathrm{phy}} \cdot f_{\text {lim, dia }}^{\mathrm{N}: \mathrm{Cmax}}}_{\text {Diatiom excretion }}+\underbrace{\text { Agg }}_{\text {Aggregation }}) \cdot \mathrm{PhySi} \\
& +\underbrace{G_{\mathrm{dia}} \cdot q^{\mathrm{Si}: \mathrm{N}}}_{\text {Sloppy feeding }}-\underbrace{\rho_{\text {S }}^{T} \cdot f_{T} \cdot \operatorname{DetSi}}_{\text {Remineralization to DSi }}
\end{aligned}
$$

The state variables PhySi and DetSi are described in Table A1. The limiter function $\left(f_{\text {lim }}^{\mathrm{N}: \mathrm{Cmax}}\right)$ is described in Sect. A6.1. The aggregation rate (Agg) is calculated in Eq. (A27), the grazing on diatoms $\left(G_{\text {dia }}\right)$ in Eq. (A53), the remineralization rate $\left(\rho_{\mathrm{Si}}^{T}\right)$ in Eq. (A4) and the temperature dependency of remineralization $\left(f_{T}\right)$ is calculated in Eq. (A54). The value of the excretion parameter $\left(\epsilon_{\mathrm{N}}^{\mathrm{phy}}\right)$ is listed in Table A3. The intracellular ratio between diatom silicon and carbon is defined as $q^{\mathrm{Si}: \mathrm{N}}=\mathrm{PhySi} / \mathrm{PhyN}_{\text {dia }}$.

Loss to benthos: when the sinking detritus reaches the bottom grid point it is assumed that it continues sinking into the benthic compartment with the speed $w_{\text {det }}$ (Eq. A28). This leads to a detrital flux (BenF $F_{\text {DetSi }}$, Table A5) from the water column to the benthos:

$\operatorname{BenF}_{\text {DetSi }}=-w_{\text {det }} \cdot \operatorname{DetSi}$.

The state variable DetSi is described in Table A1.

\section{A1.13 Detritus $\mathrm{CaCO}_{3}$}

$$
\begin{aligned}
& \operatorname{SMS}(\text { DetCalc })=\underbrace{\epsilon_{\mathrm{C}}^{\mathrm{phy}} \cdot f_{\text {lim, nano }}^{\mathrm{N}: \text { Cmax }} \cdot \text { PhyCalc }}_{\text {Nanophytoplankton excretion }} \\
&+(\underbrace{\mathrm{Agg}}_{\text {Aggregation }}+\underbrace{r_{\text {nano }}}_{\text {Respiration }}) \cdot \text { PhyCalc } \\
&+\underbrace{G_{\text {nano }} \cdot q_{\text {nano }}^{\text {CaCO }}: \mathrm{N}_{-}}_{\text {Grazing loss }}- \\
& \underbrace{\text { Diss } \text { calc }_{\text {DetCalc }} \cdot \text { DetCalc }}_{\text {Dissolution to DIC }}
\end{aligned}
$$

The state variables PhyCalc and DetCalc are described in Table A1. The limiter function $\left(f_{\mathrm{lim}}^{\mathrm{N}: \mathrm{Cmax}}\right)$ is described in Sect. A6.1. The aggregation rate (Agg) is calculated in Eq. (A27), the respiration rate $\left(r_{\text {nano }}\right)$ in Eq. (A45) and 
the nanophytoplankton grazing rate $\left(G_{\text {nano }}\right)$ in Eq. (A52). The excretion rate $\left(\epsilon_{\mathrm{C}}^{\text {phy }}\right)$ is listed in Table A3, the ratio $q_{\text {nano }}^{\mathrm{CaCO}_{3}: \mathrm{N}}=$ PhyCalc $/ \mathrm{PhyN}_{\text {nano }}$ and the calcite dissolution rate will now be explained.

Calcite dissolution: as the detritus calcite sinks through the water column it is subject to dissolution (Diss calc $_{\text {, Table A4) }}$ occurring on a length scale of $3500 \mathrm{~m}$ (Yamanaka and Tajika, 1996).

Diss $_{\text {calc }}=\frac{w_{z}}{3500 \mathrm{~m}}$

$w_{z}$ denotes the sinking speed at depth $z$ and is calculated in Eq. (A28).

Loss to benthos: when the sinking detritus reaches the bottom grid point it is assumed that it continues sinking into the benthic compartment with the speed $w_{\text {det }}$ (Eq. A28). This leads to a detrital flux $\left(\mathrm{BenF}_{\text {DetCalc }}\right.$, Table A5) from the water column to the benthos:

$\mathrm{BenF}_{\text {DetCalc }}=-w_{\text {det }} \cdot \operatorname{DetCaCO}{ }_{3}$.

The state variable DetCalc is described in Table A1.

\section{A1.14 Dissolved organic material}

$$
\begin{aligned}
& \operatorname{SMS}(\mathrm{DON})=\underbrace{\epsilon_{\mathrm{N}}^{\mathrm{phy}} \cdot f_{\text {lim, nano }}^{\mathrm{N}: \text { Cmax }} \cdot \text { PhyN }_{\text {nano }}}_{\text {Nanophytoplankton excretion }} \\
& +\underbrace{\epsilon_{\mathrm{N}}^{\mathrm{phy}} \cdot f_{\text {lim, dia }}^{\mathrm{N}: \text { Cmax }} \cdot \text { PhyN }_{\mathrm{dia}}}_{\text {Diatom excretion }} \\
& +\underbrace{\epsilon_{\mathrm{N}}^{\text {zoo }} \cdot \mathrm{ZooN}}_{\text {Zooplankton excretion }}+\underbrace{\rho_{\operatorname{DetN}} \cdot f_{T} \cdot \operatorname{DetN}}_{\text {Detritus degradation }} \\
& -\underbrace{\rho_{\mathrm{N}} \cdot f_{T} \cdot \mathrm{DON}}_{\text {Remineralization }} \\
& \mathrm{SMS}(\mathrm{DOC})=\underbrace{\epsilon_{\mathrm{C}}^{\mathrm{phy}} \cdot f_{\text {lim, nano }}^{\mathrm{N}: \text { Cmax }} \cdot \mathrm{PhyC}_{\text {nano }}}_{\text {Nanophytoplankton excretion }} \\
& +\underbrace{\epsilon_{\mathrm{C}}^{\mathrm{phy}} \cdot f_{\text {lim, dia }}^{\mathrm{N}: \text { Cmax }} \cdot \text { PhyC }_{\mathrm{dia}}}_{\text {Diatom excretion }} \\
& +\underbrace{\epsilon_{\mathrm{C}}^{\mathrm{zoo}} \cdot \mathrm{ZooC}}_{\text {Zooplankton excretion }}+\underbrace{\rho_{\mathrm{DetC}} \cdot f_{T} \cdot \operatorname{DetC}}_{\text {Detritus degradation }} \\
& -\underbrace{\rho_{\mathrm{C}} \cdot f_{T} \cdot \mathrm{DOC}}_{\text {Remineralization }}
\end{aligned}
$$

The state variables are described in Table A1. The values for excretion of nitrogen and carbon from phyto- and zooplankton $\left(\epsilon_{\mathrm{N}}^{\mathrm{phy}}, \epsilon_{\mathrm{C}}^{\mathrm{phy}}, \epsilon_{\mathrm{N}}^{\mathrm{zoo}}\right.$ and $\left.\epsilon_{\mathrm{C}}^{\mathrm{zoo}}\right)$ are listed in Table A3 along with the degradation rates for detritus $\left(\rho_{\operatorname{det} N}\right.$ and $\left.\rho_{\operatorname{detC}}\right)$ and remineralization rates of DON and $\operatorname{DOC}\left(\rho_{\mathrm{N}}\right.$ and $\left.\rho_{\mathrm{C}}\right)$. The limitation factors $\left(f_{\lim , \text { nano }}^{\mathrm{N}: \mathrm{Cmax}}\right.$ and $\left.f_{\lim \text {, dia }}^{\mathrm{N}: \mathrm{Cmax}}\right)$ are described in Sect. A6.1 and the temperature dependency $\left(f_{T}\right)$ is calculated in Eq. (A54).

\section{A2 Sources minus sinks, benthos}

The model has a benthos compartment which consists of one layer. Matter is supplied to this layer through sinking detritus, and it hence has pools of nitrogen, silicon, carbon and calcite. When sinking detritus reaches the bottom it continues sinking into the benthos with the speed, $w_{\text {det }}$, calculated by Eq. (A28) and is thus lost from the water column. In the benthos, the detritus is assumed to be remineralized to dissolved inorganic matter. This is then re-released to the water's pools of dissolved inorganic matter (DIN, DIC, Alk and DSi):

$$
\begin{aligned}
\operatorname{SMS}(\text { BenthosN })= & w_{\text {det }} \cdot \operatorname{DetN}-\rho_{\mathrm{N}}^{\text {ben }} \cdot \text { BenthosN } \\
\operatorname{SMS}(\text { BenthosSi })= & w_{\text {det }} \cdot \operatorname{DetSi}-\rho_{\mathrm{Si}}^{\text {ben }} \cdot \text { BenthosSi } \\
\operatorname{SMS}(\text { BenthosC })= & w_{\text {det }} \cdot \operatorname{DetC}-\rho_{\mathrm{C}}^{\text {ben }} \cdot \text { BenthosC } \\
\operatorname{SMS}(\text { BenthosCalc })= & w_{\text {det }} \cdot \operatorname{DetCalc}-\text { Diss }_{\text {calc }} \\
& \cdot \text { BenthosCalc. }
\end{aligned}
$$

The state variables are described in Table A1 (DetN, DetSi, DetC and DetCalc) and Table A2 (BenthosN, BenthosSi, BenthosC and BenthosCalc). The remineralization rates $\left(\rho_{\mathrm{N}}^{\text {ben }}, \rho_{\mathrm{Si}}^{\text {ben }}\right.$ and $\left.\rho_{\mathrm{C}}^{\text {ben }}\right)$ are listed in Table A3 and the calcite dissolution rate (Diss calc $_{\text {) }}$ ) is calculated in Eq. (A34).

\section{A3 Phytoplankton growth}

\section{A3.1 Photosynthesis}

The rate of the $\mathrm{C}$-specific photosynthesis is calculated for both nanophytoplankton and diatoms $\left(P_{\text {nano }}\right.$ and $P_{\text {dia }}$, Table A4).

The calculation is based on the work by Geider et al. (1998) and differs between nanophytoplankton and diatoms in the nutrient limitation; nanophytoplankton is limited by iron and nitrogen while diatoms are additionally limited by silicon.

$$
\begin{aligned}
P_{\max }^{\mathrm{nano}} & =\mu_{\mathrm{C}}^{\max } \cdot \min \left(f_{\text {lim, nano }}^{\mathrm{Fe}}, f_{\text {lim, nano }}^{\mathrm{N}: \mathrm{Cmin}}\right) \cdot f_{T} \\
P_{\max }^{\mathrm{dia}} & =\mu_{\mathrm{C}}^{\max } \cdot \min \left(f_{\text {lim, dia }}^{\mathrm{Fe}}, f_{\text {lim, dia }}^{\mathrm{N}: \mathrm{Cmin}}, f_{\text {lim, dia }}^{\mathrm{Si}: \mathrm{Cmin}}\right) \cdot f_{T}
\end{aligned}
$$

Nutrient limitation is calculated using the Liebig law of the minimum, in which the most limiting nutrient limits production (O'Neill et al., 1989).

The value of $\mu_{\mathrm{C}}^{\max }$ can be found in Table A8. The limitation terms $\left(f_{\lim }^{\mathrm{N} \text { : Cmin }}, f_{\lim }^{\mathrm{Si}: \mathrm{Cmin}}\right.$ and $\left.f_{\lim }^{\mathrm{Fe}}\right)$ differ somewhat from the formulation in Geider et al. (1998) and are described in Sect. A6.2 and the temperature dependency $\left(f_{T}\right)$ is calculated in Eq. (A54).

The actual C-specific photosynthesis rate depends on how much photosynthetically available radiation (PAR, Table A4) the cell can harvest. This is controlled by the light harvesting efficiency $(\alpha)$ and the intracellular $\mathrm{Chl}$ : $\mathrm{C}$ ratio as well as the 
Table A8. Parameters for phytoplankton growth.

\begin{tabular}{|c|c|c|}
\hline Parameter & Value & Description and unit \\
\hline$\alpha_{\text {nano }}$ & 0.19 & Light harvesting efficiency for nanophytoplankton $\left[\mathrm{mmolC}^{2}(\mathrm{mgChlW} \text { day })^{-1}\right]$ \\
\hline$\alpha_{\mathrm{dia}}$ & 0.23 & Light harvesting efficiency for diatoms $\left[\mathrm{mmol} \mathrm{C} \mathrm{m}^{2}(\mathrm{mgChl} \mathrm{W} \text { day })^{-1}\right]$ \\
\hline$K_{\mathrm{N}}^{\mathrm{Nano}}$ & 0.55 & Half-saturation constant for nanophyto $\mathrm{N}$ uptake $\left[\mathrm{mmolNm}^{-3}\right]$ \\
\hline$K_{\mathrm{N}}^{\mathrm{Dia}}$ & 1.00 & Half-saturation constant for diatom $\mathrm{N}$ uptake $\left[\mathrm{mmol} \mathrm{N} \mathrm{m}^{-3}\right]$ \\
\hline$K_{\mathrm{Si}}$ & 4.00 & Half-saturation constant for diatom Si uptake $\left[\mathrm{mmol} \mathrm{Si} \mathrm{m}^{-3}\right]$ \\
\hline$\mu_{\mathrm{C}}^{\max }$ & 3.0 & Rate of C-specific photosynthesis $\left[\right.$ day $\left.^{-1}\right]$ \\
\hline$q_{\max }^{C h l}: \mathrm{N}$ & 4.2 & Maximum $\mathrm{Chl}: \mathrm{N}$ ratio for phytoplankton $\left[\mathrm{mg} \mathrm{Chl} \mathrm{mmol} \mathrm{N}{ }^{-1}\right]$ \\
\hline res & 0.01 & Maintenance respiration rate constant $\left[\mathrm{day}^{-1}\right]$ \\
\hline$\sigma_{\mathrm{N}}: \mathrm{C}$ & 0.2 & Maximum uptake ratio $\mathrm{N}: \mathrm{C}\left[\mathrm{mmolN} \mathrm{mmol}^{-1}\right]$ \\
\hline$\sigma_{\mathrm{Si}: \mathrm{C}}$ & 0.2 & Maximum uptake ratio $\mathrm{Si}: \mathrm{C}\left[\mathrm{mmol} \mathrm{Si} \mathrm{mmolC^{-1 } ]}\right.$ \\
\hline$\tau$ & 0.01 & Timescale for zooplankton respiration $\left[\mathrm{day}^{-1}\right]$ \\
\hline$V_{\mathrm{cm}}$ & 0.7 & Scaling factor for C-specific $\mathrm{N}$ uptake, dimensionless \\
\hline$\zeta$ & 2.33 & Cost of biosynthesis of $\mathrm{N}\left[\mathrm{mmolC} \mathrm{mmol} \mathrm{N}^{-1}\right]$ \\
\hline
\end{tabular}

available light.

$$
P=P_{\max } \cdot\left(1.0-\exp \left(\frac{-\alpha \cdot q^{\mathrm{Ch} 1: \mathrm{C}} \cdot \mathrm{PAR}}{P_{\max }}\right)\right)
$$

The C-specific photosynthesis rate is calculated for both nanophytoplankton and diatoms; $P_{\text {nano }}$ and $P_{\mathrm{dia}}$, respectively (Table A4).

The values for the light harvesting efficiencies $\left(\alpha_{\text {nano }}\right.$ and $\left.\alpha_{\text {dia }}\right)$ are listed in Table A8, the apparent maximum photosynthetic rate $\left(P_{\max }\right)$ is calculated in Eqs. (A42) and (A43) and we define $q^{\mathrm{Chl}: \mathrm{C}}=\mathrm{PhyChl} / \mathrm{PhyC}$.

\section{A3.2 Respiration}

Phytoplankton: the phytoplankton respiration rate is calculated for both nanophytoplankton and diatoms $\left(r_{\text {nano }}\right.$ and $r_{\text {dia }}$, Table A4):

$r=\underbrace{\text { res } \cdot f_{\text {lim }}^{\mathrm{N}: \text { Cmax }}}_{\text {Cost of maintenance }}+\underbrace{\zeta \cdot V^{\mathrm{N}}}_{\text {Cost of } \mathrm{N} \text { assim }}$.

The values for the maintenance respiration rate (res) and the cost of biosynthesis $(\zeta)$ can be found in Table A8. The limiter function $\left(f_{\text {lim }}^{\mathrm{N}: \mathrm{Cmax}}\right)$ is described in Sect. A6.1 and the nitrogen assimilation rate $\left(V_{\text {nano }}^{\mathrm{N}}\right.$ and $\left.V_{\text {dia }}^{\mathrm{N}}\right)$ is calculated in Eq. (A48).

Zooplankton: when the intracellular $\mathrm{C}: \mathrm{N}$ ratio in zooplankton exceeds the Redfield ratio, a temperature dependent respiration $\left(r_{\mathrm{zoo}}\right.$, Table A4) is assumed to drive it back with a timescale $\tau$. Otherwise, the respiration is zero.

$r_{\mathrm{zoo}}=\max \left(0\right.$ day $\left.^{-1}, \frac{q_{\mathrm{zoo}}^{\mathrm{C}: \mathrm{N}}-q_{\mathrm{Standard}}^{\mathrm{C}: \mathrm{N}}}{\tau} \cdot f_{T}\right)$

The timescale for respiration $(\tau)$ is given in Table A8. The temperature dependence $\left(f_{T}\right)$ is calculated in Eq. (A54), and we define the ratios $q_{\mathrm{zoo}}^{\mathrm{C}: \mathrm{N}}=\mathrm{ZooC} / \mathrm{ZooN}$ and $q_{\mathrm{Standard}}^{\mathrm{C}: \mathrm{N}}=$ $106 \mathrm{C} / 16 \mathrm{~N}$.

\section{A3.3 Chlorophyll $a$ synthesis}

Chlorophyll $a$ synthesis is coupled to N uptake in REcoM2. The uptake of nitrogen by the phytoplankton $\left(V^{\mathrm{N}}\right)$ is converted to chlorophyll units with a maximum $\mathrm{Chl}: \mathrm{N}$ ratio $\left(q_{\max }^{\mathrm{Chl}: \mathrm{N}}\right)$. This highest possible chlorophyll synthesis rate can then be downregulated by the ratio between the actual photosynthesis and the light absorption, leading to a smaller rate when photosynthesis is small.

The chlorophyll $a$ synthesis is calculated for both nanophytoplankton and diatoms ( $S_{\text {nano }}^{\mathrm{Chl}}$ and $S_{\text {dia }}^{\mathrm{Chl}}$, Table A4).

$S^{\mathrm{chl}}=V^{\mathrm{N}} \cdot q_{\max }^{\mathrm{Chl}: \mathrm{N}} \cdot \min \left(1, \frac{P}{\alpha \cdot q^{\mathrm{Chl}: \mathrm{C}} \cdot \mathrm{PAR}}\right)$

The nitrogen assimilation $\left(V_{\text {nano }}^{\mathrm{N}}\right.$ and $\left.V_{\mathrm{dia}}^{\mathrm{N}}\right)$ is calculated in Eq. (A48), and the value for the maximum $\mathrm{Chl}: \mathrm{N}$ ratio $\left(q_{\max }^{\mathrm{Chl}: \mathrm{N}}\right)$ can be seen in Table A8.

The C-specific photosynthesis $\left(P_{\text {nano }}\right.$ and $\left.P_{\mathrm{dia}}\right)$ is calculated in Eq. (A44), and the values for $\alpha_{\text {nano }}$ and $\alpha_{\text {dia }}$ are listed in Table A8. PAR denotes the photosynthetically available radiation and we define $q^{\mathrm{Chl}: \mathrm{C}}=\mathrm{PhyChl} / \mathrm{PhyC}$.

\section{A3.4 Nitrogen and silicon assimilation}

Nitrogen: the carbon-specific $\mathrm{N}$ assimilation rate is based on the maximum rate of carbon-specific photosynthesis $\left(P_{\max }\right)$, which is then modulated by the maximum $\mathrm{N}: \mathrm{C}$ uptake ratio $\left(\sigma_{\mathrm{N}}: \mathrm{C}\right)$ and by the intracellular quota between $\mathrm{N}$ and $\mathrm{C}$ $\left(f_{\lim }^{\mathrm{N}: \mathrm{Cmax}}\right)$, which downregulates $\mathrm{N}$ assimilation when the $\mathrm{N}: \mathrm{C}$ ratio approaches a maximum value (Sect. A6.1). The concentration of DIN in the surrounding water modifies the $\mathrm{N}$ assimilation through Michaelis-Menten kinetics.

$\mathrm{N}$ assimilation is calculated for both diatoms and nanophytoplankton $\left(V_{\text {nano }}^{\mathrm{N}}\right.$ and $V_{\mathrm{dia}}^{\mathrm{N}}$, Table A4).

$V^{\mathrm{N}}=V_{\mathrm{cm}} \cdot P_{\max } \cdot \sigma_{\mathrm{N}}: \mathrm{C} \cdot f_{\mathrm{lim}}^{\mathrm{N}: \mathrm{Cmax}} \cdot \frac{\mathrm{DIN}}{K_{\mathrm{N}}+\mathrm{DIN}}$ 
The values of the parameters for $V_{\mathrm{cm}}, \sigma_{\mathrm{N}}: \mathrm{C}, K_{\mathrm{N}}^{\text {nano }}$ and $K_{\mathrm{N}}^{\text {dia }}$ are listed in Table A8. The maximum rates of photosynthesis $\left(P_{\max }^{\text {nano }}\right.$ and $\left.P_{\max }^{\text {dia }}\right)$ are calculated in Eqs. (A42) and (A43), respectively, and $f_{\text {lim }}^{\mathrm{N} \text { C Cmax }}$ is described in Sect. A6.1. DIN denotes the surrounding water's concentration of dissolved inorganic nitrogen.

Silicon: silicon assimilation $\left(V^{\mathrm{Si}}\right.$, Table A4) only occurs in diatoms. The maximum silicon uptake rate is calculated as the maximum photosynthetic rate $\left(\mu_{\mathrm{C}}^{\max }\right)$ multiplied by the maximum $\mathrm{Si}: \mathrm{C}$ ratio $\left(\sigma_{\mathrm{Si}: \mathrm{C}}\right)$ and the scaling factor for the maximum nitrogen uptake $\left(V_{\mathrm{cm}}\right)$. The actual uptake depends on the surrounding water's silicon concentration through Michaelis-Menten kinetics and the temperature dependency $\left(f_{T}\right)$. It is additionally downregulated when the $\mathrm{N}: \mathrm{C}$ or $\mathrm{Si}: \mathrm{C}$ ratios become too high $\left(f_{\lim }^{\mathrm{Si}: \mathrm{Cmax}}\right.$ and $\left.f_{\text {lim dia }}^{\mathrm{N} \text { : Cmax }}\right)$. The $\mathrm{N}: \mathrm{C}$ ratio is taken into account, as a too high ratio indicates that the intracellular concentration of energy rich carbon molecules becomes too low to use energy on silicon uptake.

$$
\begin{aligned}
V^{\mathrm{Si}} & =V_{\mathrm{cm}} \cdot \mu_{\mathrm{C}}^{\max } \cdot f_{T} \cdot \sigma_{\mathrm{Si}: \mathrm{C}} \cdot f_{\mathrm{lim}}^{\mathrm{SiCmax}} \cdot f_{\mathrm{lim} \text { dia }}^{\mathrm{NCmax}} \\
& \cdot \frac{\mathrm{DSi}}{K_{\mathrm{Si}}+\mathrm{DSi}}
\end{aligned}
$$

The scaling factor for the $\mathrm{N}$ uptake $\left(V_{\mathrm{cm}}\right)$ and the $\mathrm{C}$-specific photosynthesis rate $\left(\mu_{\mathrm{C}}^{\max }\right)$ are listed in Table A8 along with the maximum $\mathrm{Si}: \mathrm{C}$ uptake ratio $\left(\sigma_{\mathrm{Si}: \mathrm{C}}\right)$. The temperature dependency $\left(f_{T}\right)$ is calculated in Eq. (A54), and the limitation by the intracellular ratios $\mathrm{Si}: \mathrm{C}$ and $\mathrm{N}: \mathrm{C}\left(f_{\mathrm{lim}}^{\mathrm{Si}: \mathrm{Cmax}}\right.$ and $\left.f_{\text {lim, dia }}^{\mathrm{N} \text { : } \operatorname{cmax}}\right)$ are described in Sects. A6.3 and A6.1, respectively. $K_{\mathrm{Si}}$ is listed in Table , and DSi denotes the surrounding water's concentration of dissolved inorganic silicon.

\section{A4 Grazing}

REcoM2 has a single zooplankton class, which is also the highest trophic level in the model. Grazing on both nanophytoplankton and diatoms is calculated using a Type 3 Sigmoidal model as described by Gentleman et al. (2003).

The maximum grazing rate $\left(G_{\max }\right)$ is modulated by the temperature through the Arrhenius function $\left(f_{T}\right)$ and by the prey availability through a quadratic Michaelis-Menten function. The model has fixed preferences for both phytoplankton classes and $G^{\prime}$ (Table A4) is the phytoplankton concentration available for food intake, in our case:

$G^{\prime}=\mathrm{PhyN}_{\text {nano }}+\mathrm{PhyN}_{\text {dia }} \cdot f_{\mathrm{Z}}^{\text {dia }}$.

Here, the parameter $f_{\mathrm{Z}}^{\text {dia }}$ (Table A9) specifies the relative grazing preference for diatoms.

The total grazing ( $G_{\text {tot }}$, Table A4) is calculated as follows:

$G_{\mathrm{tot}}=G_{\max } \cdot \frac{G^{\prime 2}}{K_{\mathrm{G}}+G^{\prime 2}} \cdot f_{T} \cdot \mathrm{ZooN}$
This total grazing can be divided into the grazing on nanophytoplankton and diatoms ( $G_{\text {nano }}$ and $G_{\text {dia }}$, Table A4):

$$
\begin{aligned}
G_{\text {nano }} & =G_{\text {tot }} \cdot \frac{\text { PhyN }_{\text {nano }}}{G^{\prime}} \\
G_{\text {dia }} & =G_{\text {tot }} \cdot \frac{\text { PhyN }_{\text {dia }} \cdot f_{\mathrm{Z}}^{\text {dia }}}{G^{\prime}} .
\end{aligned}
$$

The values for the maximum grazing rate $\left(G_{\max }\right)$, the halfsaturation constant $\left(K_{\mathrm{G}}\right)$ and the fraction of diatoms available for grazing $\left(f_{\mathrm{Z}}^{\text {dia }}\right)$ are listed in Table A9. The temperature dependency $\left(f_{T}\right)$ is calculated in Eq. (A54) and the state variables are described in Table A1.

\section{A5 Temperature dependence of rates}

Temperature dependence of metabolic rates $\left(f_{T}\right.$, Table A4) is taken into account through an Arrhenius function:

$f_{T}=\exp \left(-4500 \mathrm{~K} \cdot\left(T^{-1}-T_{\text {ref }}{ }^{-1}\right)\right)$.

Here, $T$ is the local temperature in Kelvin and $T_{\text {ref }}$ is a reference temperature (Table A10). The value $4500 \mathrm{~K}$ is the slope of the linear part of the Arrhenius function. Figure A1 illustrates how the metabolic rates decrease for $T<T_{\text {ref }}$ and increase for $T>T_{\text {ref. }}$.

\section{A6 Nutrient limitation}

One factor controlling the metabolic processes in the phytoplankton is the intracellular ratios between nutrients and carbon.

Five different limiters are used for this; one that downregulates uptake of $\mathrm{N}$ and release of $\mathrm{C}$ when the $\mathrm{N}$ : $\mathrm{C}$ ratio becomes too high $\left(f_{\lim }^{\mathrm{N} \text { : Cmax }}\right.$, Sect. A6.1), three that downregulate photosynthesis when the nutrient: $\mathrm{C}$ ratios become too low $\left(f_{\lim }^{\mathrm{N} \text { : Cmin }}, f_{\mathrm{lim}}^{\mathrm{Si}: \mathrm{Cmin}}\right.$ and $f_{\mathrm{lim}}^{\mathrm{Fe}}$, Sect. A6.2) and one that downregulates silicon assimilation when the $\mathrm{Si}: \mathrm{C}$ ratio becomes too high $\left(f_{\text {lim }}^{\text {Si: Cmax }}\right.$, Sect. A6.3).

These limiters will now be described after a general explanation of the function.

The way the intracellular ratios between nutrients and carbon limit uptake in the model is based on the work by Geider et al. (1998), but has been modified to the non-linear function, which is calculated as follows:

$$
f_{\text {lim }}\left(\text { slope }, q_{1}, q_{2}\right)=1-\exp \left(-\operatorname{slope}(|\Delta q|-\Delta q)^{2}\right) \text {. }
$$

Here, $\Delta q=q_{1}-q_{2}$ is the difference between the intracellular nutrient : $\mathrm{C}$ quota and a prescribed max or min quota, which is chosen depending on the situation.

The dimensionless constant slope regulates the degree of limitation for a given $\Delta q$.

\section{A6.1 Intracellular regulation of $\mathrm{N}$ uptake and $\mathrm{C}$ release}

Here we take a closer look at the limiter $f_{\lim }^{\mathrm{N} \text { : Cmax }}$, which downregulates the metabolic processes listed in Table A11 when the intracellular $\mathrm{N}: \mathrm{C}$ ratio becomes too high. 
Table A9. Parameters for grazing.

\begin{tabular}{lll}
\hline Parameter & Value & Description and unit \\
\hline$f_{\mathrm{Z}}^{\text {dia }}$ & 0.50 & Relative grazing preference for diatoms, dimensionless \\
$G_{\max }$ & 2.40 & Maximum grazing rate at $0^{\circ} \mathrm{C}[$ day \\
$K_{G}$ & 0.35 & Half-saturation constant for grazing loss $\left[\left(\mathrm{mmol} \mathrm{N}^{-3}\right)^{2}\right]$ \\
\hline
\end{tabular}

Table A10. Parameters for limitation functions.

\begin{tabular}{|c|c|c|}
\hline Parameter & Value & Description and unit \\
\hline$K_{\mathrm{Fe}}^{\text {nano }}$ & 0.04 & Half-saturation constant for nanophytoplankton $\mathrm{Fe}$ uptake $\left[\mu \mathrm{molFe} \mathrm{m}^{-3}\right]$ \\
\hline$K_{\mathrm{Fe}}^{\mathrm{dia}}$ & 0.12 & Half-saturation constant for diatom Fe uptake $\left[\mu \mathrm{molFe} \mathrm{m}^{-3}\right]$ \\
\hline$q^{\mathrm{N}: \mathrm{Cmin}}$ & 0.04 & Min intracellular $\mathrm{N}: \mathrm{C}$ ratio for nanophytoplankton $\left[\mathrm{mmolN} \mathrm{mmol \textrm {C } ^ { - 1 } ]}\right.$ \\
\hline$q^{\mathrm{N}: \mathrm{Cmax}}$ & 0.2 & Max intracellular $\mathrm{N}: \mathrm{C}$ ratio for nanophytoplankton $\left[\mathrm{mmol} \mathrm{mmolC}^{-1}\right]$ \\
\hline$q^{\mathrm{Si}: \mathrm{Cmin}}$ & 0.04 & Min intracellular $\mathrm{Si}: \mathrm{C}$ ratio for diatoms $\left[\mathrm{mmol} \mathrm{Si} \mathrm{mmolC^{-1 } ]}\right.$ \\
\hline$q^{\mathrm{Si}: \mathrm{Cmax}}$ & 0.8 & Max intracellular $\mathrm{Si}: \mathrm{C}$ ratio for diatoms $\left[\mathrm{mmol} \mathrm{Si} \mathrm{mmolC^{-1 }}\right.$ ] \\
\hline $\operatorname{slope}_{\min }^{\mathrm{N}}$ & 50 & Minimum limiter regulator for $\mathrm{N},\left[\mathrm{mmolC} \mathrm{mmolN}^{-1}\right]$ \\
\hline slope $_{\max }^{N}$ & 1000 & Maximum limiter regulator for $\mathrm{N},\left[\mathrm{mmolC} \mathrm{mmol}^{-1}\right]$ \\
\hline $\operatorname{slope}_{\min }^{\mathrm{Si}}$ & 1000 & Minimum limiter regulator for $\mathrm{Si},\left[{\left.\mathrm{mmol} \mathrm{C} \mathrm{mmolN}^{-1}\right]}\right.$ \\
\hline slope $_{\max }^{\mathrm{Si}}$ & 1000 & Maximum limiter regulator for $\mathrm{Si},\left[\mathrm{mmol} \mathrm{Cmmol}^{-1}\right]$ \\
\hline$T_{\text {ref }}$ & 288.15 & Reference temperature for Arrhenius function [K] \\
\hline
\end{tabular}

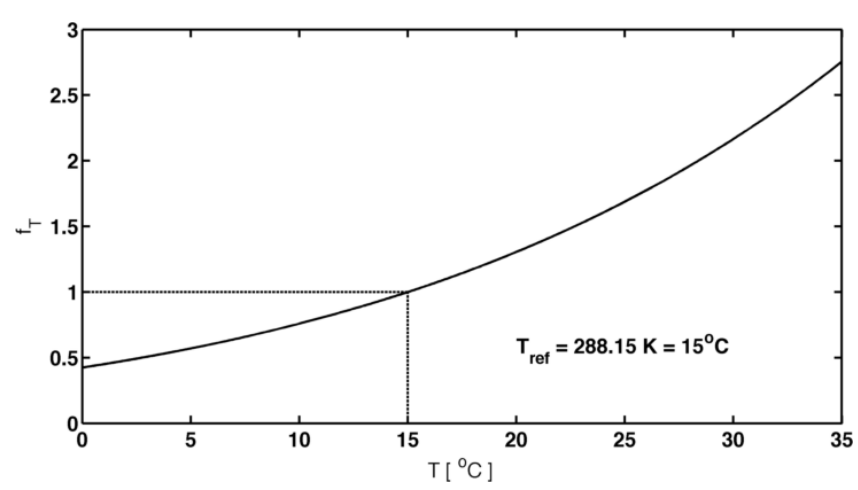

Figure A1. The Arrhenius function plotted with the parameters used in REcoM2.

It is calculated with Eq. (A55) using the following parameters:

slope $=$ slope $_{\max }^{\mathrm{N}}, q_{1}=q^{\mathrm{N}: \mathrm{Cmax}}, q_{2}=q^{\mathrm{N}: \mathrm{C}}$,

where slope $\mathrm{e}_{\max }^{\mathrm{N}}$ is listed in Table A10 along with the prescribed maximum $\mathrm{N}: \mathrm{C}$ quota $\left(q^{\mathrm{N}: \mathrm{Cmax}}\right) \cdot q^{\mathrm{N}: \mathrm{C}}$ is the current intracellular quota.

In Fig. A2 it is illustrated how the limiter function changes with changing intracellular N : C quota; when the intracellular concentration of nitrogen increases as compared to carbon, the rate of the processes that are affected by the limiter will be downregulated. Total limitation $\left(f_{\mathrm{lim}}^{\mathrm{N}: \mathrm{Cmax}}=0\right)$ oc-
Table A11. Processes modulated by the limiter function $f_{\lim }^{\mathrm{N}: \text { Cmax }}$.

\begin{tabular}{ll}
\hline Process & Effect of $q^{\mathrm{N}: \mathrm{C}} \rightarrow q_{\mathrm{N}: \mathrm{Cmax}}$ \\
\hline Nitrogen assimilation & Ends uptake of $\mathrm{N}$ \\
Silicon assimilation & Ends uptake of $\mathrm{Si}$ \\
Respiration by phytoplankton & Ends release of C \\
Phytoplankton DOC excretion & Ends release of C \\
Phytoplankton DON excretion & Ends release of $\mathrm{N}$ \\
Phytoplankton calcite excretion & Ends release of C \\
\hline
\end{tabular}

curs when the quota becomes equal to or higher than 0.2 , or the equivalent of $21.2 \mathrm{~N}: 106 \mathrm{C}$.

\section{A6.2 Intracellular regulation of C uptake}

Photosynthesis is limited by the nutrients iron, nitrogen and in the case of diatoms also silicon.

Nitrogen and silicon limitation: in the case of $\mathrm{N}$ and $\mathrm{Si}$, the regulation is controlled by the intracellular ratios $\mathrm{N}: \mathrm{C}$ $\left(f_{\text {lim }}^{\mathrm{N}: \mathrm{Cmin}}\right)$ and $\mathrm{Si}: \mathrm{C}\left(f_{\mathrm{lim}}^{\mathrm{Si}: \mathrm{Cmin}}\right)$. These limiters downregulate the rate of photosynthesis when the intracellular nutrient: C ratios become too low (Fig. A3). 


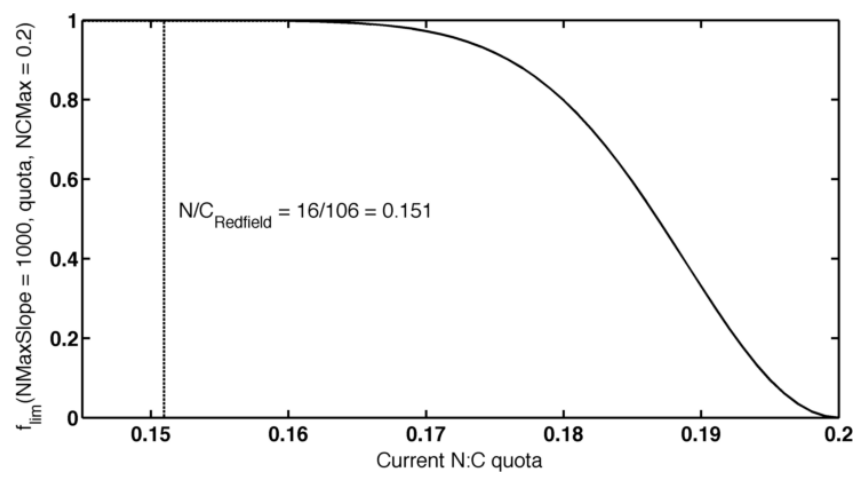

Figure A2. Change in limiter function $f_{\lim }^{\mathrm{N}: \mathrm{Cmax}}$ with $\mathrm{N}: \mathrm{C}$ quota.
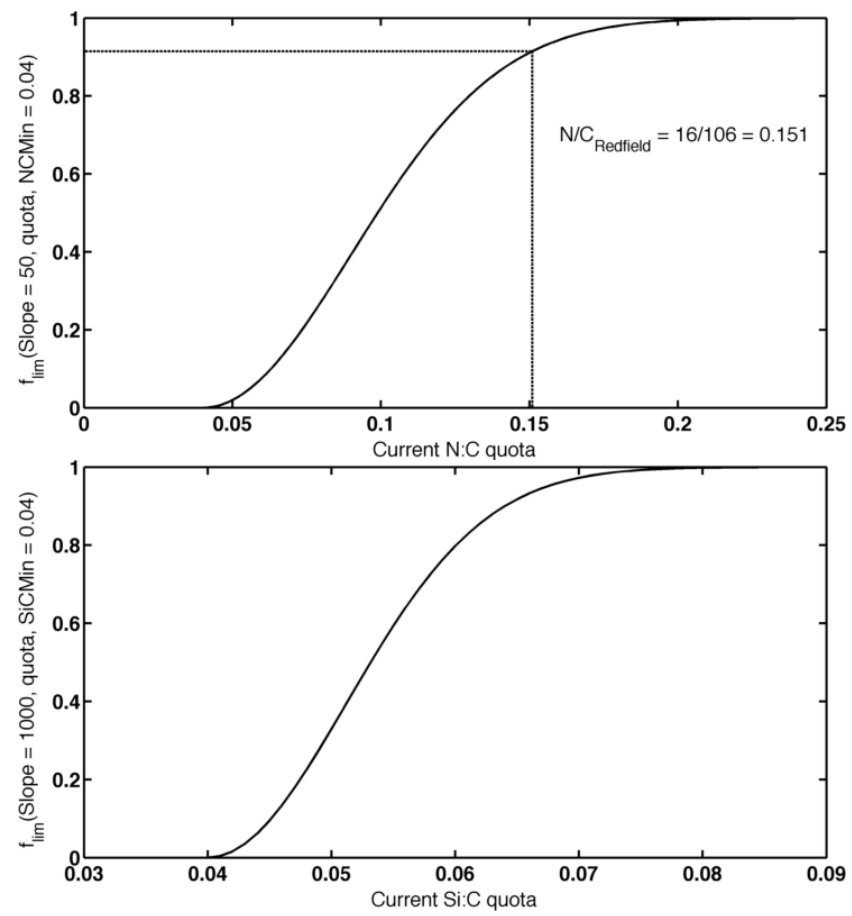

Figure A3. Change in the limiter function $f_{\text {lim }}^{\mathrm{N}: \text { Cmin }}$ with $\mathrm{N}: \mathrm{C}$ quota.

They are calculated with Eq. (A55) using the following parameters (Table A10):

slope $=$ slope $_{\min }^{\mathrm{N}}, q_{1}=q^{\mathrm{N}: \mathrm{Cmin}}, q_{2}=q^{\mathrm{N}: \mathrm{C}}$

slope $=\operatorname{slope}_{\min }^{\mathrm{Si}}, q_{1}=q^{\mathrm{Si}: \mathrm{Cmin}}, q_{2}=q^{\mathrm{Si}: \mathrm{C}}$.

Iron: for iron, the water's concentration is used to calculate the limitation. This is done using Michaelis-Menten kinetics:

$f_{\mathrm{lim}}^{\mathrm{Fe}}=\frac{\mathrm{Fe}}{K_{\mathrm{Fe}}+\mathrm{Fe}}$.

The half-saturation constants $\left(K_{\mathrm{Fe}}^{\text {nano }}\right.$ and $\left.K_{\mathrm{Fe}}^{\text {dia }}\right)$ are listed in Table A10.

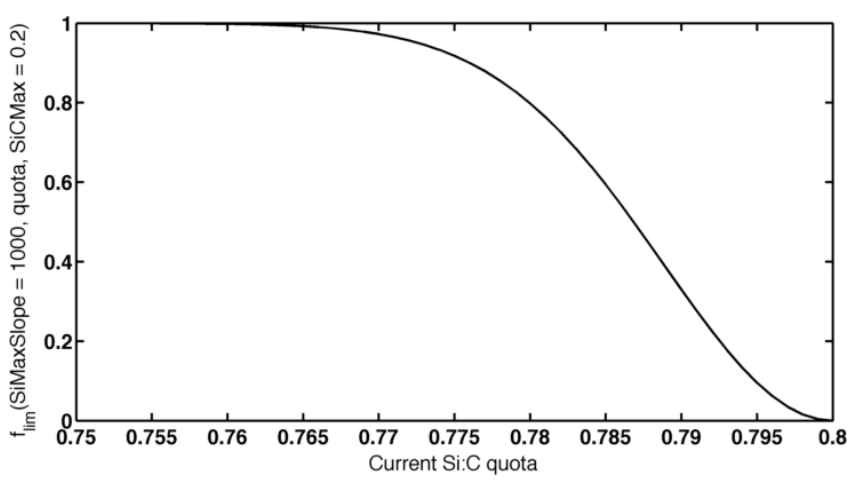

Figure A4. Change in limiter function with $\mathrm{Si}$ : C quota.

\section{A6.3 Intracellular regulation of Si uptake}

Diatom uptake of silicon is downregulated by the function $f_{\lim }^{\mathrm{Si} \text { : Cmax }}$ (Fig. A4) when the intracellular Si : C ratio exceeds a set limit. The limiter function is described in Eq. (A55) and is calculated using the following variables (Table A10):

slope $=\operatorname{slope}_{\max }^{\mathrm{Si}}, q_{1}=q^{\mathrm{Si}: \mathrm{C}}, q_{2}=q^{\mathrm{Si}: \mathrm{Cmax}}$. 


\section{Supplementary material}

The supplements contain the full code for REcoM2 along with a manual for FESOM-REcoM2, containing an overview of the code structure and instructions for running the coupled model.

\section{The Supplement related to this article is available online at doi:10.5194/gmd-7-2769-2014-supplement.}

Acknowledgements. We would like to thank Sergey Danilov for many discussions regarding the understanding and handling of the FESOM finite-element model. We also thank two anonymous reviewers for their constructive comments that helped very much to improve the manuscript. C. Völker was supported through EU FP7 project CARBOCHANGE (grant agreement no. 264879). Computational resources were made available by the "Norddeutscher Verbund für Hoch- und Höchstleistungsrechnen” (HLRN).

Edited by: J. Williams

\section{References}

Alvain, S., Moulin, C., Dandonneau, Y., and Bréon, F.: Remote sensing of phytoplankton groups in case 1 waters from global SeaWiFS imagery, Deep-Sea Res. Pt. I, 52, 1989-2004, doi:10.1016/j.dsr.2005.06.015, 2005.

Assmann, K. M., Bentsen, M., Segschneider, J., and Heinze, C.: An isopycnic ocean carbon cycle model, Geosci. Model Dev., 3, 143-167, doi:10.5194/gmd-3-143-2010, 2010.

Aumont, O. and Bopp, L.: Globalizing results from ocean in situ iron fertilization studies, Global Biogeochem. Cy., 20, GB2017, doi:10.1029/2005GB002591, 2006.

Aumont, O., Orr, J., Monfray, P., Madec, G., and Maier-Reimer, E.: Nutrient trapping in the equatorial Pacific: The ocean circulation solution, Global Biogeochem. Cy., 13, 351-369, doi:10.1029/1998GB900012, 1999.

Aumont, O., Maier-Reimer, E., Blain, S., and Monfray, F.: An ecosystem model of the global ocean including $\mathrm{Fe}$, $\mathrm{Si}$, P colimitations, Global Biogeochem. Cy., 17, 1060, doi:10.1029/2001GB001745, 2003.

Behrenfeld, M. J.: Abandoning Sverdrup's critical depth hypothesis on phytoplankton blooms, Ecology, 91, 977-989, doi:10.3410/f.2137018.1737130, 2010.

Behrenfeld, M. J. and Falkowski, P. G.: Photosynthetic rates derived from satellite-based chlorophyll concentration, Limnol. Oceanogr., 42, 1-20, doi:10.4319/lo.1997.42.1.0001, 1997.

Behrenfeld, M. J., O’Malley, R. T., Siegel, D. A., McClain, C. R., Sarmiento, J. L., Feldman, G. C., Milligan, A. J., Falkowski, P. G., Letelier, R. M., and Boss, E. S.: Climate-driven trends in contemporary ocean productivity, Nature, 444, 752-755, doi:10.1038/nature05317, 2006.

Bernard, C. Y., Dürr, H. H., Heinze, C., Segschneider, J., and Maier-Reimer, E.: Contribution of riverine nutrients to the silicon biogeochemistry of the global ocean - a model study, Biogeosciences, 8, 551-564, doi:10.5194/bg-8-551-2011, 2011.
Bopp, L., Resplandy, L., Orr, J. C., Doney, S. C., Dunne, J. P., Gehlen, M., Halloran, P., Heinze, C., Ilyina, T., Séférian, R., Tjiputra, J., and Vichi, M.: Multiple stressors of ocean ecosystems in the 21st century: projections with CMIP5 models, Biogeosciences, 10, 6225-6245, doi:10.5194/bg-10-6225-2013, 2013.

Broecker, W. S., Peng, T.-H., and Beng, Z.: Tracers in the Sea, Lamont-Doherty Geological Observatory, Columbia University, Palisades, New York, 1982.

Carr, M.-E., Friedrichs, M. A. M., Schmeltz, M., Noguchi Aita, M., Antoine, D., Arrigo, K. R., Asanuma, I., Aumont, O., Barber, R., Behrenfeld, M., Bidigare, R., Buitenhuis, E. T., Campbell, J., Ciotti, A., Dierssen, H., Dowell, M., Dunne, J., Esaias, W., Gentili, B., Gregg, W., Groom, S., Hoepffner, N., Ishizaka, J., Kameda, T., Le Quéré, C., Lohrenz, S., Marra, J., Mélin, F., Moore, K., Morel, A., Reddy, T. E., Ryan, J., Scardi, M., Smyth, T., Turpie, K., Tilstone, G., Waters, K., and Yamanaka, Y.: A comparison of global estimates of marine primary production from ocean color, Deep-Sea Res. Pt. II, 53, 741-770, doi:10.1016/j.dsr2.2006.01.028, 2006.

Chen, C., Liu, H., and Beardsley, R. C.: An unstructured grid, finite-volume, three-dimensional, primitive equations ocean model: application to coastal ocean and estuaries, J. Atmos. Ocean. Tech., 20, 159-186, doi:10.1175/15200426(2003)020<0159:AUGFVT>2.0.CO;2, 2003.

Danilov, S., Kivman, G., and Schröter, J.: A finite-element ocean model: principles and evaluation, Ocean Model., 6, 125-150, doi:10.1016/S1463-5003(02)00063-X, 2004.

De Baar, H. J. W., De Jong, J. T. M., Bakker, D. C., Löscher, B. M., Veth, C., Bathmann, U., and Smetacek, V.: Importance of iron for plankton blooms and carbon dioxide drawdown in the Southern Ocean, Nature, 373, 412-415, doi:10.1038/373412a0, 1995.

de Boyer Montegut, C., Madec, G., Fischer, A. S., Lazar, A., and Iudicone, D.: Mixed layer depth over the global ocean: An examination of profile data and a profile-based climatology, J. Geophys. Res., 109, C12003, doi:10.1029/2004JC002378, 2004.

Doney, S. C., Lindsay, K., Caldeira, K., Campin, J.-M., Drange, H., Dutay, J.-C., Follows, M., Gao, Y., Gnanadesikan, A., Gruber, N., Ishida, A., Joos, F., Madec, G., Maier-Reimer, E., Marshall, J. C., Matear, R. J., Monfray, P., Mouchet, A., Najjar, R., Orr, J. C., Plattner, G. K., Sarmiento, J. L., Schlitzer, R., Slater, R. D., Totterdell, I. J., Weirig, M. F., Yamanaka, Y., and Yool, A.: Evaluating global ocean carbon models: the importance of realistic physics, Global Biogeochem. Cy., 18, GB3017, doi:10.1029/2003GB002150, 2004.

Doney, S. C., Lima, I., Moore, J. K., Lindsay, K., Behrenfeld, M. J., Westberry, T. K., Mahowald, N., Glover, D. M., and Takahashi, T.: Skill metrics for confronting global upper ocean ecosystembiogeochemistry models against field and remote sensing data, J. Marine Syst., 76, 95-112, doi:10.1016/j.jmarsys.2008.05.015, 2009.

Downes, S., Farneti, R., Uotilac, P., Griffies, S. M., Marsland, S., Bailey, D., Behrens, E., Bentsen, M., Bi, D., Biastoch, A., Böning, C., Bozec, A., Chassignet, E., Danabasoglu, G., Danilov, S., Diansky, N., Drange, H., Fogli, P. G., Gusev, A., Howard, A., Illicak, M., Jung, T., Kelley, M., Large, W. G., Leboissetiero, A., Long, M., Lu, J., Masina, S., Mishra, A., Navarra, A., Nurserp, A. J. G., Patara, L., Samuels, B. L., Sidorenko, D., Spence, P., Tsujino, H., Wang, Q., and Yeager, S. G.: An assessment of 
Southern Ocean water masses and sea ice during 1988-2007 in a suite of inter-annual CORE-II simulations, Clim. Dynam., in preparation, 2014.

Droop, M.: 25 Years of algal growth kinetics a personal view, Bot. Mar., 26, 99-112, doi:10.1515/botm.1983.26.3.99, 1983.

Dunne, J. P., Sarmiento, J. L., and Gnanadesikan, A.: A synthesis of global particle export from the surface ocean and cycling through the ocean interior and on the seafloor, Global Biogeochem. Cy., 21, GB4006, doi:10.1029/2006GB002907, 2007.

Elrod, V. A., Berelson, W. M., Coale, K. H., and Johnson, K. S.: The flux of iron from continental shelf sediments: a missing source for global budgets, Geophys. Res. Lett., 31, L12307, doi:10.1029/2004GL020216, 2004.

Friedrichs, M. A., Carr, M.-E., Barber, R. T., Scardi, M., Antoine, D., Armstrong, R. A., Asanuma, I., Behrenfeld, M. J., Buitenhuis, E. T., Chai, F., Christian, J. R., Ciotti, A. M., Doney, S. C., Dowell, M., Dunne, J., Gentili, B., Gregg, W., Hoepffner, N., Ishizaka, J., Kameda, T., Lima, I., Marra, J., Mélin, F., Moore, J. K., Morel, A., O’Malley, R. T., O'Reilly, J., Saba, V. S., Schmeltz, M., Smyth, T. J., Tjiputra, J., Waters, K., Westberry, T. K., and Winguth, A.: Assessing the uncertainties of model estimates of primary productivity in the tropical Pacific Ocean, J. Marine Syst., 76, 113-133, doi:10.1016/j.jmarsys.2008.05.010, 2009.

Fung, I. Y., Meyn, S. K., Tegen, I., Doney, S. C., John, J. G., and Bishop, J. K. B.: Iron supply and demand in the upper ocean, Global Biogeochem. Cy., 14, 281-295, doi:10.1029/1999GB900059, 2000.

Garcia, H., Locarnini, R., Boyer, T., and Antonov, J.: World Ocean Atlas 2005, Nutrients (Phosphate, Nitrate, Silicate), Vol. 4, edited by: Levitus, S., Tech. rep., NOAA Atlas NESDIS 64, Washington DC, 2006.

Garcia, H., Locarnini, R., Boyer, T., Antonov, J., Zweng, M., Baranova, O., and Johnson, D.: World Ocean Atlas 2009, Nutrients (phosphate, nitrate, silicate), edited by: Levitus, S., Vol. 4, Tech. rep., NOAA Atlas NESDIS, Washington DC, 2010.

Geider, R. J., MacIntyre, H. L., and Kana, T. M.: A dynamic model of photoadaptation in phytoplankton, Limnol. Oceanogr., 41, 1-15, 1996.

Geider, R. J., MacIntyre, H. L., and Kana, T. M.: A dynamic regulatory model of phytoplanktonic acclimation to light, nutrients, and temperature, Limnol. Oceanogr., 43, 679-694, doi:10.4319/lo.1998.43.4.0679, 1998 .

Gent, P. R. and Mcwilliams, J. C.: Isopycnal mixing in ocean circulation models, J. Phys. Oceanogr., 20, 150-155, doi:10.1175/1520-0485(1981)011<1443:POVMIN>2.0.CO;2, 1990.

Gent, P. R., Yeager, S. G., Neale, R. B., Levis, S., and Bailey, D. A.: Improvements in a half degree atmosphere/land version of the CCSM, Clim. Dynam., 34, 819-833, doi:10.1007/s00382-0090614-8, 2010.

Gentleman, W., Leising, A., Frost, B., Strom, S., and Murray, J.: Functional responses for zooplankton feeding on multiple resources: a review of assumptions and biological dynamics, DeepSea Res. Pt. II, 50, 2847-2875, doi:10.1016/j.dsr2.2003.07.001, 2003.

Globcolour - Globcolour project, the European Service for Ocean Colour, available at: http://www.globcolour.info, last access: 1 December 2012.
Gordon, R. M., Coale, K. H., and Johnson, K. S.: Iron distributions in the equatorial Pacific: implications for new production, Limnol. Oceanogr., 42, 419-431, 1997.

Gregg, W. W. and Casey, N. W.: Global and regional evaluation of the SeaWiFS chlorophyll data set, Remote Sens. Environ., 93, 463-479, doi:10.1016/j.rse.2003.12.012, 2004.

Griffies, S. M., Biastoch, A., Böning, C., Bryan, F., Danabasoglu, G., Chassignet, E. P., England, M. H., Gerdes, R., Haak, H., Hallberg, R. W., Hazeleger, W., Jungclaus, J., Large, W. G., Madec, G., Pirani, A., Samuels, B. L., Scheinert, M., Gupta, A. S., Severijns, C. A., Simmons, H. L., Treguier, A. M., Winton, M., Yeager, S., and Yin, J.: Coordinated oceanice reference experiments (COREs), Ocean Model., 26, 1-46, doi:10.1016/j.ocemod.2008.08.007, 2009.

Haid, V. and Timmermann, R.: Simulated heat flux and sea ice production at coastal polynyas in the southwestern Weddell Sea, J. Geophys. Res., 118, 2640-2652, doi:10.1002/jgrc.20133, 2013.

Hashioka, T., Vogt, M., Yamanaka, Y., Le Quéré, C., Buitenhuis, E. T., Aita, M. N., Alvain, S., Bopp, L., Hirata, T., Lima, I., Sailley, S., and Doney, S. C.: Phytoplankton competition during the spring bloom in four plankton functional type models, Biogeosciences, 10, 6833-6850, doi:10.5194/bg-10-6833-2013, 2013.

Hauck, J., Völker, C., Wang, T., Hoppema, M., Losch, M., and Wolf-Gladrow, D.: Seasonally different carbon flux changes in the Southern Ocean in response to the Southern Annular Mode, Global Biogeochem. Cy., 27, 1-10, doi:10.1002/2013GB004600, 2013.

Hill, J., Popova, E. E., Ham, D. A., Piggott, M. D., and Srokosz, M.: Adapting to life: ocean biogeochemical modelling and adaptive remeshing, Ocean Sci., 10, 323-343, doi:10.5194/os-10323-2014, 2014.

Hirata, T., Hardman-Mountford, N. J., Brewin, R. J. W., Aiken, J., Barlow, R., Suzuki, K., Isada, T., Howell, E., Hashioka, T., Noguchi-Aita, M., and Yamanaka, Y.: Synoptic relationships between surface Chlorophyll- $a$ and diagnostic pigments specific to phytoplankton functional types, Biogeosciences, 8, 311-327, doi:10.5194/bg-8-311-2011, 2011.

Hohn, S.: Coupling and decoupling of biogeochemical cycles in marine ecosystems, Ph.D. thesis, Bremen University, Germany, 2009.

Holzer, M., Primeau, F. W., DeVries, T., and Matear, R.: The Southern Ocean silicon trap: data-constrained estimates of regenerated silicic acid, trapping efficiencies, and global transport paths, J. Geophys. Res., 119, 313-331, doi:10.1002/2013JC009356, 2014.

Hoppema, M., de Baar, H. J., Fahrbach, E., Hellmer, H. H., and Klein, B.: Substantial advective iron loss diminishes phytoplankton production in the Antarctic Zone, Global Biogeochem. Cy., 17, 1025, doi:10.1029/2002GB001957, 2003.

Jakobsson, M., Macnab, R., Mayer, L., Anderson, R., Edwards, M., Hatzky, J., Schenke, H. W., and Johnson, P.: An improved bathymetric portrayal of the Arctic Ocean: Implications for ocean modeling and geological, geophysical and oceanographic analyses, Geophys. Res. Lett., 35, L07602, doi:10.1029/2008GL033520, 2008.

Jin, X., Gruber, N., Dunne, J. P., Sarmiento, J. L., and Armstrong, R. A.: Diagnosing the contribution of phytoplankton functional groups to the production and export of particulate 
organic carbon, $\mathrm{CaCO}_{3}$, and opal from global nutrient and alkalinity distributions, Global Biogeochem. Cy., 20, GB2015, doi:10.1029/2005GB002532, 2006.

Johnson, G. C., McPhaden, M. J., and Firing, E.: Equatorial Pacific Ocean horizontal velocity, divergence, and upwelling, J. Phys. Oceanogr., 31, 839-849, doi:10.1175/15200485(2001)031<0839:EPOHVD>2.0.CO;2, 2001.

Kamatani, A.: Dissolution rates of silica from diatoms decomposing at various temperatures, Mar. Biol., 68, 91-96, doi:10.1007/BF00393146, 1982.

Key, R. M., Kozyr, A., Sabine, C. L., Lee, K., Wanninkhof, R., Bullister, J. L., Feely, R. A., Millero, F. J., Mordy, C., and Peng, T.-H.: A global ocean carbon climatology: Results from Global Data Analysis Project (GLODAP), Global Biogeochem. Cy., 18, GB4031, doi:10.1029/2004GB002247, 2004.

Kriest, I. and Oschlies, A.: On the treatment of particulate organic matter sinking in large-scale models of marine biogeochemical cycles, Biogeosciences, 5, 55-72, doi:10.5194/bg-5-55-2008, 2008.

Lam, P. J. and Bishop, J. K.: The continental margin is a key source of iron to the HNLC North Pacific Ocean, Geophys. Res. Lett., 35, L07608, doi:10.1029/2008GL033294, 2008.

Lancelot, C., de Montety, A., Goosse, H., Becquevort, S., Schoemann, V., Pasquer, B., and Vancoppenolle, M.: Spatial distribution of the iron supply to phytoplankton in the Southern Ocean: a model study, Biogeosciences, 6, 2861-2878, doi:10.5194/bg-62861-2009, 2009.

Large, W. G. and Yeager, S. G.: Diurnal to Decadal Global Forcing for Oceans and Sea-Ice Models: The Data Sets and Flux Climatologies, NCAR/TN-460+STR, Tech. rep., National Center for Atmos. Res., Boulder, Colorado, 2004.

Large, W. G. and Yeager, S. G.: The global climatology of an interannually varying air-sea flux data set, Clim. Dynam., 33, 341-364, doi:10.1007/s00382-008-0441-3, 2009.

Laws, E. A., Falkowski, P. G., Smith, W. O., Ducklow, H., and McCarthy, J. J.: Temperature effects on export production in the open ocean, Global Biogeochem. Cy., 14, 1231-1246, doi:10.1029/1999GB001229, 2000.

Le Quéré, C., Aumont, O., Monfray, P., and Orr, J.: Propagation of climatic events on ocean stratification, marine biology, and $\mathrm{CO}_{2}$ : Case studies over the 1979-1999 period, J. Geophys. Res., 108, 3375, doi:10.1029/2001JC000920, 2003.

Löscher, B. M., De Baar, H. J. W., De Jong, J. T. M., Veth, C., and Dehairs, F.: The distribution of $\mathrm{Fe}$ in the Antarctic circumpolar current, Deep-Sea Res. Pt. II, 44, 143-187, doi:10.1016/S09670645(96)00101-4, 1997.

Luo, C., Mahowald, N. M., and Del Corral, J.: Sensitivity study of meteorological parameters on mineral aerosol mobilization, transport, and distribution, J. Geophys. Res., 108, 4447, doi:10.1029/2003JD003483, 2003.

Mahowald, N., Luo, C., Del Corral, J., and Zender, C. S.: Interannual variability in atmospheric mineral aerosols from a 22-year model simulation and observational data, J. Geophys. Res., 108, 4352, doi:10.1029/2002JD002821, 2003.

Martin, J. H., Gordon, R. M., and Fitzwater, S. E.: The case for iron, Limnol. Oceanogr., 36, 1793-1802, 1991.

Moore, J. K. and Braucher, O.: Sedimentary and mineral dust sources of dissolved iron to the world ocean, Biogeosciences, 5, 631-656, doi:10.5194/bg-5-631-2008, 2008.
Moore, J. K., Abbott, M. R., and Richman, J. G.: Location and dynamics of the Antarctic Polar Front from satellite sea surface temperature data, J. Geophys. Res., 104, 3059-3073, 1999.

Moore, J. K., Doney, S. C., Glover, D. M., and Fung, I. Y.: Iron cycling and nutrient-limitation patterns in surface waters of the World Ocean, Deep-Sea Res. Pt. II, 49, 463-507, doi:10.1016/S0967-0645(01)00109-6, 2002.

Moore, J. K., Doney, S. C., and Lindsay, K.: Upper ocean ecosystem dynamics and iron cycling in a global threedimensional model, Global Biogeochem. Cy., 18, GB4028, doi:10.1029/2004GB002220, 2004.

Najjar, R. G., Jin, X., Louanchi, F., Aumont, O., Caldeira, K., Doney, S. C., Dutay, J.-C., Follows, M., Gruber, N., Joos, F., Lindsay, K., Maier-Reimer, E., Matear, R. J., Matsumoto, K., Monfray, P., Mouchet, A., Orr, J. C., Plattner, G.-K., Sarmiento, J. L., Schlitzer, R., Slater, R. D., Weirig, M.-F., Yamanaka, Y., and Yool, A.: Impact of circulation on export production, dissolved organic matter, and dissolved oxygen in the ocean: results from Phase II of the Ocean Carbon-cycle Model Intercomparison Project (OCMIP-2), Global Biogeochem. Cy., 21, GB3007, doi:10.1029/2006GB002857, 2007.

Nevison, C., Keeling, R., Kahru, M., Manizza, M., Mitchell, B., and Cassar, N.: Estimating net community production in the Southern Ocean based on atmospheric potential oxygen and satellite ocean color data, Global Biogeochem. Cy., 26, GB1020, doi:10.1029/2011GB004040, 2012.

O’Neill, R. V., DeAngelis, D. L., Pastor, J. J., Jackson, B. J., and Post, W. M.: Multiple nutrient limitations in ecological models, Ecol. Model., 46, 147-163, doi:10.1016/0304-3800(89)90015X, 1989.

Orr, J., Najjar, R., Sabine, C. L., and Joos, F.: Abiotic-HOWTO, Tech. rep., Internal OCMIP Report, LSCE/CEA Saclay, Gif-surYvette, France, 1999.

Pacanowski, R. C. and Philander, S. G. H.: Parameterization of vertical mixing in numerical models of tropical oceans, J. Phys. Oceanogr., 11, 1443-1451, doi:10.1175/15200485(1981)011<1443:POVMIN>2.0.CO;2, 1981.

Parekh, P., Follows, M. J., and Boyle, E. A.: Decoupling of iron and phosphate in the global ocean, Global Biogeochem. Cy., 19, GB2020, doi:10.1029/2004GB002280, 2005.

Parkinson, C. L. and Washington, W. M.: A large-scale numerical model of sea ice, J. Geophys. Res., 84, 311-337, doi:10.1029/JC084iC01p00311, 1979.

Piggott, M. D., Gorman, G. J., Pain, C. C., Allison, P. A., Candy, A. S., Martin, B. T., and Wells, M. R.: A new computational framework for multi-scale ocean modelling based on adapting unstructured meshes, Int. J. Numer. Meth. Fl., 56, 1003-1015, doi:10.1002/fld.1663, 2008.

Redi, M.: Oceanic isopycnal mixing by coordinate rotation, J. Phys. Oceanogr., 12, 1154-1158, doi:10.1175/15200485(1982)012<1154:OIMBCR>2.0.CO;2, 1982.

Schlitzer, R.: Carbon export fluxes in the Southern Ocean: Results from inverse modeling and comparison with satellite-based estimates, Deep-Sea Res. Pt. II, 49, 1623-1644, doi:10.1016/S09670645(02)00004-8, 2002.

Schlitzer, R.: Export production in the equatorial and North Pacific derived from dissolved oxygen, nutrient and carbon data, J. Oceanogr., 60, 53-62, doi:10.1023/B:JOCE.0000038318.38916.e6, 2004. 
Schneider, B., Bopp, L., Gehlen, M., Segschneider, J., Frölicher, T. L., Cadule, P., Friedlingstein, P., Doney, S. C., Behrenfeld, M. J., and Joos, F.: Climate-induced interannual variability of marine primary and export production in three global coupled climate carbon cycle models, Biogeosciences, 5, 597-614, doi:10.5194/bg-5-597-2008, 2008.

Schourup-Kristensen, V., Hauck, J., Wolf-Gladrow, D. A., and Völker, C.: Vertical supply of iron to the mixed layer of the Southern Ocean: The ocean model effect, J. Geophys. Res., in preparation, 2014

SeaWIFS: available at: Ocean productivity home page, http:// www.science.oregonstate.edu/ocean.productivity/index.php, last access: 1 December 2012

Sidorenko, D., Danilov, S., Wang, Q., Huerta-Casas, A., and Schröter, J.: On computing transports in finite-element models, Ocean Model., 28, 60-65, doi:10.1016/j.ocemod.2008.09.001, 2009.

Sidorenko, D., Wang, Q., Danilov, S., and Schröter, J.: FESOM under coordinated ocean-ice reference experiment forcing, Ocean Dynam., 61, 881-890, doi:10.1007/s10236-011-0406-7, 2011.

Siegel, D. A., Buesseler, K. O., Doney, S. C., Sailley, S. F., Behrenfeld, M. J., and Boyd, P. W.: Global assessment of ocean carbon export by combining satellite observations and food-web models, Global Biogeochem. Cy., 28, 181-196, doi:10.1002/2013GB004743, 2014.

Steele, M., Morley, R., and Ermold, W.: PHC: A global ocean hydrography with a high-quality Arctic Ocean, J. Climate, 14, 2079-2087, doi:10.1029/2006GL026152, 2001.

Steinacher, M., Joos, F., Frölicher, T. L., Bopp, L., Cadule, P., Cocco, V., Doney, S. C., Gehlen, M., Lindsay, K., Moore, J. K., Schneider, B., and Segschneider, J.: Projected 21st century decrease in marine productivity: a multi-model analysis, Biogeosciences, 7, 979-1005, doi:10.5194/bg-7-979-2010, 2010.

Sunda, W. G. and Huntsman, S. A.: Iron uptake and growth limitation in oceanic and coastal phytoplankton, Mar. Chem., 50, 189-206, doi:10.1016/0304-4203(95)00035-P, 1995.

Tagliabue, A., Bopp, L., and Aumont, O.: Evaluating the importance of atmospheric and sedimentary iron sources to Southern Ocean biogeochemistry, Geophys. Res. Lett., 36, L13601, doi:10.1029/2009GL038914, 2009.

Tagliabue, A., Mtshali, T., Aumont, O., Bowie, A. R., Klunder, M. B., Roychoudhury, A. N., and Swart, S.: A global compilation of dissolved iron measurements: focus on distributions and processes in the Southern Ocean, Biogeosciences, 9, 2333-2349, doi:10.5194/bg-9-2333-2012, 2012.

Tagliabue, A., Sallée, J.-B., Bowie, A. R., Lévy, M., Swart, S., and Boyd, P. W.: Surface-water iron supplies in the Southern Ocean sustained by deep winter mixing, Nat. Geosci., 7, 314-320, doi:10.1038/ngeo2101, 2014

Taylor, K. E.: Summarizing multiple aspects of model performance in a single diagram, J. Geophys. Res., 106, 7183-7192, doi:10.1029/2000JD900719, 2001.

Taylor, M. H., Losch, M., and Bracher, A.: On the drivers of phytoplankton blooms in the Antarctic marginal ice zone: A modeling approach, J. Geophys. Res., 118, 63-75, doi:10.1029/2012JC008418, 2013.

Timmermann, R., Danilov, S., Schröter, J., Böning, C., Sidorenko, D., and Rollenhagen, K.: Ocean circulation and sea ice distri- bution in a finite element global sea ice-ocean model, Ocean Model., 27, 114-129, doi:10.1016/j.ocemod.2008.10.009, 2009.

Timmermann, R., Le Brocq, A. M., Deen, T., J., Domack, E. W., Dutrieux, P., Galton-Fenzi, B., Hellmer, H. H., Humbert, A., Jansen, D., Jenkins, A., Lambrecht, A., Makinson, K., Niederjasper, F., Nitsche, F.-O., Nøst, O. A., Smedsrud, L. H., and Smith, W.: Antarctic ice sheet topography, cavity geometry, and global bathymetry (RTopo 1.0.5-beta), doi:10.1594/PANGAEA.741917, 2010.

Vichi, M. and Masina, S.: Skill assessment of the PELAGOS global ocean biogeochemistry model over the period 1980-2000, Biogeosciences, 6, 2333-2353, doi:10.5194/bg-6-2333-2009, 2009.

Vogt, M., Hashioka, T., Payne, M. R., Buitenhuis, E. T., Quéré, C. Le, Alvain, S., Aita, M. N., Bopp, L., Doney, S. C., Hirata, T., Lima, I., Sailley, S., and Yamanaka, Y.: The distribution, dominance patterns and ecological niches of plankton functional types in Dynamic Green Ocean Models and satellite estimates, Biogeosciences Discuss., 10, 17193-17247, doi:10.5194/bgd10-17193-2013, 2013.

Wadley, M. R., Jickells, T. D., and Heywood, K. J.: The role of iron sources and transport for Southern Ocean productivity, Deep-Sea Res. Pt. I, 87, 82-94, doi:10.1016/j.dsr.2014.02.003, 2014.

Wagener, T., Guieu, C., Losno, R., Bonnet, S., and Mahowald, N.: Revisiting atmospheric dust export to the Southern Hemisphere ocean: Biogeochemical implications, Global Biogeochem. Cy., 22, GB2006, doi:10.1029/2007GB002984, 2008.

Wang, Q., Danilov, S., and Schröter, J.: Finite element ocean circulation model based on triangular prismatic elements, with application in studying the effect of topography representation, J. Geophys. Res., 113, C05015, doi:10.1029/2007JC004482, 2008.

Wang, Q., Danilov, S., Sidorenko, D., Timmermann, R., Wekerle, C., Wang, X., Jung, T., and Schröter, J.: The Finite Element Sea Ice-Ocean Model (FESOM) v.1.4: formulation of an ocean general circulation model, Geosci. Model Dev., 7, 663-693, doi:10.5194/gmd-7-663-2014, 2014.

Wang, S., Bailey, D., Lindsay, K., Moore, J. K., and Holland, M.: Impact of sea ice on the marine iron cycle and phytoplankton productivity, Biogeosciences, 11, 4713-4731, doi:10.5194/bg11-4713-2014, 2014.

Wanninkhof, R.: Relationship between wind speed and gas exchange over the ocean, J. Geophys. Res., 97, 7373-7382, doi:10.1029/92JC00188, 1992.

Wekerle, C., Wang, Q., Danilov, S., Jung, T., and Schröter, J.: The Canadian Arctic Archipelago throughflow in a multiresolution global model: model assessment and the driving mechanism of interannual variability, J. Geophys. Res., 118, 4525-4541, doi:10.1002/jgrc.20330, 2013.

Wilhelm, S. W., King, A. L., Twining, B. S., LeCleir, G. R., DeBruyn, J. M., Strzepek, R. F., Breene, C. L., Pickmere, S., Ellwood, M. J., Boyd, P. W., and Hutchins, D. A.: Elemental quotas and physiology of a southwestern Pacific Ocean plankton community as a function of iron availability, Aquat. Microb. Ecol., 68, 185-194, doi:10.3354/ame01611, 2013.

Wolf-Gladrow, D. A., Zeebe, R. E., Klaas, C., Körtzinger, A., and Dickson, A. G.: Total alkalinity: the explicit conservative expression and its application to biogeochemical processes, Mar. Chem., 106, 287-300, 2007. 
Yamanaka, Y. and Tajika, E.: The role of the vertical fluxes of particulate organic matter and calcite in the oceanic carbon cycle: studies using an ocean biogeochemical general circulation model, Global Biogeochem. Cy., 10, 361-382, doi:10.1029/96GB00634, 1996.
Yool, A., Popova, E. E., and Anderson, T. R.: Medusa-1.0: a new intermediate complexity plankton ecosystem model for the global domain, Geosci. Model Dev., 4, 381-417, doi:10.5194/gmd-4381-2011, 2011. 